\title{
Media and Google:
}

\section{The Impact of Information Supply and Demand on Stock Returns}

\author{
Yanbo Wang ${ }^{1}$ \\ INSEAD
}

Nov 20, 2012

\begin{abstract}
This paper gives the first empirical examination of the joint effect of information supply and demand on stock returns. Unlike previous studies, I examine the relationship between cross-sectional stock returns and "pairs" of shifts in information supply and demand. I use the number of news articles and Google search volume (for a company) as proxies for information supply and demand respectively. The results show that only an upward shift in both information supply and demand predicts future returns among shift pairs. A monthly rebalanced portfolio of buying stocks with this shift "pair" and short selling the other stocks generates an abnormal return between $16 \%$ and $22 \%$ per year with the Sharpe ratio between 0.85 and 0.9 (compared with a Sharpe ratio of 0.049 for the S\&P500 during the same period). The abnormal return increases to between $23 \%$ and $34 \%$ per year in a subsample of small stocks. These findings imply that an econometric model with only information supply (demand) under-estimates the price impact of an increase in information supply (demand) when information demand (supply) increases, and overestimates the impact when information demand (supply) decreases. The results are consistent with the hypothesis that an increase in information supply drives stock prices up only when an increase in information demand confirms that information supply succeeds in raising new investors' awareness and existing investors' additional learning effort. The good news due to ostrich effect can also partially explain the abnormal return, but it only explains a small component of the total abnormal return. The empirical findings affirm the importance of incorporating both information supply and demand in predicting stock returns.
\end{abstract}

Keywords: Stock returns, Information Supply and Demand, Estimation Bias, Media, Google, News, Search Volume, Awareness, Learning, Ostrich Effect

JEL Codes: G12, G14

\footnotetext{
${ }^{1}$ Yanbo Wang is a PhD candidate in Finance at INSEAD; address: 1 Ayer Rajah Avenue 138676 Singapore ; email: yanbo.wang@insead.edu; phone: 65-83608052.
} 


\section{Introduction}

Media news is an important supply of public information, especially for individual investors (Tetlock (2010)), while Google search volume captures information demand among investors (Drake, Roulstone and Thornock (2012)). I use the number of news articles and Google search volume as proxies for information supply and demand to study their impact on stock returns. I treat the information supply as exogenous variable and study its impact on stock returns conditional on the information demand ${ }^{2}$.

The joint use of both information supply and demand is crucial in studying the impact of information on stock prices, especially the cognitive impact of information ${ }^{3}$. The increase in information demand ensures that an increase in information supply succeed in attracting investors' attention and thus affect prices. I show that an econometric model with only information supply under-estimates the price impact of an increase in information supply when information demand increases, and over-estimates the impact when information demand decreases. On the other hand, the increase in information supply helps to differentiate whether real news contents or pure emotional sentiments cause an increase in information demand which predict stock returns differently. I show that the estimated impact of an increase in information demand on stock returns unconditional on the information supply is biased downward when information supply increases and biased upward when information supply decreases.

An increase in information supply of a stock can affect the stock price in various ways. On one hand, information contents with good news would push stock prices up. On the other hand, via the cognitive impacts on investors, the effect of the information persists even when the probabilities of having good versus bad news are equal. For one thing, it makes new investors aware of the existence of the stock. For another, it also induces existing investors (those who are holding the stocks or those who are aware of the stocks but not holding it) to acquire more information about the stock. Both channels increase the stock price even when the news contents are natural (i.e. the odds to have equally important good and bad news is $50 \%$ to $50 \%$ ). In the first channel, an increase in information supply gets more individual investors aware of the stock. These individual investors are chasing after attention grabbing stocks. They tend to buy rather than sell

\footnotetext{
${ }^{2}$ There are two central issues in research on information supply and demand and their effects. The first question is what underlying mechanisms are driving information supply. The second question is what is the impact of a given information supply scenario on stock returns conditional on the information demand dynamic. This paper empirically addresses the second question, which is a common focus in both theoretical and empirical asset pricing research. The focus is similar to various empirical research on the relationship between stock returns and information (Chan (2003), Fang and Peress(2009), Savor (2012), Barber and Odean (2008), Da, Engelberg, and Gao (2011)). Moreover, many theoretical models treat the arrival of information as a random shock. The reason why the second question can be addressed separately from the first question is that the stock price is affected by information supply all through investors' interpretation no matter what is the force that drives the information supply.

${ }^{3}$ Information affects stock prices in two aspects. For one thing, the information contents (e.g. good and bad news) affect stock prices. For another, the cognitive effect on investors (e.g. awareness and learning) also affects stock prices even when the odds to have equally important good versus bad news are $50 \%$ to $50 \%$. The focus of the paper is the latter aspect. I also investigate the first aspect briefly (Section V. C) and show that the first aspect only explains a small portion of the total abnormal return documented.
} 
those stocks, which drives up the stock prices (Barber and Odean (2008) and Da, Engelberg and Gao (2011)). In the second channel, when there is more information, the posterior variance of the asset payoff conditional on the abundant information is lower. Lower risks make the stocks more attractive to existing investors and increase their demands and raise the price (Veldkamp (2006)).

Information demand is important to ensure the channels working. Firstly, an increase in the supply of information per se is no guarantee of attracting more investors to be aware of the stock since it depends on its reception. If investors still have no interest because the news is not sufficiently attention grabbing, the news will have a limited impact on the stock returns. Information demand plays a crucial role to ensure that the link between information supply and investor awareness is well established. Secondly, the conditional variance of the payoff is lower so that the price goes higher only if investors actively acquire information to update their posterior variance of the payoff (i.e. an increase in information demand). Thirdly, information demand helps to pin down whether the information content is good news or bad news through ostrich effect (Loewenstein and Seppi (2005)). They show that investors tend to monitor their portfolios more frequently in rising markets than when markets are flat or falling. If this also applies to individual stocks, news accompanied by a surge in information demand is more likely to be good news, which push stock prices up. In summary, an increase in information demand is a necessary condition for an increase in information supply to raise the stock price. Empirically, I find that an increase in news coverage is positively related to future stock returns only if the search volume also rises.

On the other hands, is information demand alone sufficient to affect the stock price? The answer is no. An increase in information demand per se cannot tell us whether investors are responding to important corporate news or to their emotions - these different forces may predict future returns in entirely different directions. Savor (2012) provides evidence that the stock market events which are driven by news exhibit price momentum while those driven by pure sentiment exhibit price reversal. If the rise in Google search coincides with an important corporate news release, then the increase in information demand may predict a subsequent price momentum. Otherwise, a rise in information demand may predict a subsequent price reversal as the sentiment fades. Empirically, the paper shows that an increase in search volume predicts positive stock returns only when it is accompanied by an increase in news coverage.

Therefore, separating out the effects of information supply and demand is a crucial but overlooked aspect of the empirical literature on stock returns and information release, dissemination and reception. The average effect of a single-sided supply of information (or demand for information) is not good enough because I show that the stock return prediction of the information demand (or supply) is, in fact, conditional on the other half of the shift "pair". Only by making the distinction can I pin down the theoretical channels driving the relationship among the news coverage, search volume and stock returns.

In this paper, I propose a new framework for testing the relationship between stock returns and the shift "pairs" of information supply and demand. With a novel panel 
dataset consisting of news articles and Google search volumes, I employ an empirical approach to isolate various underlying forces that link information supply and demand dynamics to the stock return. Using an approach similar to Cohen, Diether, and Malloy (2007), I classify the shift in supply and demand for information into nine scenarios. There are three scenarios for information supply: increase in supply, decrease in supply, and zero information supply. I define a shift as an increase (decrease) of information supply if its current value is above (below) its 12 month moving average, and "zero" supply if there is no supply in the past 12 months. Similarly, I divide information demand into three categories: increase in demand, decrease in demand, and zero demand. This accounts for the nine $(3 \times 3)$ possible combinations of supply and demand shift. I focus on the four "non-zero" scenarios of the nine scenarios for the empirical tests. These supply and demand shift "pairs" enable us to pin down the information supply and demand state.

I find that only an upward shift in both information supply and demand is an economically and statistically significant predictor of future returns (denoted as "upward shift pair" later on). The other pairs do not have prediction power of future returns. The findings imply that there is no price impact of an increase in information supply (demand) when information demand (supply) decreases, i.e. the price impact is over-estimated. On the other hands, the price impact of an increase in information supply (demand) with an increase in information demand (supply) is 2 to 3 times larger than the average price impact of an increase in information supply (demand) unconditional on information demand (supply), i.e. the estimated price impact is bias downward. The regression coefficients imply a $15 \%-21 \%$ risk-adjusted outperformance against other stocks. The result is robust to controlling for price reversal, price momentum, trading volume, institutional ownership, analyst coverage, news coverage, market equity, market equity to book equity ratio, firm profitability, firm liquidity, firm operating efficiency and industry. An attempt to disentangle the information supply and demand in the financial market is not only theoretically appealing but also practically meaningful. A portfolio strategy of buying stocks with the "upward shift pair" and short selling the other stocks delivers a 16\%-22\% abnormal return per year, with the Sharpe ratio between 0.85 and 0.9 (compared with a Sharpe ratio of 0.049 for the S\&P500 during the same period).

Since media news and Google search capture individual investors' information supply and demand ${ }^{4}$, I conjecture that the empirical finding will be stronger among stocks held by individual investors. Barber, Brad, and Odean (2000) found that individual investors tilted their common stock investment towards high-beta, small and value stocks. Consistent with this hypothesis, I find that the outperformance increases to $23 \%-34 \%$ per year in the below-median size subsample and the above-median return volatility subsample. The results also indicate that the finding is not driven by any particular event type. To reach this conclusion, I test whether the upward shift "pair" predicts future return only in the month when a particular type of corporate events occurs (e.g. earning announcement, strategy alliance and M\&A etc.). I test 30 top corporate event types. The regressions reject that any single event type subsumes the full effects.

\footnotetext{
${ }^{4}$ Barber, Odean, and Zhu (2009) shows that retail investors' trading is an important force that moves stock market.
} 
After documenting the impact of information supply and demand on stock returns, I attempt to explain the phenomenon. The first explanation is that the rise in information supply increases the awareness of the stock. The increase in information demand confirms that individual investors, who do not have this stock in their mind previously, include the stock in their consideration set now. The stock price goes up because these investors tend to buy rather than sell the attention grabbing stocks. If this explanation is true, I should observe that investors intensively buy stocks with good news, but less intensively sell stocks with bad news when both information supply and demand rise. I use the change in average analyst recommendation in IBES as the proxy for good and bad news. The result shows a significantly large outperformance of stocks with good news and a marginally moderate underperformance of stocks with bad news among stocks with an upward shift in both information supply and demand. I did not observe this market reaction asymmetry for stocks with other information supply and demand shift "pairs".

The second explanation is that an increase in the information supply induces the existing investors, who already have this particular stock in their mind, to learn more and thus reduce their posterior variance of the asset payoff conditional on the abundant information. Therefore, lower risk makes the asset more attractive to investors, increases demand and raises the price. Veldkamp (2006) shows that price goes up when number of news goes up in market aggregation level. However, it is hard to show it in the cross sectional level because it is hard to pin down whether investors who do not hold the stock are not aware of the stock or do not regard the stock as a good investment despite being aware of it. I use the web traffic to the company page on Wikipedia to address the difficulty partially. If the assumption that the traffic to Wikipedia is a proxy for the learning of investors who have little general knowledge about the firm holds, then the Google search volume net of the Wikipedia traffic should capture the learning of investors who already have some basic knowledge of the stock (i.e. investors who have the stock in their mind). For each firm, I run the regression of the search volume on Wikipedia traffic and use the sum of the constant term and residual term as the measure of search volume net of Wikipedia traffic. I show that the upward shift "pair" predicts positive stock returns when I use either Wikipedia traffic or Google search volume net of Wikipedia traffic as the proxy for information demand. This implies that both the current explanation and the previous explanation are driving the phenomenon.

The third explanation is that the upward shift "pair" in information supply and demand corresponds to better news than the other shift "pairs". This possibility arises because of "ostrich effect". For example, Loewenstein and Seppi (2005) provide evidence that investors monitor their portfolios more frequently in rising markets than when markets are flat or falling. The upward shift "pair" implies that investors embracing good news for the stock and learn more. I show that stocks with the upward shift "pair" indeed have a higher probability to have good news. However, if an abnormal return is driven by fundamentals, it should not reverse over time but be a persistent component in the stock price. I provide evidence that good news only explains a small component of the total abnormal return because the majority of the abnormal return reverses over time. 
I also argue that a risk-based explanation is less likely. First, factor models and DGTW adjustment cannot fully explain the abnormal return. Secondly, Bernard and Thomas (1989) argue that if a portfolio strategy yields a positive average return because it is risky, then the risk must periodically manifest itself in the form of a loss. Following this notion, I plot the profit and loss of the portfolio over the sample period in Figure 1. The figure shows that the portfolio is almost always making a profit and has no substantial loss, which is inconsistent with the risk-based hypothesis. Thirdly, if an upward shift in both information supply and demand corresponds to some risk premium, then the evaluation of the stock should be lower to compensate the risk. Therefore, we should observe that the market equity to book equity ratio is lower for stocks with the upward shift "pair". However, I found no significant price difference (measured by market equity to book equity ratio difference) between the stocks with upward shift "pair" and the other stocks. Fourthly, Tetlock (2010) and Drake, Roulstone, and Thornock (2012) show that the increase in information supply and information demand is more likely to help to reduce the risk instead of increasing the risk.

As a byproduct of this study, I make some stylized observations about the different behavior in information supply and demand. Firstly, the frequency at which the supply shift and demand shift move in different directions is $33.2 \%-39.5 \%$ (Section III.A). The significant presence of the opposite directional movement strongly supports the necessity to analyze both elements rather than just one. Secondly, the top five corporate events that attract media coverage are remarkably different from the top five that attract Google search volume, which implies that journalists' preferences are different from those of investors. For example, an M\&A transition announcement tends to attract news coverage, while M\&A rumors tend to attract investors' search in Google (Section VI.B). Thirdly, information supply (news) tends to change more frequently while information demand (search volume) tends to persist (Section V. C).

The remainder of the paper is organized as follows. I review the related literature in session II. Section III describes the data collection procedure and the research design. Section IV and V present and explain the empirical findings. Section VI provides some minor side comments on the research. In Section VII, I draw conclusions.

\section{Related Literature}

The information supply literature related to my study is on media and stock returns. For example, Chan (2003) examines momentum and reversal patterns following large price moves with or without news, finding that price events without news exhibit a reversal, while price events with accompanying news exhibit price momentum. Antiweiler and Frank (2004) document that stock messages predict market volatility. Tetlock (2007) does a linguistic analysis of news articles and reports that pessimistic tone predicts downward pressure on price and a subsequent reversal. Tetlock, Tsechansky, and Sofus Macskassy (2008) find that the fraction of negative words in the news articles predicts earnings and stock returns. Fang and Peress (2009) document a persistent no-mediacoverage premium whereby stocks without media coverage have a higher cross-sectional 
stock returns. I add to this literature by arguing that whether news (information supply) has an impact on stock return depends on whether there is a demand for information. If investors show no interest in the news, then it will have little impact on stock returns via the investors' attention channel. Information demand plays a crucial role to ensure that the link between information supply and attention is well established.

This research is also related to the information demand literature. Drake, Roulstone, and Thornock (2012) study the dynamics of the information demand by investors around earnings announcements. They document that abnormal Google search increases about two weeks prior to the earnings announcement, spikes markedly at the announcement, and continues at high levels for a period after the announcement. They also find that when investors search for more information in the days just prior to the announcement, preannouncement price and volume changes reflect more of the upcoming earnings news. Investors indeed demand more information during important corporate events (e.g. preearning announcement), and Google search seems an effective tool for investors to find extra information (evidenced by the finding that a higher Google search volume is accompanied by a stronger alignment between the pre-announcement price and the upcoming earnings news). Vlastakis and Markellos (2012) find that the information supply (measured by return volatility and trading) drives information demand (measured by Google search volume) among a sample of 30 largest NYSE stocks, although their study is not about the relationship between stock returns and the interaction of information supply and demand. In fact, the literature on information demand focuses on the determinants of the information demand either in time series or cross section. This paper's contribution to the literature is to differentiate whether company news or pure emotional sentiment drives an increase in information. The empirical finding shows that the former predicts positive future return, and the later has no prediction power.

One explanation of the documented phenomenon is related to the breadth of investors' participation, and the other explanation is related to the in-depth of investors' participation. When a rise in information supply causes an increase in awareness of a stock and a rise in information demand confirms it, more investors start considering investing in the stock (i.e., an increase in breath). Barber and Odean (2008) show that individual investors are net buyers of attention grabbing stocks. Therefore, there is a positive price pressure when more individual investors are aware of a stock. Da, Engelberg, and Gao (2011), for the first time, use Google search volume to measure investors' attention directly and document a strong predictability of search volume on future stock returns by arguing the similar channel of an increase in individual investors presence. The second explanation is that when a rise in information supply induces an increase in learning of a stock and a rise in information demand provides supportive evidence, existing investors know more about the stock (i.e. an increase in in-depth). Veldkamp (2006) shows that when more information is provided to the market, the posterior variance of the asset payoff conditional on the abundant information is lower. Lower risk makes the asset more attractive to investors, increases demand and raises the price. Therefore, both channels drive the stock price up. The third explanation is the ostrich effect (Loewenstein and Seppi (2005)). They provide evidence that investors monitor their portfolios more frequently in rising markets than when markets are flat or 
falling. If the finding also applies to individual stocks, then the rise in information demand upon the rise of a corporate event signals that the information content is good news, which pushes the price up. Empirically, I show that all the three channels are playing a role in driving the result with the non-fundamental channels play a larger role.

\section{Research Design}

\section{A. Data}

\section{A1. Company and Security Data}

I restrict the sample to each firm listed in NYSE, Nasdaq and Amex in CRSP/Compastat merged database, excluding REITS, Closed-End Funds, ADRs, Canadian Firms (and Other Non-U.S. Incorporated Firms), Primes and Scores, and HOLDRs. The accounting data is from Compastat and stock data is from CRSP. I keep firms that have both return and accounting data between 2004 and 2011 and drop firm-month that has a price in the previous month below 5 dollars, ending up with a sample of 5607 firms. DGTW stock deciles of Daniel, Grinblatt, Titman, and Wermers (1997) are obtained from Wermers' website. The analyst coverage data is from IBES, corporate events information is from CapitalIQ and the institutional ownership data is from Thomson Reuters.

\section{A2. News Article (Supply of Information)}

I follow Veldkamp (2006) to use the number of news articles as proxy for information supply. The news articles are from Factiva. I searched news articles related to a given firm in two ways.

Following Fang and Peress (2009), I searched news articles relevant to a given firm using tickers, but via Factiva instead of LexisNexis. More specifically, Factiva provides functionality called "Intelligent Index Search", which enables the user to search the news related to a firm by specifying the ticker symbol defined by Factiva universe. The ticker symbol used by Factiva is different from the official symbol by the stock exchanges, but Factiva provides a search functionality to search the firm by the firm's official ticker. A search for the Factiva symbol for each firm by its official exchange tickers yielded the Factiva ticker symbol for 3,516 firms out of the 5,607 firms. Factiva firm search functionality returned no result for the rest of the firms. I focused on the 3,516 firms in the analysis when using the data searched by ticker. Using the Factiva ticker, I searched the top published sources suggested by Factiva, including "Dow Jones Newswires", "Major News and Business Publications", "Press Release Wires", "Reuters Newswires", "The Wall Street Journal - All sources". I also limited the search to the region of "United States" and language of "English" for the period 2004 to 2011.

The second way to search the news articles is to follow Griffin, Hirschey and Patrick (2011) to search news related to a given firm by name. I used the same news source, region and language as previously described. I also limited the search to news articles 
with the name in the title or leading paragraph. Since I did not need to locate the Factiva Intelligent Index ticker, I obtained the search result for all 5607 firms.

\section{A3. Google Search Volume (Demand for Information)}

I follow Drake, Roulstone and Thornock (2012) to use Google search volume as the proxy for information demand. The search volume data is from Google Trends, which provides the time series of the search volume of the queried keywords, starting from 2004. The value of Google Trends is the percentage of the total search volume, and is further scaled by the maximum percentage of the keyword over time. Similar to the news article case, I searched for the firm by both stock ticker and company name. The search volume by stock ticker ensures that the search volume for a company most likely come from investors. In fact, the search volume by ticker and that by name are highly correlated. This implies that either the search volume by company name comes from investors or the search volume of investors is highly correlated to the total search volume by company name. I limited the geographical location of the search to "United States". Google Trends returned the message "Not enough search volume to show graphs" when the search volume was too low to form meaningful statistics. In this situation, I set the search volume of the entire time series to 0 . The value 0 does not mean no search at all, but that the search volume is extremely low.

I am studying the stocks that are properly covered by media and have meaningful search volume statistics. Therefore, I dropped the stocks without news articles and non-zero search volume statistics over the entire sample periods. I ended up with 3,133 stocks in the sample searched by ticker, denoting this sample as the "query-by-ticker" sample. In the "query-by-name" sample, I had 3378 firms.

\section{B. Supply and Demand "Pairs"}

My empirical strategy is to define 9 (3 by 3) scenarios of the information supply and demand shift and use them to test the theoretical predictions.

I divide the supply of information into three scenarios: no news coverage, increase in news coverage and decrease in news coverage. A firm-month is defined as no news coverage (denoted as News_Zero $=1$, and 0 otherwise) if there is no news coverage of the firm in the past 12 months. A firm-month is defined as an increase in news coverage (denoted as $\mathrm{News}_{-} U p=1$ and 0 otherwise) if the number of the current news articles on the firm is above the 12 month moving average of the articles on the same firm. A firmmonth is defined as a decrease in news coverage (denoted as News_Down $=1$, and 0 otherwise) if the number of the current news articles on the firm is below its 12 month moving average.

Similarly, I define the demand for information into three scenarios: no search volume, increase in search volume, and decrease in search volume. I define a firm-month as no search volume (denoted as Search_Zero $=1$ and 0 otherwise) if search volume is zero for the last 12 months. Then I define a firm-month as an increase in search volume 
(denoted as Search_Up $=1$ and 0 otherwise) and a decrease in search volume (denoted as Search_Down $=1$, and 0 otherwise) if the search volume is above and below its 12 month moving average respectively.

I then define a supply and demand shift "pair" by combing any supply shift and any demand shift, which yields nine supply and demand "pairs" (i.e. 3 supply shifts by 3 demand shifts). The main shift variables are four of the nine scenarios, i.e. SUDU=1 if "News Up" (i.e. Supply Upp) and "Search Up" (i.e. Demand Up), SUDD= 1 if "News Up" and "Search Down", SDDU=1 if "News Down" and "Search Up", SDDD=1 if "News Down" and "Search Down". The pairs with a "zero" scenario are not my main focus because my interest is in what happens in different supply and demand shift scenarios, whereas "zero" gives an ambiguous direction for the shift. Thus, I run the main tests on the four scenarios which give a clear cut on the direction of shifts.

Table 1 reports the summary statistics for both the query-by-ticker sample and query-byname sample. Table 1 Panel A reports the summary of firms' number of news articles and search volume as well as the ratio to their 12 month moving average. A majority of the firm-months have non-zero news articles and search volume. The number of news articles is positively skewed, while the search volume is symmetric. The ratio of the current value to the 12 month moving average is used to define the direction of the demand (or supply) shift. The mean (and median) of the ratios is close to 1, which implies that the unconditional probability of an upward and downward shift is close to even. Panel B confirms that the frequency to have upward (or downward) shift is close to $50 \%$ for both news and Google search. Panel B also shows that the probability of no news coverage in the past 12 months is only $1 \%-4 \%$, while the probability of an extremely low search volume is $11 \%-20 \%$. This means that I conduct the tests within the media-covered stock sample instead of a sample with a significant share of no-mediacoverage stocks. Panel C reports the summary of stocks by information supply and demand shift deciles. Contrary to the common conception that the shifts in news and Google search should have a strong positive correlation, the frequency of the four major shift scenarios are fairly evenly distributed. Taking query-by-ticker as an example, the probability that both news and search volume rise or fall is slightly higher: $23.4 \%$ and $24.8 \%$, while the probability to have one dimension rise and the other fall is slightly lower: $17.9 \%$ and $21.6 \%$. The shifts of supply and demand in the opposite direction are strongly presented in the sample, which supports the necessity of tackling the supply and demand jointly instead of only dealing with one of the two. Moreover, most of the firmmonths belong to the four main shift pairs ("non-zero" combinations). In Table A2 of the appendix, I show that the corporate events that drive the information supply are remarkably different from the events that drive the information demand. For example, an M\&A transition announcement tends to attract news coverage, while M\&A rumors tend to attract investor searches in Google (More detailed discussion in Section VI. B).

\section{Cross-Sectional Regressions}

I follow Cohen, Diether, and Malloy (2007) for the econometrics specification. They use both pooled panel regression with monthly fixed effects and a Fama Macbeth regression. 
They report their results in pooled panel regressions and note that Fama Macbeth results are robust. Their reason for reporting pooled panel regressions is that there are time periods when all their shift dummies are 0 . Since I have no such problem, I report Fama Macbeth regression results in the main tables and run a robustness check for pooled panel regression.

My baseline test model is a Fama Macbeth regression with Newey-West for 3 lags. DGTW adjusted return is used to measure stock abnormal returns. Following Daniel, Grinblatt, Titman, and Wermers (1997) and Wermers (2003), I subtract the corresponding DGTW portfolio return from the raw return of the stock. In the unreported robustness check, I also use CAPM, 3 Factor and 4 Factor alphas to measure abnormal returns, and the result is robust. In addition to the abnormal return, I also use the past 1 month return to control for reversal and control the return between the lagged 12 month and the lagged 2 month for momentum on the right hand side.

More specifically, I regress the abnormal return at time $t$ on $S U D U_{t-1}, S U D D_{t-1}$, $S D D U_{t-1}, r_{t-1}$ (last month's return), $r_{t-12,-2}$ (the return from month $t-12$ to $t-2$ ), $I O_{t-3}$ (the institutional ownership measured as the percentage of shares held by intuitional investors in the previous quarter), Volume $_{t-7,-1}$ (the average monthly trading volume of the past 6 months scaled by the total number of shares outstanding). I only include 3 of the 4 shift "pairs" because the summation of the four dummies is close to 1 and the constant term in the regression only allows at most 3 shift "pairs".

I also include additional control variables in the robust tests. First, I control for analyst coverage $\log (1+\#$ Analyst $)$, news coverage $\log (1+\# N e w s)$ and market equity $\log (M E)$, where \#Analyst is the number of analysts covering the stock, \#News is the number of news articles about the stock and $M E$ is the market equity value. Secondly, I control for industry fixed effect by including industry dummies in the Fama Macbeth regressions. Thirdly, I include the financial ratios to measure the company's profitability (profit margin and EPS/price), liquidity (debt ratio and current ratio), operating efficiency (asset turnover) and financial market valuation (market equity to book equity ratio). The profit margin is net profit divided by net sales, EPS is earning per share, debt ratio is total liabilities divided by total assets, current ratio is the current assets divided by the current liability, and asset turnover is net sales divided by total assets. The accounting data of the previous quarter is used.

The base line model takes the form:

$$
\begin{aligned}
& \text { Abnormal_Return } \\
& \quad=\alpha_{t}+\beta_{1} S U D U_{t-1}+\beta_{2} S U D D_{t-1}+\beta_{3} S D D U_{t-1}+\beta_{4} r_{j, t-1}+\beta_{5} r_{j, t-12,-2}+\beta_{6} I O_{j, t-3} \\
& +\beta_{7} \text { Volume }_{j, t-7, t-1}+\text { Additonal_Controls } \\
& +\epsilon_{t} \\
& \text { where Abnormal_Return is the DGTW adjusted return. }
\end{aligned}
$$

\section{Empirical Results}

\section{A. Shift in Information Supply and Demand on Stock Return}


Table A1 in Appendix 1 shows that the shift in supply alone (demand alone) predicts the future return by itself on average. However, in this section, I will show that the prediction might strengthen or vanish conditional on the demand shift (supply shift), which defends the idea that jointly taking both information supply and demand into consideration is important.

Table 2 reports the main hypothesis tests. Panel A reports the results for the query-byticker sample and Panel B presents the findings of the query-by-name sample. I drop firm-month with News_Zero $=1$ or Search_Zero $=1$ to eliminate the possibility that the shifts with "zero" drive the significance. Since the summation of the four main shifts dummies is 1 , I only include three of the four main shift dummies in the regression. Panel A indicates that an upward shift in both information supply and demand (SUDU=1) consistently exhibits high predictability while the other shift "pairs" show no significance. The shift "pair" $S D D U$ shows a marginal significance but the t-statistics is too low (only 1.58-1.771) and it is not persistent with additional control variables, hence I conclude that it has no significant prediction power. I also do the robustness check by including SDDD and excluding either SUDD or SDDU from the model, and the result is persistent. Namely, only SUDU has statistically significant coefficient. The findings imply that there is no price impact of an increase in information supply (demand) when information demand (supply) decreases, i.e. the price impact is over-estimated. On the other hands, the coefficient estimates of News_Up (Search_Up) are between 0.00517 and 0.00867 (reported in Table 1A in the appendix), while the coefficients of SUDU are between 0.0123 and 0.0174 . This means that the price impact of an increase in information supply (demand) when information demand (supply) increases is 2 to 3 times larger than the average price impact of an increase in information supply (demand) unconditional on information demand (supply), i.e. the estimated price impact is bias downward.

Since $S U D U$ is a dummy, the coefficient can be simply interpreted as the monthly return difference between stocks with $S U D U=1$ (i.e. both information supply and demand rise) and other stocks. For example, Model 1 indicates that stocks with an upward shift in both information supply and demand outperform other stocks by $15.6 \%$ per year. Models 2 to 6 show that the results are robust even after controlling for trading volume, institutional ownership, analyst coverage, news coverage, equity market value, company profitability, company operation efficiency, company liquidity and market to book ratio, and industry. Panel B shows similar results from the query-by-name sample. The only difference is that the economic scale is larger. For example, Model 1 implies an annual performance impact of $19.2 \%$, which is higher than $15.6 \%$ in the query-by-ticker sample.

Since only the shift "pair" SUDU (i.e. an upward shift for both information supply and demand) predicts stock returns, I focus on the "pair" SUDU and conduct portfolio analysis in the next section.

\section{B. Portfolio Strategy}


To demonstrate that the predictability is tradable, I do a portfolio analysis, and find that the economic scale of the portfolio strategy is striking. The portfolio analysis is summarized in Table 3. I form a long-short portfolio of buying the stocks with an upward shift in both information supply and demand and short selling the other stocks. The result shows that stocks with an upward shift in both supply and demand outperform the other stocks in various risk adjusted performance measures. The result is robust for both queryby-ticker and query-by-name samples. The economic significance is stunning. The longshort portfolio generates abnormal returns between $16 \%$ and $22 \%$ per year. The sharp ratio is between 0.85 and 0.9, which is much higher than S\&P500 Sharpe ratio of 0.049 in the same period. This implies that the portfolio delivers a higher return NOT at the cost of higher return volatility.

\section{Supply and Demand Shift on Stock Returns in Various Subsamples}

Barber, Brad, and Odean (2000) demonstrate that individual investors tilt their common stock investment toward high-beta, small, and value stocks. I expect the individual investors to heavily rely on news and Google search for information. Therefore, the effect I find should be more salient in the subsample of small stocks, high market-equity to book-equity ratio stocks, high beta stocks and the high return volatility stocks.

I test this conjecture by doing portfolio analysis within each subsample by size, market equity to book equity ratio, beta and return volatility. Table 4 reports the results. Panel A splits the sample into large size and small size subsamples. I directly obtain the size decile from Wermers' website and classify deciles 1 and 2 as the small size subsample and the rest as the large size sample. The result shows that the upward shift of both supply and demand predicts positive return in both the small and large size sample. However, the economic significance in the small size subsample (23\%-34\% per year) is much larger than that in the large size subsample (only $7 \%-12 \%$ per year). Panels B and $\mathrm{C}$ report the results for book-equity to market equity deciles and beta deciles respectively, where the BE/ME decile is obtained from Wermer's website and beta decile is obtained from CRSP. I found no significant difference in these deciles. Panel D reports the test in volatility deciles which are obtained from CRSP. The high volatility decile shows an annual impact of $24 \%-32 \%$ while the low volatility decile has a performance impact of only $3 \%-5 \%$ per year.

\section{Supply and Demand Shift on Stock Returns Conditional on Event Types}

In this subsection, I show that the return predictability is not driven by one single type of events. If the finding is driven by one single event type (e.g. earnings announcements), then only the upward shift "pair" in the months when this particular type of events occurs can predict future returns. To test this hypothesis, I use the following Fama Macbeth regression with Newey-West 3 lags:

$$
\begin{aligned}
& \text { Abnormal_Return }_{t}=\alpha_{t}+\beta_{1} \text { Event }_{k, t-1} \times S U D U_{t-1}+\beta_{2}\left(1-\text { Event }_{k, t-1}\right) \times \\
& S U D U_{t-1}+\text { Controls }+\epsilon_{t},
\end{aligned}
$$


where Abnormal_Return $_{t}$ is measured by DGTW adjusted return and Event $_{k, t-1}$ is 1 if event type $k$ happens for the firm in month $t$-1. If the predictability of $S U D U_{t-1}$ is entirely driven by event $k$, then $\beta_{1}$ should capture the full significance of $S U D U_{t-1}$ and leave $\beta_{2}$ insignificant. I collect the event dates for the top 30 types of corporate events, which account for $87 \%$ of all the corporate events by the frequency of occurrence. I run the regressions for each event type and Table 5 reports the results. In Table 5, the first four columns are outputs of the regression for query-by-ticker sample. Column 1 reports the coefficient $\beta_{1}$ with the t-statistics in Column 2. Similarly, Column 3 reports the coefficient $\beta_{2}$ with the t-statistics in Column 4. Each row reports the result for one type of corporate events. The result shows that no single corporate event type can subsume the entire significance found in $S U D U_{t-1}$ because $\beta_{2}$ is always highly significant although some event types (e.g. earning announcement) indeed play a larger role than the other event types (e.g. regular dividends).

\section{Explaining the Phenomenon}

In this section, I discuss four possible causes of the documented phenomenon: the increase in new investors' awareness (i.e. the breadth of investors' participation), the increase in existing investors' learning effort (i.e. the in-depth of investors' participation), good news driven and risk based explanation. Awareness and learning can push stock prices up even when the odd to have good and bad news of equal importance is $50 \%$ to $50 \%$ while good news driven channel works if the odds to have good news are higher.

\section{A. The Increase in Investors' Awareness}

An individual has limited cognitive resources and is unlikely to be able to consider every stock in the stock market. Barber and Odean (2008) argue that investors only include the first few stocks that catch their attention for their consideration. An upward shift in both information supply and demand implies that more investors have noticed the existence of the stock as a potential investment opportunity. Furthermore, the investors that are attracted by news tend to buy rather than sell the stocks that grab their attention. The asymmetric behavior will drive the price up even when the information content is neutral (i.e., neither good nor bad on average).

If this channel is true, individual investors would intensively buy stocks with good news, but less intensively sell stocks with bad news when both information supply and demand rise. The buy-sell asymmetry would cause the outperformance if investors exhibited such behavior to a less extent in the other shift "pairs". I use the average analyst recommendation as the proxy for good news and bad news. IBES summarize the analyst recommendation in a score from 1 to 5 , with 5 to be "highly recommended". If the score for a stock rises over the month, then it is most likely that the news during the month is good news in aggregation. I define Good_News $=1$ if the analyst recommendation score is above its 12 months moving average and 0 otherwise. Moreover, Bad_News = 1Good_News. Then I run the following Fama Macbeth regression with Newey-West for 3 lags. 


\section{Abnormal_Return}

$$
\begin{aligned}
& =\alpha_{t}+\beta_{1} \text { Good_NewS }_{t-1} \times S U D U_{t-1}+\beta_{2} \text { Bad_New }_{t-1} \times S U D U_{t-1} \\
& +\beta_{3} \text { Good_News }_{t-1} \times S U D D_{t-1}+\beta_{4} \text { Bad_News }_{t-1} \times S U D D_{t-1} \\
& +\beta_{5} \text { Good_NewS }_{t-1} \times S D D U_{t-1}+\beta_{6} \text { Bad_News }_{t-1} \times S D D U_{t-1} \\
& +\beta_{7} r_{j, t-1}+\beta_{8} r_{j, t-12,-2}+\beta_{9} I O_{j, t-3}+\beta_{10} \text { Volume }_{j, t-7, t-1} \\
& + \text { Additonal_Controls }+\epsilon_{t}
\end{aligned}
$$

Table 8 reports the regression results. The table indicates that only the upward shift in both supply and demand accompanied by the good news predicts stock returns both statistically and economically. The result confirms that investors exhibit significant asymmetric buy-sell behavior only when both information supply and demand rise, which drives the outperformance of stocks with this particular shift "pair". I verify the finding in a portfolio analysis in Table 9. I split stocks into good news subsample and bad news subsample. Panel A in Table 9 reports the abnormal return of a portfolio to go long the stocks with the increase in both information supply and demand (i.e. SUDU=1) and go short the other stocks (i.e. SUDU=0) within each subsample. The result shows that stocks with the upward shift "pair" significantly outperform the other in the good news subsample. On the other hand, stocks with the upward shift "pair" only marginally underperform the other stocks in the bad news subsample, which shows that the buy-sell asymmetry exists. The result also shows that good/bad news is not the only force driving the finding because I form the portfolios within in either good news or bad news subsample and the performance difference between the upward shift "pair" and the other shift "pairs" still persist. Panel B of Table 9 investigates the impact of the information supply and demand on the performance difference between the stocks with good news and bad news. A portfolio of buying stocks with good news and short selling stocks with bad news within each information demand and supply shift "pair" is constructed. The result shows that performance difference between good news stocks and bad news stocks are only significant in the subsample in which the upward shift in both information supply and demand happens. This implies that information supply and demand dynamics play a crucial role in driving the incorporation of good news and bad news into the stock price.

\section{B. The Increase in Existing Investors' Learning}

When the information supply is abundant and less costly to search and access, existing investors learn more about the stock and thus investors' posterior variance of the payoff is lower, which makes the asset more attractive to investors. Therefore, the demand for the stock increases and stock price rises. Veldkamp (2006) shows empirically that price goes up when the number of news goes up at the country level and she also demonstrates, in a numerical simulation of her model, that stock prices display over-reactions to changes in fundamental when information is abundant.

However, it is difficult to verify the channel of existing investors' learning at stock level because it is hard to differentiate whether the increase in search volume (information demand) comes from the new investors who are not aware of the stock or from the 
existing investors. I use the web traffic to the company page on Wikipedia to address the issue partially. The Wikipedia page for a firm usually appears in the first page of the search result when I search the company name on Google. Differently from new investors who do not have the stock in mind and even lack the basic information about the firm, existing investors already possess some basic knowledge about the firm. Therefore, I assume that the existing investors are less likely to click the link to the Wikipedia page from the result page of a Google search than new investors who are just aware of the stock and resort to Wikipedia link for some mere basic information about the company. If this assumption holds, then the Wikipedia traffic is a proxy for the learning of new investors and the Google search volume net of Wikipedia traffic captures more about the learning of the existing investors.

I construct the Google search volume net of Wikipedia traffic as Search_Residual ${ }_{s, t}=$ Search_Volume ${ }_{s, t}-\hat{\gamma}_{s} \times W i k i \_V_{\text {Volume }}, t$ where $\hat{\gamma}_{s}$ is the coefficient of the regression Search_Volume ${ }_{s, t}=\gamma_{s} \times W i k i_{-} V o l u m e_{s, t}+\epsilon_{s, t}$, where Search_Volume is the Google search volume and Wiki_Volume is the web traffic to the company page on Wikipedia. I managed to obtain the Wikipedia web traffic data from 2008 to 2011 for companies listed in NYSE. I use Search_Residual and Wiki_Volume as the proxies for information demand of investors who have already known some basic information about the stock and those who have not even possess such basic knowledge respectively. Using Search_Residual and Wiki_Volume as alternative information demand measures, I construct the shift "pairs" in the same manner as before. Specifically, SUDU_Wiki=1 if "News Up" (i.e. Supply Up) and "Wiki Up" (i.e. Demand Up, where "Wiki Up" happens if the Wikipedia traffic to the company page is above its 12 months moving average), SUDD_Wiki= 1 if "News Up" and "Wiki Down", SDDU_Wiki=1 if "News Down" and "Wiki Up", SDDD_Wiki=1 if "News Down" and "Wiki Down", SUDU_Residual=1 if "News Up" (i.e. Supply Up) and "Search_Residual Up" (i.e. Demand Up, where "Search_Residual Up" happens if the Google search volume net of Wikipedia traffic is above its 12 months moving average), SUDD_Residual = 1 if "News Up" and " Search_Residual Down", SDDU_Residual =1 if "News Down" and "Search_Residual Up", SDDD_Residual =1 if "News Down" and "Search_Residual Down". The regression model is Fama Macbeth regression with Newey-West for 3 lags.

$$
\begin{aligned}
& \text { Abnormal_Return } n_{t} \\
& =\alpha_{t}+\beta_{1} S U D U_{-} W i k i_{t-1}+\beta_{2} S U D D_{-} W i k i_{t-1}+\beta_{3} S D D U \_W i k i_{t-1} \\
& +\beta_{4} r_{j, t-1}+\beta_{5} r_{j, t-12,-2}+\beta_{6} I_{j, t-3}+\beta_{7} \text { Volume }_{j, t-7, t-1} \\
& + \text { Additonal_Controls }+\epsilon_{t}
\end{aligned}
$$

\section{Abnormal_Return $n_{t}$}

$$
\begin{aligned}
& =\alpha_{t}+\beta_{1} \text { SUDU_Residual }{ }_{t-1}+\beta_{2} \text { SUDD_Residual }_{t-1} \\
& +\beta_{3} \text { SDDU_Residual } \\
& +\beta_{7-1}+\beta_{4} r_{j, t-1}+\beta_{5} r_{j, t-12,-2}+\beta_{6} I_{j, t-3} \\
& \text { olume }_{j, t-7, t-1}+\text { Additonal_Controls }+\epsilon_{t}
\end{aligned}
$$

Table 10 and 11 report the results respectively for the two alternative information demand measures. Both tables show that the upward shift "pair" predicts the stock returns, 
which implies that both the learning of new investors and the learning of the existing investors play a partial role in driving the main result.

\section{Good News Driven}

Loewenstein and Seppi (2005) document that investors monitor their portfolios more frequently in rising markets than when markets are flat or falling. If this ostrich effect applies to individual stocks, the upward shift "pair" implies that investors embracing good news for the stock and therefore learn more, and the good fundamentals push up the prices. To verify the channel, I compare the percentage of stocks with good news in the upward shift "pair" decile with that of stocks in the other deciles. I plot the time series of the percentage in Figure 2. Figure 2 shows that stocks with upward shift "pair" have a higher probability to embrace good news than the rest of the stocks in every period. This finding implies that the good fundamentals are indeed driving the prices up but the question is what percentage of the abnormal return is due to good fundamentals.

To address the question, I make the assumption that an abnormal return driven by fundamentals should not reverse over time but be a persistent component in the stock prices. Then I study the relationship between the shift and the accumulated abnormal return over various time horizons. The component due to fundamentals should be a permanent component in the prices even when I increase the duration of the portfolio holding period. I follow Jegadeesh and Titman (1993) to form an overlapping portfolio over different time horizons. Taking a 12 months overlapping portfolio as an example, in each month, I rebalance 1/12 of the portfolio to buy stocks with an upward shift in both information supply and demand and short sell the other stocks, while keeping the rest of 11/12 portfolio intact. Table 6 reports the results of 1 month, 3 month, 6 month and 12 month overlapping portfolios in various risk adjusted returns. The result indicates that the portfolio has a small persistent abnormal return component. For instance, the 4 factors alpha in the query-by-name sample is $18 \%$ per year in the 1 month overlapping portfolio while the alpha decreases to $4.36 \%$ per year in the 12 months overlapping portfolio. I plot the 4 factor alpha over various holding periods in Figure 3. Figure 3 shows that there is a persistent component, which is about $25 \%$ of the total abnormal return ${ }^{5}$. The result shows that good fundamentals only explain a small component $(25 \%)$ of the total abnormal return documented. Non-fundamental reasons are driving the rest of the $75 \%$ abnormal return, which reverses over time.

I also document an interesting observation. Since the accumulated abnormal return decays fast within the first few months, I would expect a high probability of stocks being in different shift "pair" deciles over different periods. To understand this, I compute the transition probability of a stock from one shift "pair" decile to another over time. I tabulate the transitional probability up to 12 months in Table 7. Panel A reports the transitional probability in 1 month. For example, the figure of $35 \%$ in the first column and third row means that the transitional probability from $S U D U=1$ to $S D D U=1$ in one month is $35 \%$ given that the current state is $S U D U=1$. This shows that there is a

\footnotetext{
${ }^{5}$ In the unreported tests, I extend the holding period up to 2 years and the scale of the persistent component
} of the abnormal return remains at about $4 \%$ a year. 
high probability for a stock to be in different shift deciles over two adjoining months. Another interesting observation is that the number of news articles is the dimension that has a higher probability to transit to other deciles. For example, the probability from $S U D U=1$ to $S U D D=1$ in one month is only $10 \%$ compared to $35 \%$ in the shift from $S U D U=1$ to $S D D U=1$. This shows that information supply (news) tends to change frequently while information demand (search volume) tends to be persistent.

\section{Risk Based Explanations}

A risk-based hypothesis can be a potential alternative explanation. Namely, the upward shift in both supply and demand is related to a high risk level. The subsequent positive return is just the compensation to investors to bear the risk. However, I argue that the risk-based explanation is less likely. First, in the analysis, I used factor models and DGTW adjusted return to control for the well-known risk factors, which cannot fully explain the abnormal returns. Secondly, Bernard and Thomas (1989) argues that if a portfolio strategy yields a positive average return because it is risky, then the risk must periodically manifest itself in the form of loss. I follow this notion and plot the profit and loss of the portfolio over the sample period in Figure 1. The figure shows that the portfolio is almost always making a positive profit and has no substantial loss, which is inconsistent with the risk based hypothesis. In the query-by-ticker sample, out of the 84 months, only 7 months make a loss and the remaining 77 months make a profit. Moreover, the loss in the 7 months is very moderate, all below 1\%. The query-by-name sample shows a similar pattern: only 6 out of 84 months incur very small losses. The two samples have mean returns of $1.54 \%$ and $1.74 \%$ respectively, and standard deviations of $1.7 \%$ and $2 \%$. The S\&P500 mean return and standard deviation are $0.25 \%$ and $5.02 \%$. Therefore, the portfolio, in fact, is a low risk and high return portfolio rather than a high risk and high return portfolio, which causes the Sharpe ratio to be as high as 0.85 and 0.9 (S\&P500 Sharpe ratio is 0.049 during the same period). Thirdly, if an upward shift in both information supply and demand corresponds to some risk premium, then the evaluation of the stock should be lower to compensate the risk. Therefore, we should observe that the market equity to book equity ratio is lower for stocks with the upward shift "pair". However, I did not find a significant price difference (measured by market equity to book equity ratio difference) between the stocks with an upward shift "pair" and the other stocks. Fourthly, Tetlock (2010) shows that news reduces the information asymmetry between informed traders and uninformed traders. In addition, Drake, Roulstone, and Thornock (2012) find a higher Google search volume is accompanied by a higher alignment between the pre-announcement price and the upcoming earning news. Both papers show that the increase in information supply and information demand is more likely to help to reduce the risk instead of increasing the risk. Based on these evidences, risk based explanation is less likely.

\section{Some Side Comments}

\section{A. Is Google Search Volume a Measure of Level?}


In Google Trends, the actual search volume is normalized by the total search volume of all the keywords at each point in time. Then the entire time series of the normalized search volume is further scaled by the maximum point of the time series. The scaling process makes the search volume for each keyword nicely presented in a $[0,100]$ interval. However, unfortunately, due to the scaling, the search volume of two keywords is not comparable in scale. For example, both keyword $\mathrm{X}$ and keyword $\mathrm{Y}$ in month $\mathrm{t}$ have a scaled search volume of 2, but the maximum search volume for $\mathrm{X}$ and $\mathrm{Y}$ are $1 \%$ and $0.01 \%$ of the search volume of all the keywords. Then the actual search volume of $\mathrm{X}$ is 100 times of the actual search volume of $\mathrm{Y}$ even though they have the same scaled search volume. This scaling process makes it conceptually incorrect to test anything related to the level of the search volume across different keywords. The only valid comparison is along the time series. I use the change in the scaled search volume along each time series to construct the supply shift measure to avoid the incomparability problem across keywords.

\section{B. Event Types on Information Supply and Demand}

Table 5 shows heterogeneity among different event types in driving the predictability of the upward shift "pair". A natural question to investigate is which event types are playing larger roles in driving the information supply and demand shifts. I try to see the correlation between the occurrence of a type of corporate events and the information supply and demand dynamics using the following Fama Macbeth regression model:

Shift $_{t}=\alpha_{t}+\beta_{1}$ Event $_{k, t}+\epsilon_{t}$

where Shift $t_{t} \in\left\{N e w s_{-} U p_{t}, S_{e a r c h} U p_{t}, S U D U_{t}\right\}$ and $E v e n t_{k, t}$ is 1 if event type $k$ happens for the firm in month $t$. The coefficient $\beta_{1}$ measures how more likely for Shift $t_{t}$ to happen in cross section in month $t$ if Event ${ }_{k, t}$ happens. I conduct the tests for information supply shift alone, information demand shift alone and the shift "pair". Table A 2 in the appendix reports the regression results. For the query-by-ticker sample, the top five corporate events which induce media coverage, are "Announcement of Earnings", "Earning Calls", "M\&A Transaction Announcement", "Delayed SEC Filing" and "Corporate Guidance-New/Confirmed", while the top 5 corporate events which attract search volume, are "Fixed Income Offering", "M\&A Rumor and Discussion", "Corporate Guidance-New/Confirmed", "Discontinued Operations/Downsizing" and "Index Constituent Drop". The list shows that the corporate event types that draw attention from the media and investors are remarkably different. Only corporate guidance makes it in both lists. It seems that media tend to report affirmative news while investors tend to search for ambiguous events, e.g. M\&A announcement v.s. M\&A rumor. Compared to information supply, information demand is less predictable by the occurrence of a particular event type. This finding also shows that the information supply and information demand behave differently with the same corporate events, which is strong evidence in support of the notion of analyzing both supply and demand rather than relying on only one of the two.

\section{Dynamic State and Static Status}


This research is related to but different from the empirical test about Merton (1987) which shows that in a market with incomplete information, stocks with fewer investors to include the stocks in their investment sets need to offer higher returns as compensation. The hypothesis is evidenced in Fang and Peress (2009), who find that stocks with no media coverage earn a higher return than those with extensive media coverage because no media coverage firms suffer a high information problem and have a higher expected future return as a compensation for the risk. Fang and Peress (2009) focus on whether the company is covered by media, which I rephrase as a 'status', meaning that whether there are journalists to monitor the firm's activities and report the activities when something happens. In contrast, this research focuses on what is happening when the number of news reports deviates from the company's normal coverage level given that the firm is already properly monitored by media outlets. I phrase the focus as a 'state'. In summary, I position the research as a study about firm 'state' compared to Fang and Peress (2009) as a firm 'status'.

The argument is evidenced by the transitional probability in Table 7. The four "non-zero" shift "pairs" have extremely low probability to transit out of the four deciles, which shows that the decile with and without "zeros" are very different. Furthermore, the "zero" shift "pairs" mainly jump along the "non-zero" dimension (e.g. in Panel A, $($ News_Zero $=1$,Search_Up $=1)$ has $60 \%$ probability to stay where it is and $17 \%$ probability to jump to $($ News_Zero $=1$,Search_Down $=1)$ ). This evidence shows that zero news coverage and zero search volume are more likely to be a time persistent "status" instead of a time varying "state".

\section{Search by Ticker and Search by Name}

I report the result for both query-by-ticker and query-by-name sample to ensure a robust statistical inference. The benefit in query-by-ticker sample is that tickers are less ambiguous than names. The search volume for ticker captures exactly the search activities of investors because the consumers are less likely to look for products by company ticker. However, the benefit of unambiguity might come at the cost of precision to the research. I view the Google search volume as a residual information demand of investors on top of their normal information source without a need of Google search. It is more likely that the investors will search by the company name to look for extra news they demand. Further, the search volume by name is highly correlated to the search volume by tickers. It either implies that search volume by name also captures the investors' search activities or implies that search activities of investors are highly correlated to the overall search volume for companies' names. Both cases make search volume by company name a good proxy of investors' searching activities. In fact, the test result of query-by-name sample seems to support this possibility. This is evidenced by a larger economical scale. The by-product of this research shows that it is undetermined whether the sample should be collected by using company name or ticker in the research about news and Google search volume. Which one fits better depends on the research story under investigation. 


\section{Conclusion}

The key message of the paper is that it is important to incorporate both information supply and demand to study the impact of information on stock prices. Information affects stock prices in two aspects. For one thing, the information contents (e.g. good news and bad news) affect stock prices. For another, the cognitive impact of the information on investors (e.g. investors' awareness and learning) can also affect stock prices even when the news is neutral (i.e. the odds to have good versus bad news of equal importance are 50\% to 50\%). The focus of the paper is the latter aspect although I also briefly investigate the first channel (i.e. good news in the information content). Both channels involve an occurrence of news and the simultaneous actions of investors to digest the news, making both information supply and demand jointly important.

I propose to use the joint shifts in both information supply and demand to isolate the channel through which the information affects stock prices. Employing an identification strategy of using information supply and demand shifts "pairs", I am able to determine whether an information supply shift (or an information demand shift) goes through the right channel which can affect stock returns. Specifically, for the cognitive channels, an information demand shift helps to determine whether an information supply shift indeed succeeds in increasing investors' awareness and information learning effort and, therefore, predict positive future returns. On the other hand, for the fundamental channels, a rise in information supply upon the occurrence of news indicates a high likelihood of good news by ostrich effect. Similarly, an information supply shift helps to ensure that an information demand shift is caused by real corporate news instead of pure sentiment, which predict stock returns differently.

Empirically, I show that only the upward shift of both supply and demand for information dominates the predicting power over the other shifts in supply and demand. This implies that the information supply affects stock return only if there is a demand for information. The result is robust after controlling for price reversal, price momentum, trading volume, institutional ownership, analyst coverage, news coverage, market equity value, market equity to book equity ratio, firm profitability, firm liquidity, firm operating efficiency and industry.

I demonstrate that the cross sectional difference in return is tradable. A monthly rebalanced portfolio to buy stocks with this shift "pair" and short sell the other stocks delivers an abnormal return between $16 \%$ and $22 \%$ per year with a Sharpe ratio between 0.85 and 0.9 (S\&P500 sharp ratio is 0.049 in the same period). The abnormal return increases to $23 \%-34 \%$ per year in the small stocks subsample.

There are three explanations for the documented observation. The first explanation is that the rise in information supply increases the awareness of the stock. The increase in information demand confirms that individual investors who do not have this stock in their mind start considering investing in the stock. The stock price is pushed up because these investors tend to buy rather than sell the attention grabbing stocks. Consistent with the explanation, I observe that investors intensively buy stocks with good news but less 
intensively sell stocks with bad news when both information supply and demand rise. The second explanation is that an increase in the information supply induces the existing investors (i.e. investors with this particular stock in their mind) to learn more and thus reduces their posterior variance of the asset payoff conditional on the abundant information. Therefore, lower risk makes the asset more attractive to investors, increases demand and raises the price. The result shows that the upward shift with Google search volume net of the Wikipedia traffic as information demand proxy also predict stock returns, which implies that the learning of existing investors (who already possess some basic knowledge of the firm and less likely to visit Wikipedia) play a role in the predictability. The third explanation is that upward shift implies higher likelihood of good news because of ostrich effect (investors monitor their portfolio more closely when the market is good). I indeed find evidence to support that. However, I assume that the rise in price due to fundamentals do not reverse over time and show that the good fundamentals only drive a small component of the total abnormal return.

The result shows that the attempt to disentangle the information supply and demand in the financial market is not only theoretically appealing but also practically meaningful. 


\section{Reference}

Andrei, Daniel, and Michael Hasler. "Investor's Attention and Stock Market Volatility." Available at SSRN 1761421 (2011).

Barber, Brad M., and Terrance Odean. "All that glitters: The effect of attention and news on the buying behavior of individual and institutional investors." Review of Financial Studies 21, no. 2 (2008): 785-818.

Barber, Brad M., and Terrance Odean. "Trading is hazardous to your wealth: The common stock investment performance of individual investors." The Journal of Finance 55, no. 2 (2000): 773806.

Barber, Brad M., Terrance Odean, and Ning Zhu. "Do retail trades move markets?." Review of Financial Studies 22, no. 1 (2009): 151-186.

Bernard, Victor L., and Jacob K. Thomas. "Post-earnings-announcement drift: delayed price response or risk premium?." Journal of Accounting research (1989): 1-36.

Chan, Wesley S. "Stock price reaction to news and no-news: Drift and reversal after headlines." Journal of Financial Economics 70, no. 2 (2003): 223-260.

Cohen, Lauren, Karl B. Diether, and Christopher J. Malloy. "Supply and demand shifts in the shorting market." The Journal of Finance 62, no. 5 (2007): 2061-2096.

Da, Zhi, Joseph Engelberg, and Pengiie Gao. "In search of attention." The Journal of Finance 66, no. 5 (2011): 1461-1499.

Daniel, Kent, Mark Grinblatt, Sheridan Titman, and Russ Wermers. "Measuring mutual fund performance with characteristic-based benchmarks." The Journal of Finance 52, no. 3 (1997): 1035-1058.

Drake, Michael S., Darren T. Roulstone, and Jacob R. Thornock. "Investor information demand: Evidence from Google searches around earnings announcements." Journal of Accounting Research (2012).

Fang, Lily, and Joel Peress. "Media Coverage and the Cross-section of Stock Returns." The Journal of Finance 64, no. 5 (2009): 2023-2052.

Griffin, John M., Nicholas H. Hirschey, and Patrick J. Kelly. "How Important Is the Financial Media in Global Markets?." Review of Financial Studies 24, no. 12 (2011): 3941-3992.

Hong, Harrison, Terence Lim, and Jeremy C. Stein. Bad news travels slowly: Size, analyst coverage and the profitability of momentum strategies. No. w6553. National Bureau of Economic Research, 1998.

Huberman, Gur, and Tomer Regev. "Contagious speculation and a cure for cancer: A nonevent that made stock prices soar." The Journal of Finance 56, no. 1 (2002): 387-396. 
Jegadeesh, Narasimhan, and Sheridan Titman. "Returns to buying winners and selling losers: Implications for stock market efficiency." The Journal of Finance 48, no. 1 (1993): 65-91.

Kahneman, Daniel. "Attention and effort." (1973).

Karlsson, Niklas, George Loewenstein, and Duane Seppi. "The ostrich effect: Selective attention to information." Journal of Risk and Uncertainty 38, no. 2 (2009): 95-115.

Kim, Oliver, and Robert E. Verrecchia. "Trading volume and price reactions to public announcements." Journal of Accounting Research (1991): 302-321.

Klibanoff, Peter, Owen Lamont, and Thierry A. Wizman. "Investor Reaction to Salient News in Closed-End Country Funds." The Journal of Finance 53, no. 2 (1998): 673-699.

Merton, Robert C. "A simple model of capital market equilibrium with incomplete information." The Journal of Finance 42, no. 3 (1987): 483-510.

Meschke, Felix. "CEO interviews on CNBC." (2003).

Miller, Edward M. "Risk, uncertainty, and divergence of opinion." The Journal of Finance 32, no. 4 (1987): 1151-1168.

Mondria, Jordi, and Thomas Wu. "Asymmetric attention and stock returns." In AFA 2012 Chicago Meetings Paper. 2011.

Peress, Joel. "Media coverage and investors' attention to earnings announcements." INSEAD, Fountainebleau, France (2008).

Romer, Paul. "Endogenous technological change." Journal of Political Economy (1990), Vol. 98, No. 5.

Savor, Pavel. "Stock returns after major price shocks: the impact of information." Journal of Financial Economics (2012).

Tetlock, Paul C. "Does public financial news resolve asymmetric information?." Review of Financial Studies 23, no. 9 (2010): 3520-3557.

Tetlock, Paul C. "Giving content to investor sentiment: The role of media in the stock market." The Journal of Finance 62, no. 3 (2007): 1139-1168.

Tetlock, Paul C., Maytal Saar-Tsechansky, and Sofus Macskassy. "More than words: Quantifying language to measure firms' fundamentals." The Journal of Finance 63, no. 3 (2008): 1437-1467.

Veldkamp, Laura L. "Media frenzies in markets for financial information." The American Economic Review (2006): 577-601.

Vlastakis, Nikolaos, and Raphael N. Markellos. "Information demand and stock market volatility." Journal of Banking \& Finance (2012). 
Wermers, Russ R., Is Money Really 'Smart'? New Evidence on the Relation Between Mutual Fund Flows, Manager Behavior, and Performance Persistence (May 2003). 


\section{Figure 1: Portfolio Performance}

Figure 1 reports the performance of a portfolio of buying the stocks with the increase in both information supply and demand and short selling the other stocks. The long and short portfolio is an equal weight portfolio and monthly rebalanced based on the information supply and demand in the previous month. The figure plots the monthly excess return (i.e. raw return-risk free rate) over time for both query-by-ticker and query-by-name samples. The sample period is from $2005 \mathrm{M} 1$ to $2011 \mathrm{M} 12$.

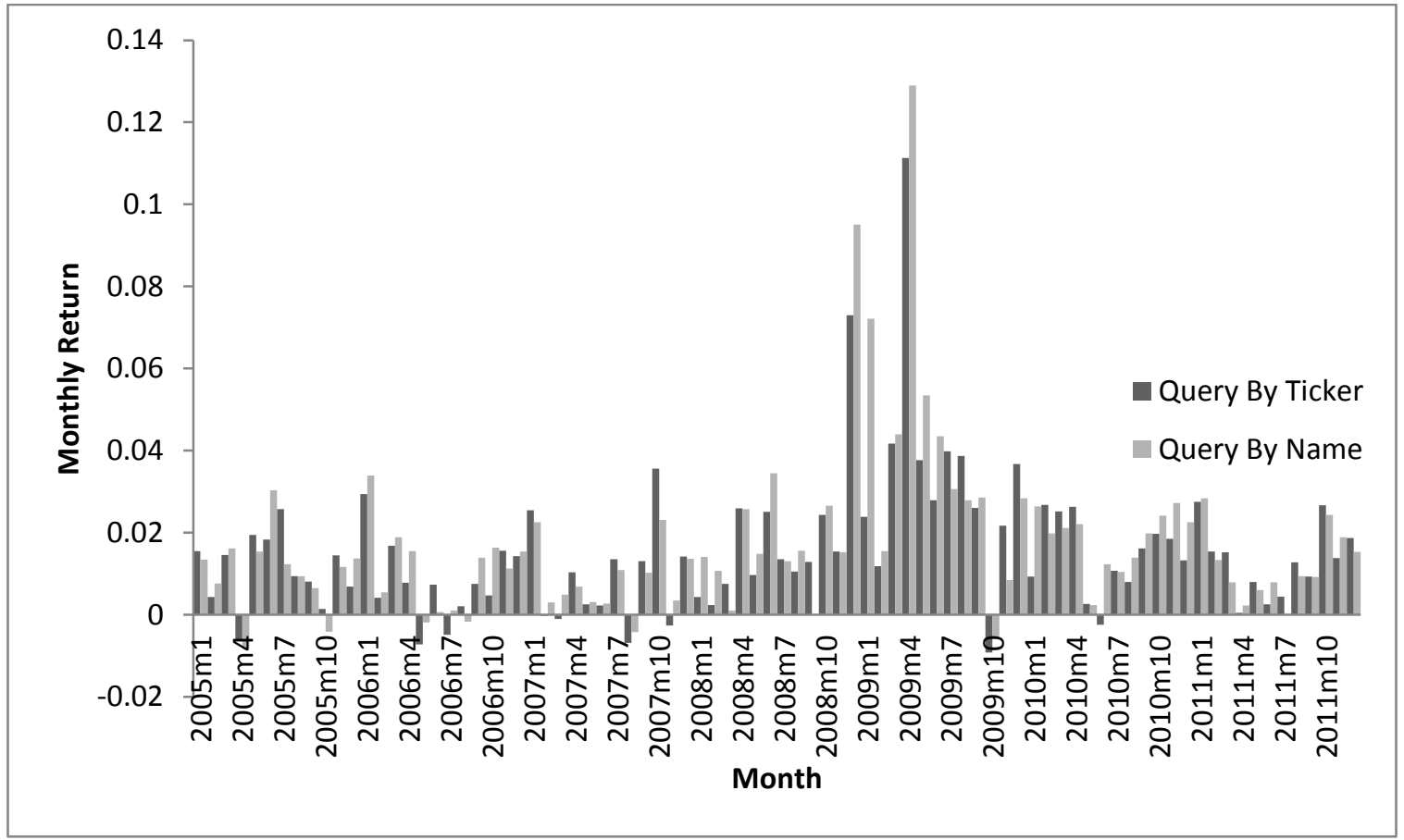


Figure 2: SUDU=1 and Good News

Figure 2 plots the percentage of stocks with good news in decile SUDU=1 and in deciles SUDU $=0$ over the sample periods. Figure 2 reports both query-by-ticker and query-by-name samples. The sample period is between 2005M1 and 2011M12.
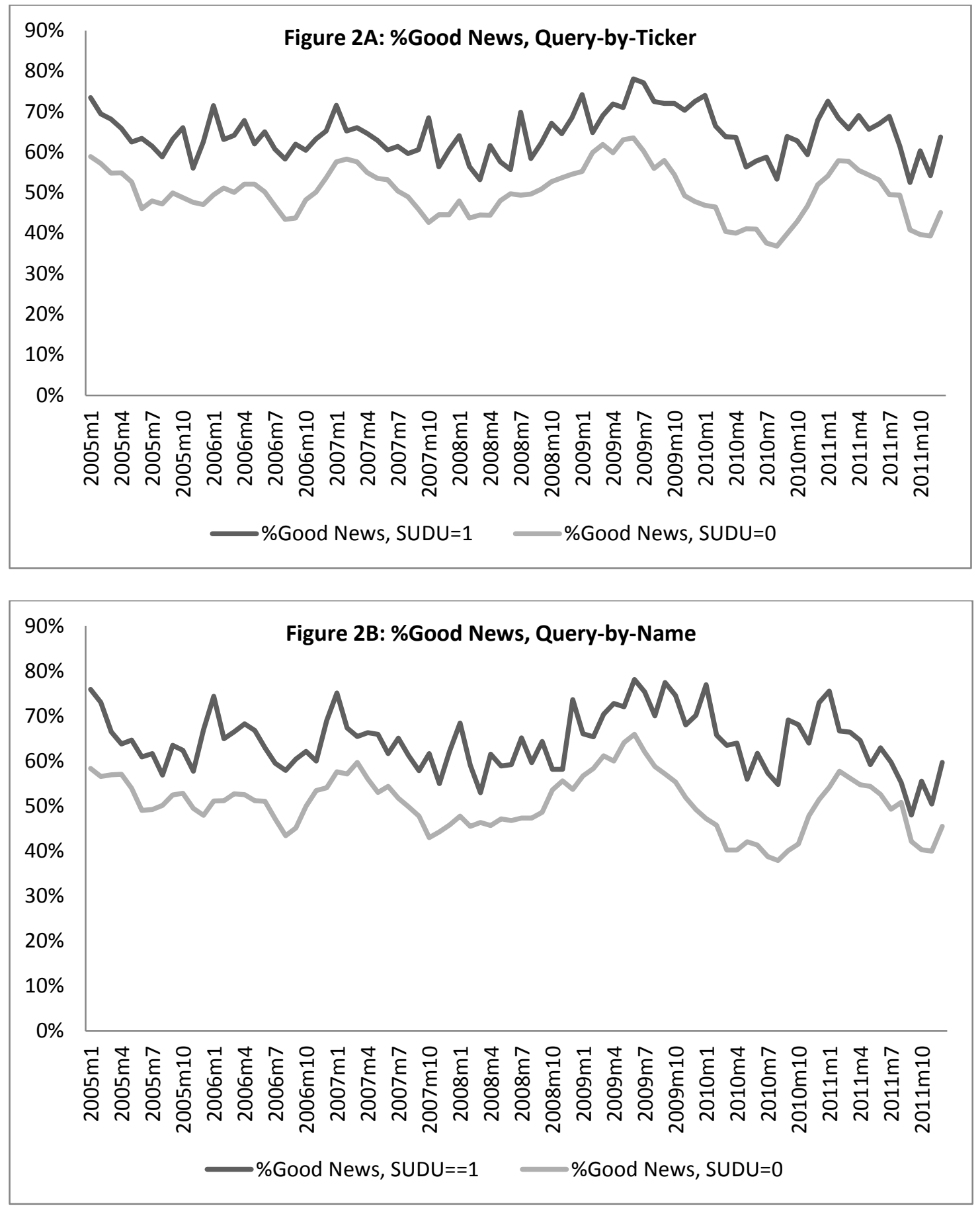


\section{Figure 3: Decomposition of Abnormal Returns into Fundamentals and Non-fundamentals}

Figure 3 plots the abnormal return of a portfolio to go long the stocks with the increase in both information supply and demand (i.e. SUDU=1) and go short the other stocks (i.e. SUDU=0) over various holding horizons. The long and short portfolio is an equal weight portfolio. I follow Jegadeesh and Titman (1993) to form overlapping portfolio over different time horizon. Taking 12 months overlapping portfolio as an example, in each month, I rebalance $1 / 12$ of the portfolio based on the information supply and demand in the previous month and the rest of the 11/12 portfolio is intact. The figure plots the abnormal returns for query-by-name sample. The sample period is from $2005 \mathrm{M} 1$ to $2011 \mathrm{M} 12$.

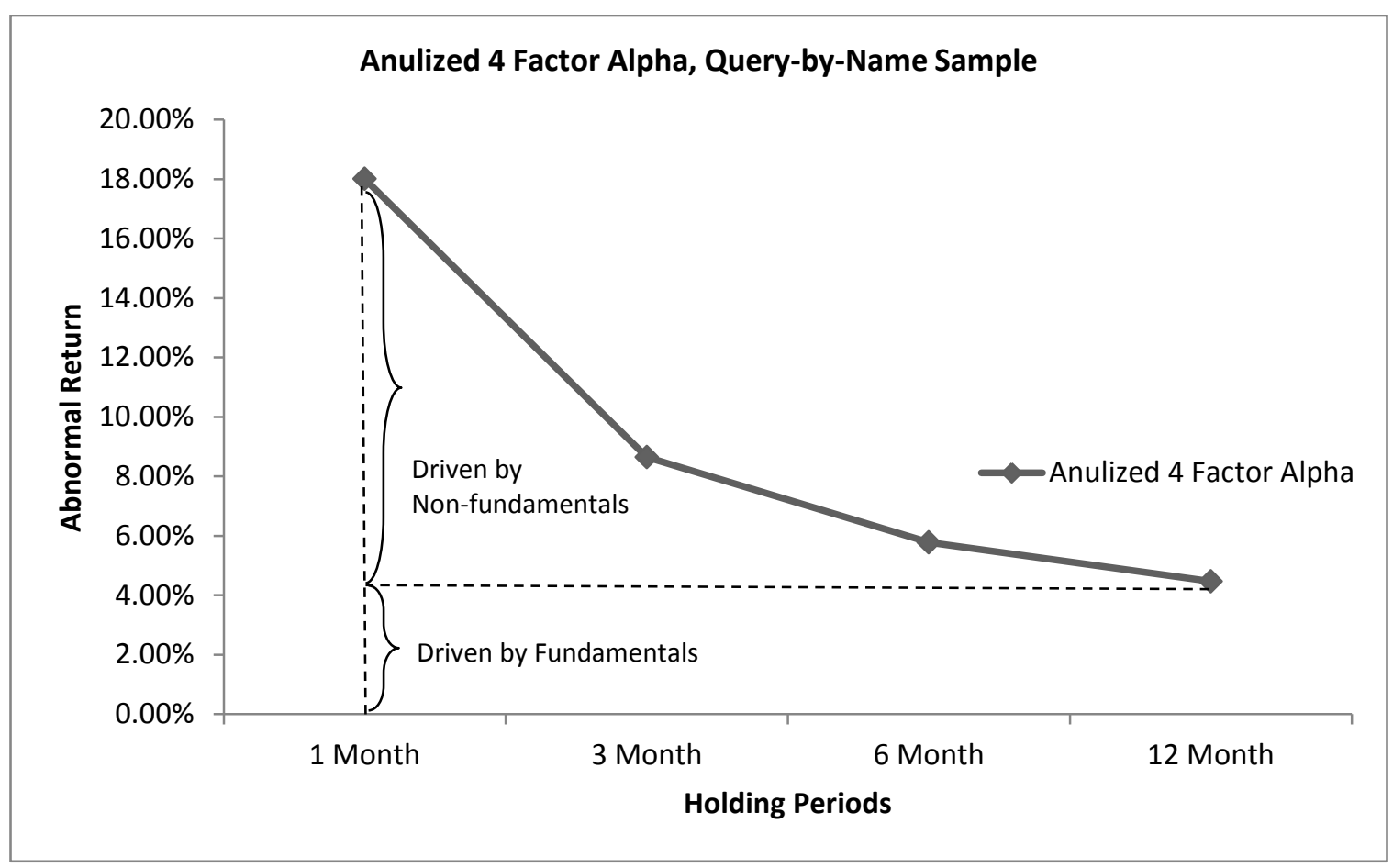




\section{Table 1: Summary Statistics}

Panel A reports the summary statistics of news and search volume. \#News is the number of news articles for a firm in the month. Search volume is the search volume value from Google Trends. The search volume is constructed by normalizing the search by the total search in a region. Then it is also scaled by the maximum value of the entire time series of the keyword. \#News/1Y \#News MA is the ratio of the \#News and its 12 month moving average. Search/1Y Search MA is the ratio of Search Volume and its 12 months moving average. Panel B presents the frequency of demand shift (or supply shift). "News Up" happens when \#News/1Y \#News MA is above 1, "News Down" happens when \#News/1Y \#News MA is below 1 and "News Zero" happens when there is no news coverage in the past 12 month. "Search Up", "Search Down" and "Search Zero" are defined in the similar manner based on Search/1Y Search MA. Panel C summarizes the statistics by supply and demand shift deciles which are defined as a combination of a supply shift and a demand shift, where SUDU=1 if "News Up" (i.e. Supply Up) and "Search Up" (i.e. $\underline{\text { Demand }}$ Up), SUDD= 1 if "News Up" and "Search Down", SUDZ=1 if "News Up" and "Search Zero", SDDU=1 if "News Down" and "Search Up", SDDD=1 if "News Down" and "Search Down", SDDZ=1 if "News Down" and "Search Zero", SZDU=1 if "News Zero" and "Search Up", $\mathrm{SZDD}=1$ if "News Zero" and "Search Down", and SZDZ=1 if "News Zero" and "Search Zero". $\mathrm{ME}$ is the market equity value, $\mathrm{ME} / \mathrm{BE}$ is the market equity to book equity ratio, \#Analyst is the number of analysts who cover the stock, \#News and Search Volume are the number of news articles and Google search volume. The sample period is from 2005M1 to 2011M12.

\begin{tabular}{|c|c|c|c|c|c|c|c|c|c|}
\hline \multicolumn{10}{|c|}{ Panel A: Summary Statistics for News and Search Volume } \\
\hline & Mean & STD & Skewness & Kurtosis & P5 & $\mathrm{P} 25$ & P50 & P75 & $\mathrm{P} 95$ \\
\hline & \multicolumn{9}{|c|}{ Query-by-Ticker Sample } \\
\hline \# News & 16.424 & 37.59 & 4.856 & 29.614 & 0 & 2 & 5 & 13 & 68 \\
\hline Search Volume & 44.522 & 27.864 & -0.155 & 2.009 & 0 & 23 & 47 & 67 & 87 \\
\hline \#News/1Y \#News MA & 1.16 & 1.107 & 2.336 & 10.975 & 0 & 0.462 & 0.923 & 1.521 & 3.086 \\
\hline \multirow[t]{2}{*}{ Search/1Y Search MA } & 1.121 & 1.379 & 5.745 & 43.129 & 0 & 0.802 & 0.977 & 1.123 & 2.376 \\
\hline & \multicolumn{9}{|c|}{ Query-by-Name Sample } \\
\hline \# News & 12.948 & 29.217 & 4.801 & 28.621 & 0 & 1 & 5 & 11 & 51 \\
\hline Search Volume & 35.493 & 27.639 & 0.155 & 2.012 & 0 & 0 & 37 & 56 & 81 \\
\hline \#News/1Y \#News MA & 1.128 & 1.209 & 2.837 & 14.684 & 0 & 0.387 & 0.886 & 1.479 & 3.051 \\
\hline Search/1Y Search MA & 1.034 & 1.571 & 5.197 & 35.023 & 0 & 0 & 0.909 & 1.108 & 2.571 \\
\hline
\end{tabular}

\begin{tabular}{lcccccc}
\hline Panel B: Frequency of Supply Shift and Demand Shift \\
\hline & News Up & News Down & News Zero & Search Up & Search Down & Search Zero \\
\cline { 2 - 6 } Frequency & $47 \%$ & $52 \%$ & Query-by-Ticker Sample \\
\hline \multicolumn{7}{c}{ Query-by-Name Sample } \\
Frequency & $44 \%$ & $51 \%$ & $4 \%$ & $38 \%$ & $42 \%$ & $20 \%$ \\
\hline
\end{tabular}




\begin{tabular}{|c|c|c|c|c|c|c|}
\hline \multicolumn{7}{|c|}{ Panel C: Summary by Supply and Demand Shift Deciles } \\
\hline & Frequency & ME & $\mathrm{ME} / \mathrm{BE}$ & \# Analyst & \# News & Search Search \\
\hline & \multicolumn{6}{|c|}{ Query-by-Ticke Sample } \\
\hline SUDU & $23.40 \%$ & 20.57 & 3.22 & 6.90 & 25.44 & 58.53 \\
\hline SUDD & $17.90 \%$ & 20.75 & 2.86 & 7.62 & 24.83 & 42.04 \\
\hline SUDZ & $5.00 \%$ & 19.43 & 2.82 & 3.24 & 7.29 & 0.00 \\
\hline SDDU & $21.60 \%$ & 20.61 & 2.95 & 6.87 & 11.64 & 58.75 \\
\hline SDDD & $24.80 \%$ & 20.71 & 2.92 & 7.54 & 12.50 & 40.72 \\
\hline SDDZ & $5.70 \%$ & 19.49 & 2.61 & 3.36 & 2.22 & 0.00 \\
\hline SZDU & $0.20 \%$ & 19.23 & 3.15 & 1.76 & 0.00 & 55.31 \\
\hline SZDD & $0.10 \%$ & 19.76 & 2.64 & 2.74 & 0.00 & 47.92 \\
\hline \multirow[t]{2}{*}{ SZDZ } & $0.10 \%$ & 18.48 & 1.88 & 0.67 & 0.00 & 0.00 \\
\hline & \multicolumn{6}{|c|}{ Query-by-Name Sample } \\
\hline SUDU & $20.00 \%$ & 20.67 & 3.18 & 7.22 & 22.21 & 56.59 \\
\hline SUDD & $16.10 \%$ & 20.85 & 2.90 & 7.78 & 20.64 & 34.81 \\
\hline SUDZ & $8.10 \%$ & 19.93 & 3.40 & 4.81 & 7.98 & 0.00 \\
\hline SDDU & $17.10 \%$ & 20.72 & 2.94 & 7.46 & 9.75 & 55.33 \\
\hline SDDD & $24.60 \%$ & 20.90 & 2.92 & 7.89 & 11.00 & 34.26 \\
\hline SDDZ & $9.50 \%$ & 20.04 & 3.22 & 5.05 & 2.45 & 0.00 \\
\hline SZDU & $0.60 \%$ & 20.62 & 3.04 & 3.87 & 0.00 & 51.98 \\
\hline SZDD & $0.60 \%$ & 20.88 & 3.39 & 4.60 & 0.00 & 33.88 \\
\hline SZDZ & $2.50 \%$ & 20.19 & 3.23 & 1.81 & 0.00 & 0.00 \\
\hline
\end{tabular}




\section{Table 2: Information Supply and Demand on Stock Return}

The table reports the relationship between the abnormal return and the lagged shift in both supply and demand for information. The regression model is Fama Macbeth regression with NeweyWest for 3 lags: Abnormal_Return $t_{t}=\alpha_{t}+\beta_{1} S U D U_{t-1}+\beta_{2} S U D D_{t-1}+\beta_{3} S D D U_{t-1}+$ $\beta_{4} r_{j, t-1}+\beta_{5} r_{j, t-12,-2}+\beta_{6} I_{j, t-3}+\beta_{7}$ Volume $_{j, t-7, t-1}+$ Additonal_Controls $_{-} \epsilon_{t}$, where Abnormal_Return $_{t}$ is measured by DGTW adjusted return, SUDU $=1$ if "News Up" (i.e.

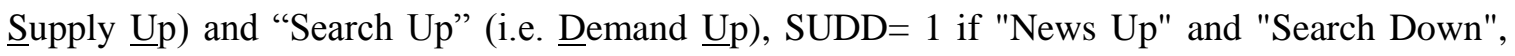
SDDU $=1$ if "News Down" and "Search Up", SDDD=1 if "News Down" and "Search Down", $r_{j, t-1}$ is the last month's return, $r_{j, t-12,-2}$ is the return from month $t-12$ to $t-2, I O_{j, t-3}$ is the institutional ownership in the previous quarter, and Volume $e_{j, t-7,-1}$ is the average trading volume during previous 6 months scaled by the total number of shares outstanding. The Additional_Controls include $\log (1+\#$ Analyst $)$ where \#Analyst is the number of analysts who cover the firm, $\log (1+\#$ News $)$ where \#News is the number of news articles about the firm, $\log (\mathrm{ME})$ where $\mathrm{ME}$ is the market equity value in time $\mathrm{t}-1$, market equity to book equity ratio, debt ratio, current ratio, asset turnover, earning per share to price ratio, and dummies for two digits SIC code. Panel A reports the result for query-by-ticker sample and Panel B presents the result for query-by-ticker sample. The sample period is between 2005M1 and 2011M12. 


\begin{tabular}{|c|c|c|c|c|c|c|}
\hline \multicolumn{7}{|c|}{ Panel A: Query-by-Ticker Sample } \\
\hline & Model1 & Model2 & Model3 & Model4 & Model5 & Model6 \\
\hline Abnormal Return & \multicolumn{6}{|c|}{ DGTW Adjusted Return } \\
\hline SUDU,t-1 & $\begin{array}{c}0.013 \\
(7.336)^{* * * *}\end{array}$ & $\begin{array}{c}0.0129 \\
(7.119)^{* * * *}\end{array}$ & $\begin{array}{c}0.0123 \\
(4.398)^{* * *}\end{array}$ & $\begin{array}{c}0.0124 \\
(7.100)^{* * *}\end{array}$ & $\begin{array}{c}0.014 \\
(7.586) * * *\end{array}$ & $\begin{array}{c}0.0125 \\
(7.523) * * *\end{array}$ \\
\hline SUDD,t-1 & $\begin{array}{l}-0.0004 \\
(-0.660)\end{array}$ & $\begin{array}{l}-0.0004 \\
(-0.620)\end{array}$ & $\begin{array}{l}-0.0012 \\
(-0.560)\end{array}$ & $\begin{array}{c}0.0001 \\
(0.16)\end{array}$ & $\begin{array}{l}-0.0004 \\
(-0.583)\end{array}$ & $\begin{array}{l}-0.0004 \\
(-0.623)\end{array}$ \\
\hline SDDU,t-1 & $\begin{array}{c}0.0013 \\
(1.681)^{*}\end{array}$ & $\begin{array}{c}0.0013 \\
(1.60)\end{array}$ & $\begin{array}{c}0.0014 \\
(1.771)^{*}\end{array}$ & $\begin{array}{c}0.0014 \\
(1.767)^{*}\end{array}$ & $\begin{array}{l}0.0015 \\
(1.62)\end{array}$ & $\begin{array}{c}0.0012 \\
(1.58)\end{array}$ \\
\hline Return, t-1 & $\begin{array}{c}-0.031 \\
(-4.038) * * *\end{array}$ & $\begin{array}{c}-0.0318 \\
(-4.184)^{* * *}\end{array}$ & $\begin{array}{c}-0.0313 \\
(-4.117)^{* * *}\end{array}$ & $\begin{array}{c}-2.96 \mathrm{E}-02 \\
(-3.745)^{* * *}\end{array}$ & $\begin{array}{c}-0.03 \\
(-3.879) * * *\end{array}$ & $\begin{array}{c}-0.0305 \\
(-3.899) * * *\end{array}$ \\
\hline Return, $\mathrm{t}-2$ to $\mathrm{t}-12$ & $\begin{array}{c}-0.00711 \\
(-1.406)\end{array}$ & $\begin{array}{c}-0.00742 \\
(-1.465)\end{array}$ & $\begin{array}{c}-0.00724 \\
(-1.432)\end{array}$ & $\begin{array}{c}-0.00735 \\
(-1.374)\end{array}$ & $\begin{array}{l}-0.0087 \\
(-1.642)\end{array}$ & $\begin{array}{c}-0.00864 \\
(-1.641)\end{array}$ \\
\hline $\mathrm{IO}, \mathrm{t}-3$ & & $\begin{array}{c}-0.00556 \\
(-3.267)^{* * * *}\end{array}$ & & & & \\
\hline Volume, $\mathrm{t}-1$ to $\mathrm{t}-6$ & & $\begin{array}{c}-8.45 \mathrm{E}-03 \\
(-1.872)^{*}\end{array}$ & & & & \\
\hline $\log (1+\#$ Analyst $), \mathrm{t}-1$ & & & $\begin{array}{c}-0.00019 \\
(-0.378)\end{array}$ & & & \\
\hline $\log (1+\#$ News $), \mathrm{t}-1$ & & & $\begin{array}{l}-0.0012 \\
(-0.366)\end{array}$ & & & \\
\hline $\log (\mathrm{ME}), \mathrm{t}-1$ & & & & $\begin{array}{c}-0.00161 \\
(-3.628)^{* * *}\end{array}$ & & \\
\hline $\mathrm{ME} / \mathrm{BE}, \mathrm{t}-1$ & & & & $\begin{array}{c}-0.00018 \\
(-1.489)\end{array}$ & & \\
\hline Debt Ratio & & & & & $\begin{array}{c}0.00246 \\
(0.71)\end{array}$ & \\
\hline Current Ratio & & & & & $\begin{array}{c}4.82 \mathrm{E}-05 \\
(0.43)\end{array}$ & \\
\hline Asset Turnover & & & & & & $\begin{array}{c}1.29 \mathrm{E}-02 \\
(5.428) * * *\end{array}$ \\
\hline Profit Margin & & & & & & $\begin{array}{c}(0.00) \\
(-1.179)\end{array}$ \\
\hline EPS/Price & & & & & & $\begin{array}{c}0.00 \\
(2.910) * * *\end{array}$ \\
\hline Constant & $\begin{array}{c}0.00662 \\
(0.70)\end{array}$ & $\begin{array}{c}0.00535 \\
(0.52)\end{array}$ & $\begin{array}{c}0.0106 \\
(1.05)\end{array}$ & $\begin{array}{c}0.0443 \\
(3.762)^{* * * *}\end{array}$ & $\begin{array}{c}0.00117 \\
(0.11)\end{array}$ & $\begin{array}{c}0.000746 \\
(0.07)\end{array}$ \\
\hline Observations & 173,793 & 173,793 & 173,793 & 169,023 & 143,509 & 169,623 \\
\hline R-squared & 0.081 & 0.084 & 0.082 & 0.086 & 0.078 & 0.086 \\
\hline Industry Dummy & Yes & Yes & Yes & Yes & Yes & Yes \\
\hline Number of groups & 84 & 84 & 84 & 84 & 84 & 84 \\
\hline
\end{tabular}




\begin{tabular}{|c|c|c|c|c|c|c|}
\hline \multicolumn{7}{|c|}{ Panel A: Query-by-Name Sample } \\
\hline & Model1 & Model2 & Model3 & Model4 & Model5 & Model6 \\
\hline & \multicolumn{6}{|c|}{ DGTW Adjusted Return } \\
\hline SUDU,t-1 & $\begin{array}{c}0.016 \\
(6.685)^{* * *}\end{array}$ & $\begin{array}{c}0.0159 \\
(6.561)^{* * *}\end{array}$ & $\begin{array}{c}0.0146 \\
(5.542)^{* * *}\end{array}$ & $\begin{array}{c}0.0147 \\
(6.825)^{* * *}\end{array}$ & $\begin{array}{c}0.0174 \\
(6.769)^{* * *}\end{array}$ & $\begin{array}{c}0.0157 \\
(6.830)^{* * * *}\end{array}$ \\
\hline SUDD,t-1 & $\begin{array}{l}-0.0006 \\
(-0.782)\end{array}$ & $\begin{array}{l}-0.0006 \\
(-0.762)\end{array}$ & $\begin{array}{l}-0.0020 \\
(-0.608)\end{array}$ & $\begin{array}{l}-0.0006 \\
(-0.855)\end{array}$ & $\begin{array}{l}-0.0008 \\
(-0.952)\end{array}$ & $\begin{array}{l}-0.0006 \\
(-0.773)\end{array}$ \\
\hline SDDU,t-1 & $\begin{array}{c}0.0017 \\
(1.885)^{*}\end{array}$ & $\begin{array}{c}0.0017 \\
(1.831)^{*}\end{array}$ & $\begin{array}{c}0.0018 \\
(1.899)^{*}\end{array}$ & $\begin{array}{c}0.0014 \\
(1.58)\end{array}$ & $\begin{array}{c}0.0021 \\
(2.057)^{* *}\end{array}$ & $\begin{array}{c}0.0016 \\
(1.719)^{*}\end{array}$ \\
\hline Return, $\mathrm{t}-1$ & $\begin{array}{c}-0.0302 \\
(-3.347)^{* * *}\end{array}$ & $\begin{array}{c}-0.0313 \\
(-3.525)^{* * *}\end{array}$ & $\begin{array}{c}-0.0302 \\
(-3.385)^{* * *}\end{array}$ & $\begin{array}{c}-3.14 \mathrm{E}-02 \\
(-3.471)^{* * *}\end{array}$ & $\begin{array}{c}-0.0283 \\
(-3.167)^{* * *}\end{array}$ & $\begin{array}{c}-0.0305 \\
(-3.469)^{* * *}\end{array}$ \\
\hline Return, $\mathrm{t}-2$ to $\mathrm{t}-12$ & $\begin{array}{c}-0.00757 \\
(-1.372)\end{array}$ & $\begin{array}{c}-0.00787 \\
(-1.424)\end{array}$ & $\begin{array}{c}-0.00756 \\
(-1.369)\end{array}$ & $\begin{array}{l}-0.0067 \\
(-1.145)\end{array}$ & $\begin{array}{c}-0.00884 \\
(-1.562)\end{array}$ & $\begin{array}{c}-0.00844 \\
(-1.462)\end{array}$ \\
\hline $\mathrm{IO}, \mathrm{t}-3$ & & $\begin{array}{c}-0.00609 \\
(-3.391)^{* * * *}\end{array}$ & & & & \\
\hline Volume, $\mathrm{t}-1$ to $\mathrm{t}-6$ & & $\begin{array}{c}-1.46 \mathrm{E}-02 \\
(-1.720)^{*}\end{array}$ & & & & \\
\hline $\log (1+\#$ Analyst $), t-1$ & & & $\begin{array}{c}-0.000215 \\
(-0.469)\end{array}$ & & & \\
\hline $\log (1+\#$ News $), t-1$ & & & $\begin{array}{c}-0.00203 \\
(-0.438)\end{array}$ & & & \\
\hline Market Equity, t-1 & & & & $\begin{array}{c}-0.00152 \\
(-3.270)^{* * *}\end{array}$ & & \\
\hline $\mathrm{ME} / \mathrm{BE}, \mathrm{t}-1$ & & & & $\begin{array}{c}-0.00032 \\
(-2.498)^{* *}\end{array}$ & & \\
\hline Debt Ratio & & & & & $\begin{array}{c}0.00128 \\
(0.32)\end{array}$ & \\
\hline Current Ratio & & & & & $\begin{array}{c}-0.0000848 \\
(-0.794)\end{array}$ & \\
\hline Asset Turnover & & & & & & $\begin{array}{c}1.11 \mathrm{E}-02 \\
(3.853) * * *\end{array}$ \\
\hline Profit Margin & & & & & & $\begin{array}{c}(0.00) \\
(-1.326)\end{array}$ \\
\hline EPS/Price & & & & & & $\begin{array}{c}0.00 \\
(2.533)^{* *}\end{array}$ \\
\hline Constant & $\begin{array}{l}-0.0145 \\
(-1.347)\end{array}$ & $\begin{array}{c}-0.0179 \\
(-1.872)^{*}\end{array}$ & $\begin{array}{l}-0.0153 \\
(-1.427)\end{array}$ & $\begin{array}{c}0.0257 \\
(2.247)^{* *}\end{array}$ & $\begin{array}{c}0.00331 \\
(0.29)\end{array}$ & $\begin{array}{c}-0.0000608 \\
(-0.00585)\end{array}$ \\
\hline Observations & 143,713 & 143,713 & 143,713 & 136,230 & 117,342 & 136,898 \\
\hline R-squared & 0.09 & 0.094 & 0.091 & 0.092 & 0.088 & 0.094 \\
\hline Industry Dummy & Yes & Yes & Yes & Yes & Yes & Yes \\
\hline Number of groups & 84 & 84 & 84 & 84 & 84 & 84 \\
\hline
\end{tabular}




\section{Table 3: Portfolio Analysis on Supply and Demand for Information}

Table 3 reports the abnormal return of a portfolio to go long the stocks with the increase in both information supply and demand (i.e. SUDU=1) and go short the other stocks (i.e. SUDU=0). The long and short portfolio is an equal weight portfolio and monthly rebalanced based on the information supply and demand in the previous month. The table reports the monthly abnormal returns for both query-by-ticker and query-by-name samples. For example, the monthly average raw return of 0.0187 in the query-by-name sample is translated into $22.44 \%$ annualized raw return (i.e. $0.0187 \times 12 \times 100 \%$ ). The sample period is from $2005 \mathrm{M} 1$ to $2011 \mathrm{M} 12$.

\begin{tabular}{lcc}
\hline Portfolio Performance of buying Stocks with SUDU $=1$ and Short Selling the other Stocks \\
\cline { 2 - 3 } Query-by-Ticker Sample & 0.0156 & Query-by-Ticker Sample \\
\cline { 2 - 3 } Raw Return & $(8.435)^{* * *}$ & 0.0187 \\
DGTW Adjust Return & 0.013 & $(8.028)^{* * *}$ \\
& $(8.917)^{* * *}$ & 0.0159 \\
CAPM Alpha & 0.0152 & $(8.327)^{* * *}$ \\
& $(8.956)^{* * *}$ & 0.0184 \\
3 Factor Alpha & 0.0149 & $(8.184)^{* * *}$ \\
& $(9.339)^{* * *}$ & 0.0179 \\
4 Factor Alpha & 0.015 & $(8.391)^{* * *}$ \\
& $(10.53)^{* * *}$ & 0.018 \\
\hline
\end{tabular}


Table 4: Portfolio Analysis for Subsamples by Size, BE/ME, Beta and Volatility

Table 4 reports the abnormal return of a portfolio to go long the stocks with the increase in both information supply and demand (i.e. SUDU=1) and go short the other stocks (i.e. SUDU=0). The protfolio analysis is conducted in various subsamples. The long and short portfolio is an equal weight portfolio and monthly rebalanced based on the information supply and demand in the previous month. The table reports the abnormal returns for both query-by-ticker and query-byname samples. Panel A reports the result by size deciles. Panel B presents the findings for book equity to market equity deciles. Panel $\mathrm{C}$ shows the relationship by beta deciles. Panel D reports the result for volatility deciles. The sample period is from 2005M1 to 2011M12.

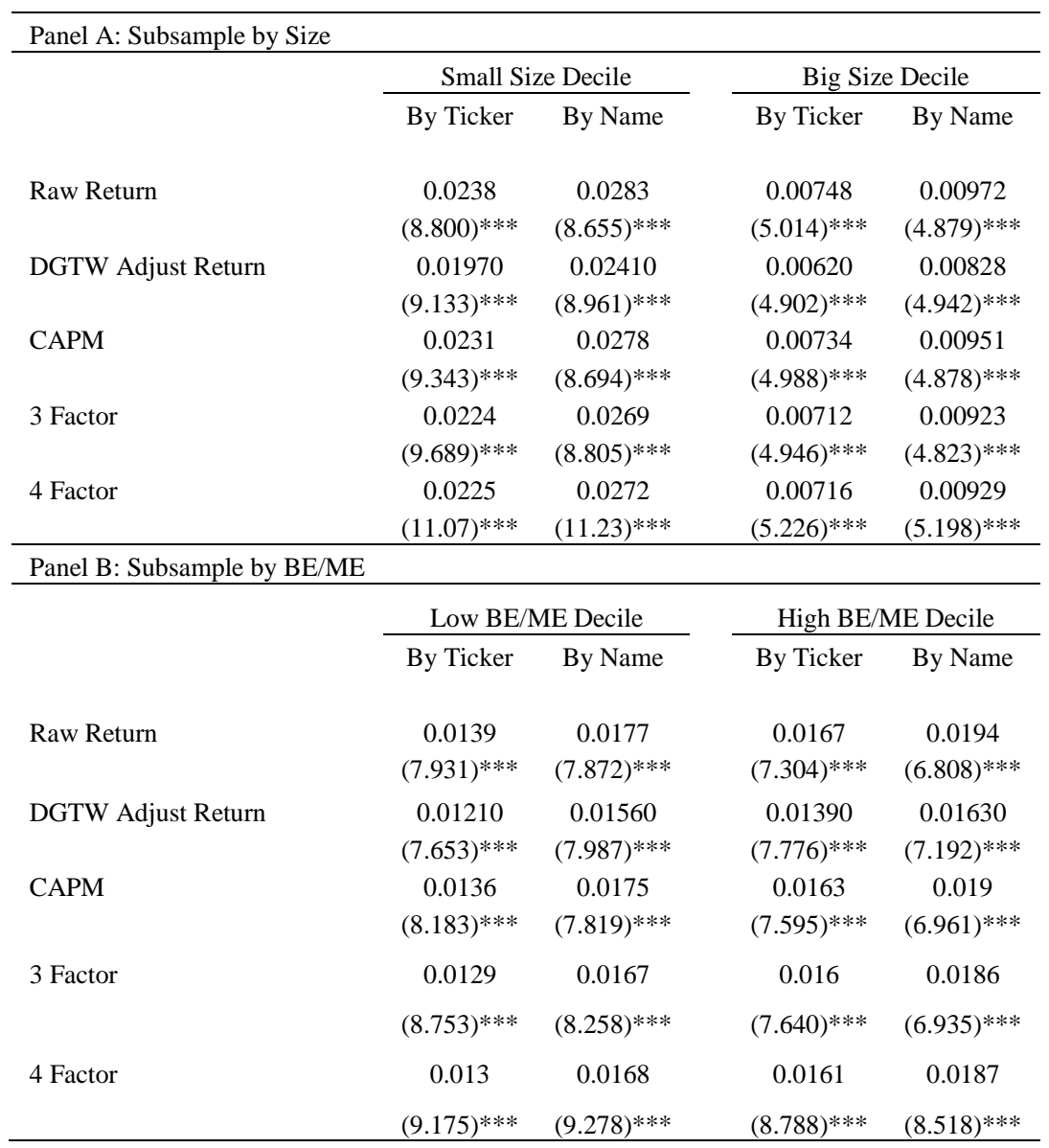




\begin{tabular}{|c|c|c|c|c|}
\hline \multicolumn{5}{|c|}{ Panel C: Subsample by Beta } \\
\hline & \multicolumn{2}{|c|}{ Low Beta Decile } & \multicolumn{2}{|c|}{ High Beta Decile } \\
\hline & By Ticker & By Name & By Ticker & By Name \\
\hline \multirow[t]{2}{*}{ Raw Return } & 0.0147 & 0.0175 & 0.0156 & 0.0192 \\
\hline & $(10.82)^{* * *}$ & $(10.45)^{* * *}$ & $(6.552)^{* * *}$ & $(6.164)^{* * *}$ \\
\hline \multirow[t]{2}{*}{ DGTW Adjust Return } & 0.01240 & 0.01530 & 0.01300 & 0.01600 \\
\hline & $(10.46)^{* * *}$ & $(10.45)^{* * *}$ & $(6.855)^{* * *}$ & $(6.285)^{* * *}$ \\
\hline \multirow[t]{2}{*}{ CAPM } & 0.0145 & 0.0175 & 0.0152 & 0.0187 \\
\hline & $(11.10)^{* * *}$ & $(10.36)^{* * *}$ & $(6.762)^{* * *}$ & $(6.300)^{* * *}$ \\
\hline \multirow[t]{2}{*}{3 Factor } & 0.0143 & 0.0172 & 0.0149 & 0.0182 \\
\hline & $(11.76)^{* * *}$ & $(10.59)^{* * *}$ & $(6.808)^{* * *}$ & $(6.345)^{* * *}$ \\
\hline \multirow[t]{2}{*}{4 Factor } & 0.0143 & 0.0172 & 0.0149 & 0.0184 \\
\hline & $(11.75)^{* * *}$ & $(11.19)^{* * *}$ & $(7.895)^{* * *}$ & $(7.829)^{* * *}$ \\
\hline \multicolumn{5}{|c|}{ Panel D: Subsample by Volatility } \\
\hline & \multicolumn{2}{|c|}{ Low Volatility Decile } & \multicolumn{2}{|c|}{ High Volatility Decile } \\
\hline & By Ticker & By Name & By Ticker & By Name \\
\hline \multirow[t]{2}{*}{ Raw Return } & 0.0027 & 0.00406 & 0.0233 & 0.027 \\
\hline & $(3.132)^{* * * *}$ & $(3.867)^{* * *}$ & $(8.984)^{* * *}$ & $(8.509)^{* * *}$ \\
\hline \multirow[t]{2}{*}{ DGTW Adjust Return } & 0.00240 & 0.00363 & 0.02000 & 0.02340 \\
\hline & $(2.954) * * *$ & $(3.524) * * *$ & $(9.647)^{* * *}$ & $(9.008)^{* * * *}$ \\
\hline \multirow[t]{2}{*}{ CAPM } & 0.00271 & 0.00415 & 0.0229 & 0.0266 \\
\hline & $(3.127)^{* * *}$ & $(3.996)^{* * *}$ & $(9.493)^{* * *}$ & $(8.713)^{* * * *}$ \\
\hline \multirow[t]{2}{*}{3 Factor } & 0.0026 & 0.00408 & 0.0225 & 0.026 \\
\hline & $(3.231)^{* * * *}$ & $(3.900)^{* * *}$ & $(9.599) * * *$ & $(8.873)^{* * * *}$ \\
\hline \multirow[t]{2}{*}{4 Factor } & 0.0026 & 0.0041 & 0.0226 & 0.0262 \\
\hline & $(3.211)^{* * *}$ & $(3.964)^{* * *}$ & $(11.17)^{* * * *}$ & $(10.83)^{* * * *}$ \\
\hline
\end{tabular}




\section{Table 5: Information Supply and Demand on Stock Return Conditional on Events Type}

The table reports the relationship between the information supply and demand on stock return conditional on various types of events. The regression model is Fama Macbeth regression with Newey-West for 3 lags: Abnormal_Return $t_{t}=\alpha_{t}+\beta_{1} E_{\text {Event }}{ }_{k, t-1} \times S U D U_{t-1}+$ $\beta_{2}\left(1-\right.$ Event $\left._{k, t-1}\right) \times S U D U_{t-1}+\beta_{3} r_{j, t-1}+\beta_{4} r_{j, t-12,-2}+\beta_{5} I O_{j, t-3}+\beta_{6}$ Volume $_{j, t-7,-1}+\epsilon_{j, t}$, where Abnormal_Return $t$ is measured by

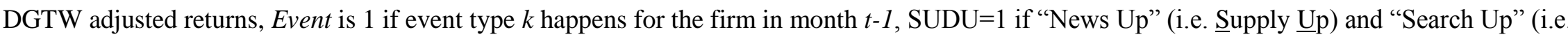
Demand Up), "News Up" happens if \#News is above its 12 month moving average, "Search Up" happens if the search volume is above its 12 month moving average, $r_{j, t-1}$ is the last month's return, $r_{j, t-12,-2}$ is the return from month $t-12$ to $t-2, I O_{j, t-3}$ is the institutional ownership in the previous quarter, and Volume $_{j, t-7,-1}$ is the average trading volume during previous 6 months scaled by the total number of shares outstanding. Model 1 is for query-by-ticker sample and Model 2 presents the result for query-by-ticker sample. The sample period is between $2005 \mathrm{M} 1$ and 2011M12.

\begin{tabular}{|c|c|c|c|c|c|c|c|c|}
\hline \multicolumn{9}{|c|}{ Information Supply and Demand on Stock Return Conditional on Events Type } \\
\hline \multirow{3}{*}{$\begin{array}{l}\text { Dependent Variable: DGTW-Adj Return } \\
\text { Independent Variable }\end{array}$} & \multicolumn{4}{|c|}{ Query-by-Ticker } & \multicolumn{4}{|c|}{ Query-by-Name } \\
\hline & \multicolumn{4}{|c|}{ Model 1} & \multicolumn{4}{|c|}{ Model 2} \\
\hline & \multicolumn{2}{|r|}{$\beta_{1}$} & \multicolumn{2}{|r|}{$\beta_{2}$} & \multicolumn{2}{|c|}{$\beta_{1}$} & \multicolumn{2}{|r|}{$\beta_{2}$} \\
\hline Client Announcement & 0.0114 & $(4.954)^{* * *}$ & 0.0129 & $(7.304)^{* * *}$ & 0.0111 & $(3.304)^{* * *}$ & 0.0161 & $(6.376)^{* * *}$ \\
\hline Announcement of Earnings & 0.0111 & $(4.451)^{* * *}$ & 0.0134 & $(7.758)^{* * *}$ & 0.0102 & $(3.240)^{* * *}$ & 0.0165 & $(6.565)^{* * *}$ \\
\hline Product-Related Announcement & 0.0109 & $(4.429)^{* * * *}$ & 0.0131 & $(7.668)^{* * * *}$ & 0.0124 & $(3.363)^{* * *}$ & 0.0158 & $(6.470)^{* * *}$ \\
\hline Ex-Div Date (Regular) & 0.00115 & $(0.65)$ & 0.0147 & $(7.165)^{* * *}$ & 0.0021 & (1.39) & 0.0173 & $(6.351)^{* * *}$ \\
\hline Executive/Board Change - Other & 0.00757 & $(3.632)^{* * *}$ & 0.0138 & $(8.076)^{* * *}$ & 0.00938 & $(3.863)^{* * *}$ & 0.0165 & $(6.533)^{* * *}$ \\
\hline Company Conference Presentation & 0.0113 & $(4.815)^{* * *}$ & 0.0138 & $(7.702)^{* * *}$ & 0.0121 & $(4.156)^{* * *}$ & 0.0164 & $(6.578)^{* * *}$ \\
\hline Earnings Call & 0.00782 & $(3.980)^{* * *}$ & 0.0171 & $(8.544)^{* * *}$ & 0.00809 & $(3.172)^{* * *}$ & 0.02 & $(6.643)^{* * *}$ \\
\hline M\&A Transaction Closing & 0.00094 & $(0.54)$ & 0.0136 & $(7.719)^{* * *}$ & 0.00229 & $(1.01)$ & 0.0162 & $(6.343)^{* * *}$ \\
\hline Business Expansion & 0.00216 & $(0.85)$ & 0.0135 & $(7.606)^{* * *}$ & 0.00101 & $(0.43)$ & 0.0162 & $(6.469)^{* * *}$ \\
\hline M\&A Transaction Announcement & 0.00489 & $(1.679)^{*}$ & 0.0133 & $(7.707)^{* * *}$ & 0.00568 & $(2.244)^{* *}$ & 0.016 & $(6.377)^{* * *}$ \\
\hline Dividend Affirmation & 0.00164 & $(1.02)$ & 0.014 & $(7.280)^{* * *}$ & 0.00102 & $(0.67)$ & 0.0166 & $(6.331)^{* * *}$ \\
\hline Private Placement & 0.0102 & $(1.725)^{*}$ & 0.0129 & $(7.262)^{* * *}$ & 0.0121 & $(1.797)^{*}$ & 0.0154 & $(6.272)^{* * *}$ \\
\hline Annual General Meeting & 0.011 & $(3.611)^{* * *}$ & 0.0132 & $(7.315)^{* * *}$ & 0.00427 & $(1.39)$ & 0.0161 & $(6.458)^{* * *}$ \\
\hline Delayed SEC Filing & 0.0199 & $(1.29)$ & 0.0127 & $(7.637)^{* * *}$ & 0.00737 & $(0.82)$ & 0.0153 & $(6.299)^{* * *}$ \\
\hline Lawsuits \& Legal Issue & 0.00751 & $(2.858)^{* * * *}$ & 0.0131 & $(7.629)^{* * *}$ & 0.011 & $(2.654)^{* * *}$ & 0.0157 & $(6.274)^{* * *}$ \\
\hline Fixed Income Offering & -0.0034 & $(-1.167)$ & 0.0132 & $(7.443)^{* * *}$ & 0.00601 & $(1.863)^{*}$ & 0.0156 & $(6.287)^{* * *}$ \\
\hline
\end{tabular}




\begin{tabular}{|c|c|c|c|c|c|c|c|c|}
\hline \multicolumn{9}{|c|}{ Information Supply and Demand on Stock Return Conditional on Events Type (Continued) } \\
\hline \multirow{3}{*}{$\begin{array}{l}\text { Dependent Variable: DGTW-Adj Return } \\
\text { Independent Variable }\end{array}$} & \multirow{2}{*}{\multicolumn{4}{|c|}{$\begin{array}{l}\text { Query-by-Ticker } \\
\text { Model } 1\end{array}$}} & \multirow{2}{*}{\multicolumn{4}{|c|}{$\begin{array}{l}\text { Query-by-Name } \\
\text { Model } 2\end{array}$}} \\
\hline & & & & & & & & \\
\hline & \multicolumn{2}{|c|}{$\beta_{1}$} & \multicolumn{2}{|c|}{$\beta_{2}$} & \multicolumn{2}{|c|}{$\beta_{1}$} & \multicolumn{2}{|r|}{$\beta_{2}$} \\
\hline $\begin{array}{l}\text { Announcement of Earnings, } \\
\text { Corporate Guidance - New/Confirmed }\end{array}$ & 0.00681 & $(3.078)^{* * *}$ & 0.0134 & $(7.444)^{* * *}$ & 0.00974 & $(3.553)^{* * *}$ & 0.016 & $(6.246)^{* * * *}$ \\
\hline Strategic Alliance & 0.0101 & $(3.714)^{* * *}$ & 0.0129 & $(7.417)^{* * *}$ & 0.0138 & $(2.676)^{* * *}$ & 0.0155 & $(6.344)^{* * * *}$ \\
\hline Debt Financing Related & 0.0119 & $(3.939)^{* * *}$ & 0.0128 & $(7.548)^{* * *}$ & 0.013 & $(2.694)^{* * *}$ & 0.0155 & $(6.511)^{* * *}$ \\
\hline Shelf Registration Filing & 0.00666 & $(1.60)$ & 0.013 & $(7.623)^{* * *}$ & 0.0172 & $(3.271)^{* * *}$ & 0.0153 & $(6.331)^{* * *}$ \\
\hline Seeking Acquisition/Investment & 0.00461 & $(1.850)^{*}$ & 0.0133 & $(7.198)^{* * *}$ & 0.00198 & $(0.77)$ & 0.0161 & $(6.174)^{* * *}$ \\
\hline Index Constituent Add & -0.00584 & $(-0.933)$ & 0.0129 & $(7.545)^{* * *}$ & -0.0131 & $(-2.448)^{* *}$ & 0.0159 & $(6.398)^{* * *}$ \\
\hline M\&A Rumors and Discussion & -0.0692 & $(-1.095)$ & 0.0133 & $(7.612)^{* * *}$ & -0.0109 & $(-3.308)^{* * *}$ & 0.0161 & $(6.376)^{* * *}$ \\
\hline Corporate Guidance - New/Confirmed & 0.00613 & $(2.457)^{* *}$ & 0.0132 & $(7.294)^{* * *}$ & 0.00827 & $(2.027)^{* *}$ & 0.0159 & $(6.263)^{* * * *}$ \\
\hline Discontinued Operations/Downsizing & 0.00318 & $(0.71)$ & 0.0131 & $(7.398)^{* * *}$ & 0.0127 & $(2.242)^{* *}$ & 0.0155 & $(6.237)^{* * *}$ \\
\hline Buyback & 0.00615 & $(2.108)^{* *}$ & 0.013 & $(7.618)^{* * *}$ & 0.00325 & $(0.91)$ & 0.0157 & $(6.314)^{* * *}$ \\
\hline Index Constituent Drop & -0.00914 & $(-1.439)$ & 0.0129 & $(7.234)^{* * * *}$ & -0.00552 & $(-0.976)$ & 0.0155 & $(6.172)^{* * *}$ \\
\hline Change in Company Bylaws/Rules & 0.00916 & $(1.62)$ & 0.0131 & $(7.025)^{* * *}$ & 0.0104 & $(1.791)^{*}$ & 0.0156 & $(6.033)^{* * *}$ \\
\hline Announcements of Sales/Trading Statement & 0.00636 & $(1.04)$ & 0.0128 & $(7.628)^{* * *}$ & 0.0128 & $(1.63)$ & 0.0153 & $(6.349)^{* * *}$ \\
\hline $\begin{array}{l}\text { Executive/Board Change - } \\
\text { Other, Executive Change - CEO }\end{array}$ & -0.00841 & $(-1.877)^{*}$ & 0.0129 & $(7.486)^{* * *}$ & -0.00176 & $(-0.263)$ & 0.0154 & $(6.253)^{* * *}$ \\
\hline
\end{tabular}


Table 6: Impact of Supply and Demand for Information over Different Time Horizon

Table 6 reports the abnormal return of a portfolio to go long the stocks with the increase in both information supply and demand (i.e. SUDU=1) and go short the other stocks (i.e. SUDU=0) over various holding horizons. The long and short portfolio is an equal weight portfolio. I follow Jegadeesh and Titman (1993) to form overlapping portfolio over different time horizon. Taking 12 months overlapping portfolio as an example, in each month, I rebalance 1/12 of the portfolio based on the information supply and demand in the previous month and the rest of the 11/12 portfolio is intact. The table reports the abnormal returns for both query-by-ticker and query-byname samples. Panel A reports the findings for query-by-ticker sample. Panel B presents the results for query-by-name sample. The sample period is from 2005M1 to $2011 \mathrm{M} 12$.

\begin{tabular}{lcccc}
\hline Panel A: Query-by-Ticker Sample & & & & \\
\hline Overlapping Periods & 1 Month & 3 Months & 6 Months & 12 Months \\
& & & & \\
Raw Return & 0.0156 & 0.00748 & 0.00509 & 0.00397 \\
& $(8.435)^{* * *}$ & $(7.575)^{* * *}$ & $(6.021)^{* * *}$ & $(5.916)^{* * *}$ \\
DGTW Adjust Return & 0.0130 & 0.0061 & 0.0040 & 0.0031 \\
& $(8.917)^{* * *}$ & $(8.189)^{* * *}$ & $(6.369)^{* * *}$ & $(6.553)^{* * *}$ \\
CAPM & 0.0152 & 0.0073 & 0.0049 & 0.0038 \\
& $(8.956)^{* * *}$ & $(8.145)^{* * *}$ & $(6.694)^{* * *}$ & $(6.973)^{* * *}$ \\
3 Factor & 0.0149 & 0.0072 & 0.0048 & 0.0037 \\
& $(9.339)^{* * *}$ & $(8.134)^{* * *}$ & $(6.700)^{* * *}$ & $(6.898)^{* * *}$ \\
4 Factor & 0.0150 & 0.0072 & 0.0048 & 0.0037 \\
& $(10.53)^{* * *}$ & $(8.185)^{* * *}$ & $(6.672)^{* * *}$ & $(6.891)^{* * *}$ \\
\hline Panel B: Query-by-Name Sample & & & & \\
\hline Overlapping Periods & 1 Month & 3 Months & 6 Months & 12 Months \\
& & & & \\
Raw Return & 0.0187 & 0.00789 & 0.00531 & 0.0036 \\
& $(8.028)^{* * *}$ & $(7.589)^{* * *}$ & $(6.459)^{* * *}$ & $(5.674)^{* * *}$ \\
DGTW Adjust Return & 0.0159 & 0.0065 & 0.0044 & 0.0031 \\
& $(8.327)^{* * *}$ & $(7.940)^{* * *}$ & $(6.901)^{* * *}$ & $(6.017)^{* * *}$ \\
CAPM & 0.0184 & 0.0078 & 0.0052 & 0.0035 \\
& $(8.184)^{* * *}$ & $(7.703)^{* * * *}$ & $(6.653)^{* * *}$ & $(5.903)^{* * *}$ \\
3 Factor & 0.0179 & 0.0076 & 0.0051 & 0.0034 \\
& $(8.391)^{* * *}$ & $(7.816)^{* * *}$ & $(6.751)^{* * *}$ & $(5.840)^{* * *}$ \\
4 Factor & 0.0180 & 0.0076 & 0.0051 & 0.0034 \\
& $(10.20)^{* * *}$ & $(8.256)^{* * *}$ & $(6.979)^{* * *}$ & $(5.815)^{* * *}$ \\
\hline
\end{tabular}




\section{Table 7: Transition Probability of Supply and Demand Shift}

Panel A reports the probability that a stock is in the decile of the row conditional on that the stock is in the decile of the column 1 month ago. Similarly, Panel B-D present the probability that a stock is in the decile of the row conditional on that the stock is in the decile of the column 3 months, 6 months and 12 months ago. The sample period is between 2005M1 and 2011M12.

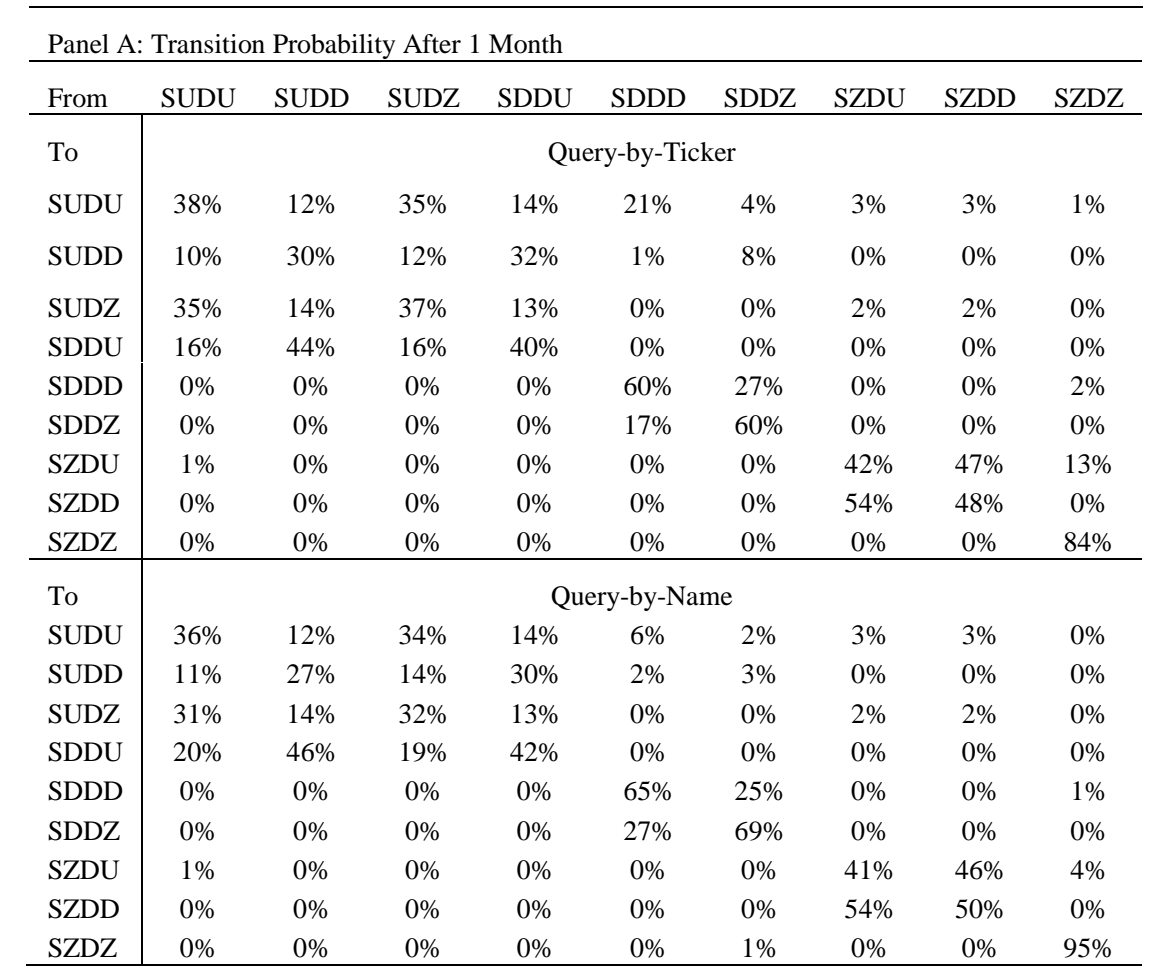

\begin{tabular}{|c|c|c|c|c|c|c|c|c|c|}
\hline \multicolumn{10}{|c|}{ Panel B: Transition Probability After 3 Month } \\
\hline From & SUDU & SUDD & SUDZ & SDDU & SDDD & SDDZ & SZDU & SZDD & SZDZ \\
\hline To & \multicolumn{9}{|c|}{ Query-by-Ticker } \\
\hline SUDU & $38 \%$ & $21 \%$ & $23 \%$ & $15 \%$ & $21 \%$ & $10 \%$ & $7 \%$ & $5 \%$ & $2 \%$ \\
\hline SUDD & $19 \%$ & $32 \%$ & $14 \%$ & $21 \%$ & $4 \%$ & $10 \%$ & $1 \%$ & $1 \%$ & $1 \%$ \\
\hline SUDZ & $26 \%$ & $16 \%$ & $35 \%$ & $22 \%$ & $15 \%$ & $4 \%$ & $4 \%$ & $5 \%$ & $0 \%$ \\
\hline SDDU & $17 \%$ & $30 \%$ & $28 \%$ & $41 \%$ & $4 \%$ & $9 \%$ & $2 \%$ & $2 \%$ & $0 \%$ \\
\hline SDDD & $0 \%$ & $0 \%$ & $0 \%$ & $0 \%$ & $37 \%$ & $27 \%$ & $0 \%$ & $0 \%$ & $2 \%$ \\
\hline SDDZ & $0 \%$ & $0 \%$ & $0 \%$ & $0 \%$ & $20 \%$ & $39 \%$ & $0 \%$ & $0 \%$ & $1 \%$ \\
\hline SZDU & $0 \%$ & $0 \%$ & $0 \%$ & $0 \%$ & $0 \%$ & $0 \%$ & $49 \%$ & $31 \%$ & $14 \%$ \\
\hline SZDD & $0 \%$ & $0 \%$ & $0 \%$ & $1 \%$ & $0 \%$ & $0 \%$ & $37 \%$ & $55 \%$ & $11 \%$ \\
\hline SZDZ & $0 \%$ & $0 \%$ & $0 \%$ & $0 \%$ & $0 \%$ & $0 \%$ & $0 \%$ & $0 \%$ & $68 \%$ \\
\hline To & \multicolumn{9}{|c|}{ Query-by-Name } \\
\hline SUDU & $36 \%$ & $21 \%$ & $22 \%$ & $15 \%$ & $8 \%$ & $5 \%$ & $6 \%$ & $4 \%$ & $2 \%$ \\
\hline SUDD & $20 \%$ & $31 \%$ & $15 \%$ & $20 \%$ & $3 \%$ & $3 \%$ & $2 \%$ & $1 \%$ & $0 \%$ \\
\hline SUDZ & $22 \%$ & $15 \%$ & $31 \%$ & $20 \%$ & $4 \%$ & $3 \%$ & $3 \%$ & $4 \%$ & $0 \%$ \\
\hline SDDU & $21 \%$ & $32 \%$ & $32 \%$ & $43 \%$ & $4 \%$ & $4 \%$ & $2 \%$ & $2 \%$ & $0 \%$ \\
\hline SDDD & $0 \%$ & $0 \%$ & $0 \%$ & $0 \%$ & $48 \%$ & $29 \%$ & $0 \%$ & $0 \%$ & $2 \%$ \\
\hline SDDZ & $0 \%$ & $0 \%$ & $0 \%$ & $0 \%$ & $33 \%$ & $55 \%$ & $0 \%$ & $0 \%$ & $1 \%$ \\
\hline SZDU & $1 \%$ & $1 \%$ & $0 \%$ & $1 \%$ & $0 \%$ & $0 \%$ & $47 \%$ & $32 \%$ & $6 \%$ \\
\hline SZDD & $0 \%$ & $1 \%$ & $0 \%$ & $1 \%$ & $0 \%$ & $0 \%$ & $40 \%$ & $55 \%$ & $3 \%$ \\
\hline SZDZ & $0 \%$ & $0 \%$ & $0 \%$ & $0 \%$ & $0 \%$ & $1 \%$ & $0 \%$ & $0 \%$ & $86 \%$ \\
\hline
\end{tabular}




\begin{tabular}{|c|c|c|c|c|c|c|c|c|c|}
\hline \multicolumn{10}{|c|}{ Panel C: Transition Probability After 6 Month } \\
\hline From & SUDU & SUDD & SUDZ & SDDU & SDDD & SDDZ & SZDU & SZDD & SZDZ \\
\hline To & \multicolumn{9}{|c|}{ Query-by-Ticker } \\
\hline SUDU & $31 \%$ & $24 \%$ & $21 \%$ & $18 \%$ & $27 \%$ & $14 \%$ & $10 \%$ & $7 \%$ & $3 \%$ \\
\hline SUDD & $21 \%$ & $28 \%$ & $18 \%$ & $20 \%$ & $9 \%$ & $13 \%$ & $4 \%$ & $3 \%$ & $2 \%$ \\
\hline SUDZ & $24 \%$ & $20 \%$ & $29 \%$ & $24 \%$ & $18 \%$ & $12 \%$ & $8 \%$ & $9 \%$ & $2 \%$ \\
\hline SDDU & $23 \%$ & $27 \%$ & $32 \%$ & $36 \%$ & $11 \%$ & $12 \%$ & $4 \%$ & $6 \%$ & $2 \%$ \\
\hline SDDD & $0 \%$ & $0 \%$ & $0 \%$ & $0 \%$ & $18 \%$ & $22 \%$ & $0 \%$ & $0 \%$ & $3 \%$ \\
\hline SDDZ & $0 \%$ & $0 \%$ & $0 \%$ & $0 \%$ & $18 \%$ & $27 \%$ & $0 \%$ & $0 \%$ & $0 \%$ \\
\hline SZDU & $0 \%$ & $1 \%$ & $0 \%$ & $1 \%$ & $0 \%$ & $0 \%$ & $40 \%$ & $27 \%$ & $19 \%$ \\
\hline SZDD & $0 \%$ & $1 \%$ & $0 \%$ & $1 \%$ & $0 \%$ & $0 \%$ & $34 \%$ & $48 \%$ & $16 \%$ \\
\hline SZDZ & $0 \%$ & $0 \%$ & $0 \%$ & $0 \%$ & $0 \%$ & $0 \%$ & $0 \%$ & $0 \%$ & $51 \%$ \\
\hline To & \multicolumn{9}{|c|}{ Query-by-Name } \\
\hline SUDU & $29 \%$ & $23 \%$ & $20 \%$ & $18 \%$ & $9 \%$ & $9 \%$ & $8 \%$ & $6 \%$ & $5 \%$ \\
\hline SUDD & $23 \%$ & $26 \%$ & $18 \%$ & $18 \%$ & $4 \%$ & $4 \%$ & $5 \%$ & $3 \%$ & $0 \%$ \\
\hline SUDZ & $20 \%$ & $18 \%$ & $25 \%$ & $23 \%$ & $9 \%$ & $8 \%$ & $5 \%$ & $7 \%$ & $1 \%$ \\
\hline SDDU & $27 \%$ & $30 \%$ & $36 \%$ & $37 \%$ & $9 \%$ & $7 \%$ & $5 \%$ & $6 \%$ & $0 \%$ \\
\hline SDDD & $0 \%$ & $0 \%$ & $0 \%$ & $0 \%$ & $35 \%$ & $28 \%$ & $0 \%$ & $0 \%$ & $3 \%$ \\
\hline SDDZ & $0 \%$ & $0 \%$ & $0 \%$ & $0 \%$ & $35 \%$ & $43 \%$ & $0 \%$ & $0 \%$ & $1 \%$ \\
\hline SZDU & $1 \%$ & $1 \%$ & $0 \%$ & $1 \%$ & $0 \%$ & $0 \%$ & $39 \%$ & $29 \%$ & $9 \%$ \\
\hline SZDD & $0 \%$ & $2 \%$ & $0 \%$ & $2 \%$ & $0 \%$ & $0 \%$ & $38 \%$ & $49 \%$ & $6 \%$ \\
\hline SZDZ & $0 \%$ & $0 \%$ & $0 \%$ & $0 \%$ & $0 \%$ & $2 \%$ & $0 \%$ & $1 \%$ & $75 \%$ \\
\hline
\end{tabular}

\begin{tabular}{|c|c|c|c|c|c|c|c|c|c|}
\hline \multicolumn{10}{|c|}{ Panel D: Transition Probability After 12 Month } \\
\hline From & SUDU & SUDD & SUDZ & SDDU & SDDD & SDDZ & SZDU & SZDD & SZDZ \\
\hline To & \multicolumn{9}{|c|}{ Query-by-Ticker } \\
\hline SUDU & $32 \%$ & $24 \%$ & $21 \%$ & $14 \%$ & $22 \%$ & $15 \%$ & $14 \%$ & $8 \%$ & $9 \%$ \\
\hline SUDD & $23 \%$ & $31 \%$ & $14 \%$ & $19 \%$ & $17 \%$ & $20 \%$ & $10 \%$ & $6 \%$ & $7 \%$ \\
\hline SUDZ & $22 \%$ & $16 \%$ & $34 \%$ & $23 \%$ & $22 \%$ & $13 \%$ & $10 \%$ & $13 \%$ & $5 \%$ \\
\hline SDDU & $22 \%$ & $27 \%$ & $30 \%$ & $41 \%$ & $23 \%$ & $25 \%$ & $10 \%$ & $14 \%$ & $8 \%$ \\
\hline SDDD & $0 \%$ & $0 \%$ & $0 \%$ & $0 \%$ & $10 \%$ & $7 \%$ & $0 \%$ & $0 \%$ & $0 \%$ \\
\hline SDDZ & $0 \%$ & $0 \%$ & $0 \%$ & $0 \%$ & $5 \%$ & $19 \%$ & $0 \%$ & $0 \%$ & $0 \%$ \\
\hline SZDU & $0 \%$ & $1 \%$ & $0 \%$ & $1 \%$ & $0 \%$ & $0 \%$ & $32 \%$ & $19 \%$ & $15 \%$ \\
\hline SZDD & $0 \%$ & $1 \%$ & $0 \%$ & $2 \%$ & $0 \%$ & $0 \%$ & $25 \%$ & $39 \%$ & $27 \%$ \\
\hline SZDZ & $0 \%$ & $0 \%$ & $0 \%$ & $0 \%$ & $0 \%$ & $0 \%$ & $0 \%$ & $0 \%$ & $28 \%$ \\
\hline To & \multicolumn{9}{|c|}{ Query-by-Name } \\
\hline SUDU & $30 \%$ & $25 \%$ & $19 \%$ & $15 \%$ & $14 \%$ & $13 \%$ & $11 \%$ & $7 \%$ & $8 \%$ \\
\hline SUDD & $24 \%$ & $29 \%$ & $14 \%$ & $17 \%$ & $4 \%$ & $6 \%$ & $10 \%$ & $6 \%$ & $1 \%$ \\
\hline SUDZ & $19 \%$ & $15 \%$ & $30 \%$ & $22 \%$ & $15 \%$ & $10 \%$ & $7 \%$ & $11 \%$ & $4 \%$ \\
\hline SDDU & $25 \%$ & $27 \%$ & $36 \%$ & $42 \%$ & $15 \%$ & $15 \%$ & $9 \%$ & $14 \%$ & $2 \%$ \\
\hline SDDD & $0 \%$ & $0 \%$ & $0 \%$ & $0 \%$ & $23 \%$ & $23 \%$ & $0 \%$ & $0 \%$ & $3 \%$ \\
\hline SDDZ & $0 \%$ & $0 \%$ & $0 \%$ & $0 \%$ & $29 \%$ & $30 \%$ & $0 \%$ & $0 \%$ & $3 \%$ \\
\hline SZDU & $1 \%$ & $3 \%$ & $0 \%$ & $1 \%$ & $0 \%$ & $0 \%$ & $34 \%$ & $19 \%$ & $11 \%$ \\
\hline SZDD & $1 \%$ & $2 \%$ & $0 \%$ & $3 \%$ & $0 \%$ & $0 \%$ & $27 \%$ & $42 \%$ & $9 \%$ \\
\hline SZDZ & $0 \%$ & $0 \%$ & $0 \%$ & $0 \%$ & $1 \%$ & $3 \%$ & $0 \%$ & $1 \%$ & $58 \%$ \\
\hline
\end{tabular}




\section{Table 8: Good/Bad News and Information Supply/Demand on Stock Returns}

The table reports the relationship between the abnormal return and the lagged shift in both supply and demand for information conditional on whether the news is good or bad on average. The regression model is Fama Macbeth regression with Newey-West for 3 lags: Abnormal_Return $_{t}=\alpha_{t}+\beta_{1}$ Good_News $s_{t-1} \times S U D U_{t-1}+\beta_{2}$ Bad_News $_{t-1} \times S U D U_{t-1}+$ $\beta_{3}$ Good_NewS $_{t-1} \times S U D D_{t-1}+\beta_{4}$ Bad_News $s_{t-1} \times S U D D_{t-1}+\beta_{5}$ Good_NewS $_{t-1} \times$ $S D D U_{t-1}+\beta_{6}$ Bad_News $_{t-1} \times S D D U_{t-1}+\beta_{7} r_{j, t-1}+\beta_{8} r_{j, t-12,-2}+\beta_{9} I O_{j, t-3}+$ $\beta_{10}$ Volume $_{j, t-7, t-1}+$ Additonal_Controls $_{+} \epsilon_{t}$, where Abnormal_Return $_{t}$ is measured by DGTW adjusted return, SUDU=1 if "News Up" (i.e. Supply $\underline{\mathrm{U}}$ ) and "Search Up" (i.e. Demand $\underline{\mathrm{U}}$ ), SUDD= 1 if "News Up" and "Search Down", SDDU=1 if "News Down" and "Search Up", $\mathrm{SDDD}=1$ if "News Down" and "Search Down", Good_News=1 if the average analyst recommendation in IBES is above its 12 month moving average and 0 otherwise, Bad_News=1Good_News, $r_{j, t-1}$ is the last month's return, $r_{j, t-12,-2}$ is the return from month $t-12$ to $t$-2, $I O_{j, t-3}$ is the institutional ownership in the previous quarter, and Volume $e_{j, t-7,-1}$ is the average trading volume during previous 6 months scaled by the total number of shares outstanding. The Additional_Controls include $\log (1+\#$ Analyst $)$ where \#Analyst is the number of analysts who cover the firm, $\log (1+\#$ News $)$ where \#News is the number of news articles about the firm, $\log (\mathrm{ME})$ where $\mathrm{ME}$ is the market equity value in time $\mathrm{t}-1$, market equity to book equity ratio, debt ratio, current ratio, asset turnover, earning per share to price ratio, and dummies for two digits SIC code. Panel A reports the result for query-by-ticker sample ad Panel B presents the result for query-by-ticker sample. The sample period is between 2005M1 and 2011M12. 


\begin{tabular}{|c|c|c|c|c|c|c|}
\hline \multicolumn{7}{|c|}{ Panel A: Query-by-Ticker Sample } \\
\hline & Model1 & Model2 & Model3 & Model4 & Model5 & Model6 \\
\hline Abnormal Return & \multicolumn{6}{|c|}{ DGTW Adjusted Return } \\
\hline SUDU*Good_News,t-1 & $\begin{array}{c}0.0155 \\
(6.316)^{* * *}\end{array}$ & $\begin{array}{c}0.0156 \\
(6.403)^{* * *}\end{array}$ & $\begin{array}{c}0.0172 \\
(4.737)^{* * *}\end{array}$ & $\begin{array}{c}0.0144 \\
(6.171)^{* * * *}\end{array}$ & $\begin{array}{c}0.0163 \\
(6.795)^{* * *}\end{array}$ & $\begin{array}{c}0.0152 \\
(6.453)^{* * *}\end{array}$ \\
\hline SUDU*Bad_News,t-1 & $\begin{array}{l}-0.0008 \\
(-0.517)\end{array}$ & $\begin{array}{l}-0.0003 \\
(-0.165)\end{array}$ & $\begin{array}{c}0.0011 \\
(0.45)\end{array}$ & $\begin{array}{c}-0.0001 \\
(-0.0560)\end{array}$ & $\begin{array}{l}-0.0008 \\
(-0.482)\end{array}$ & $\begin{array}{l}-0.0005 \\
(-0.327)\end{array}$ \\
\hline SUDD*Good_News, t-1 & $\begin{array}{c}0.0001 \\
(0.07)\end{array}$ & $\begin{array}{c}0.0004 \\
(0.45)\end{array}$ & $\begin{array}{c}0.0018 \\
(0.83)\end{array}$ & $\begin{array}{c}0.0001 \\
(0.09)\end{array}$ & $\begin{array}{c}0.0000 \\
(0.04)\end{array}$ & $\begin{array}{c}0.0001 \\
(0.09)\end{array}$ \\
\hline SUDD*Bad_News, t-1 & $\begin{array}{c}(0.00) \\
(-0.813)\end{array}$ & $\begin{array}{c}(0.00) \\
(-0.505)\end{array}$ & $\begin{array}{c}0.00 \\
(0.42)\end{array}$ & $\begin{array}{c}(0.00) \\
(-0.360)\end{array}$ & $\begin{array}{c}(0.00) \\
(-1.155)\end{array}$ & $\begin{array}{c}(0.00) \\
(-0.805)\end{array}$ \\
\hline SDDU*Good_News, t-1 & $\begin{array}{c}0.00 \\
(0.75)\end{array}$ & $\begin{array}{c}0.00 \\
(0.96)\end{array}$ & $\begin{array}{c}0.00 \\
(0.82)\end{array}$ & $\begin{array}{c}0.00 \\
(0.89)\end{array}$ & $\begin{array}{c}0.00 \\
(0.51)\end{array}$ & $\begin{array}{c}0.00 \\
(1.00)\end{array}$ \\
\hline SDDU*Bad_News, t-1 & $\begin{array}{c}0.00 \\
(0.81)\end{array}$ & $\begin{array}{c}0.00 \\
(1.22)\end{array}$ & $\begin{array}{c}0.00 \\
(0.93)\end{array}$ & $\begin{array}{c}0.00 \\
(0.86)\end{array}$ & $\begin{array}{c}0.00 \\
(0.99)\end{array}$ & $\begin{array}{c}0.00 \\
(1.06)\end{array}$ \\
\hline Return, t-1 & $\begin{array}{c}-0.0289 \\
(-3.679) * * *\end{array}$ & $\begin{array}{c}-0.031 \\
(-3.996)^{* * *}\end{array}$ & $\begin{array}{c}-0.0296 \\
(-3.773)^{* * *}\end{array}$ & $\begin{array}{c}-0.0289 \\
(-3.659)^{* * *}\end{array}$ & $\begin{array}{c}-0.0274 \\
(-3.391)^{* * * *}\end{array}$ & $\begin{array}{c}-0.0294 \\
(-3.772) * * *\end{array}$ \\
\hline Return, $\mathrm{t}-2$ to $\mathrm{t}-12$ & $\begin{array}{c}-8.12 \mathrm{E}-03 \\
(-1.528)\end{array}$ & $\begin{array}{c}-8.33 \mathrm{E}-03 \\
(-1.564)\end{array}$ & $\begin{array}{c}-8.25 \mathrm{E}-03 \\
(-1.552)\end{array}$ & $\begin{array}{c}-7.79 \mathrm{E}-03 \\
(-1.443)\end{array}$ & $\begin{array}{c}-0.00826 \\
(-1.527)\end{array}$ & $\begin{array}{c}-0.00844 \\
(-1.529)\end{array}$ \\
\hline $\mathrm{IO}, \mathrm{t}-3$ & & $\begin{array}{c}-0.0129 \\
(-4.987) * * *\end{array}$ & & & & \\
\hline Volume, $\mathrm{t}-1$ to $\mathrm{t}-6$ & & $\begin{array}{c}-0.134 \\
(-1.628)\end{array}$ & & & & \\
\hline $\log (1+\#$ Analyst $), \mathrm{t}-1$ & & & $\begin{array}{c}-0.00131 \\
(-2.738) * * *\end{array}$ & & & \\
\hline $\log (1+\#$ News $), t-1$ & & & $\begin{array}{c}2.29 \mathrm{E}-03 \\
(0.76)\end{array}$ & & & \\
\hline $\log (\mathrm{ME}), \mathrm{t}-1$ & & & & $\begin{array}{c}-0.00097 \\
(-2.281)^{* *}\end{array}$ & & \\
\hline $\mathrm{ME} / \mathrm{BE}, \mathrm{t}-1$ & & & & $\begin{array}{c}-1.10 \mathrm{E}-04 \\
(-1.215)\end{array}$ & & \\
\hline Debt Ratio & & & & & $\begin{array}{c}0.00213 \\
(0.66)\end{array}$ & \\
\hline Current Ratio & & & & & $\begin{array}{c}(0.00) \\
(-0.990)\end{array}$ & \\
\hline Asset Turnover & & & & & & $\begin{array}{c}0.01 \\
(3.503)^{* * *}\end{array}$ \\
\hline Profit Margin & & & & & & $\begin{array}{c}(0.00) \\
(-0.793)\end{array}$ \\
\hline EPS/Price & & & & & & $\begin{array}{c}0.00 \\
(3.368) * * *\end{array}$ \\
\hline Constant & $\begin{array}{c}0.00832 \\
(0.99)\end{array}$ & $\begin{array}{c}0.00778 \\
(0.85)\end{array}$ & $\begin{array}{c}0.00286 \\
(0.36)\end{array}$ & $\begin{array}{c}0.0114 \\
(1.08)\end{array}$ & $\begin{array}{c}0.000155 \\
(0.02)\end{array}$ & $\begin{array}{l}-0.0119 \\
(-1.016)\end{array}$ \\
\hline Observations & 138,383 & 138,383 & 138,383 & 135,395 & 117,688 & 136,224 \\
\hline R-squared & 0.099 & 0.105 & 0.1 & 0.101 & 0.094 & 0.103 \\
\hline Industry Dummy & Yes & Yes & Yes & Yes & Yes & Yes \\
\hline Number of groups & 84 & 84 & 84 & 84 & 84 & 84 \\
\hline
\end{tabular}




\begin{tabular}{|c|c|c|c|c|c|c|}
\hline \multicolumn{7}{|c|}{ Panel B: Query-by-Name Sample } \\
\hline \multirow[b]{2}{*}{ Abnormal Return } & Model1 & Model2 & Model3 & Model4 & Model5 & Model6 \\
\hline & \multicolumn{6}{|c|}{ DGTW Adjusted Return } \\
\hline \multirow[t]{2}{*}{ SUDU*Good_News,t-1 } & 0.0206 & 0.0208 & 0.0191 & 0.0191 & 0.0217 & 0.02 \\
\hline & $(6.588)^{* * *}$ & $(6.780)^{* * *}$ & $(6.604)^{* * *}$ & $(6.761)^{* * *}$ & $(7.148)^{* * *}$ & $(6.689)^{* * *}$ \\
\hline \multirow[t]{2}{*}{ SUDU*Bad_News,t-1 } & 0.0001 & 0.0006 & -0.0013 & 0.0004 & 0.0002 & 0.0000 \\
\hline & $(0.10)$ & $(0.50)$ & $(-0.567)$ & $(0.38)$ & $(0.16)$ & $(0.00)$ \\
\hline \multirow[t]{2}{*}{ SUDD*Good_News, t-1 } & -0.0011 & -0.0008 & -0.0026 & -0.0012 & -0.0012 & -0.0012 \\
\hline & $(-1.165)$ & $(-0.846)$ & $(-0.943)$ & $(-1.179)$ & $(-1.263)$ & $(-1.336)$ \\
\hline \multirow[t]{2}{*}{ SUDD*Bad_News, t-1 } & $(0.00)$ & 0.00 & $(0.00)$ & 0.00 & $(0.00)$ & $(0.00)$ \\
\hline & $(-0.110)$ & $(0.02)$ & $(-0.594)$ & $(0.22)$ & $(-0.562)$ & $(-0.423)$ \\
\hline \multirow[t]{2}{*}{ SDDU*Good_News, t-1 } & 0.00 & 0.00 & 0.00 & 0.00 & 0.00 & 0.00 \\
\hline & $(2.597)^{* *}$ & $(2.906)^{* * *}$ & $(2.838)^{* * * *}$ & $(2.565)^{* *}$ & $(2.959)^{* * *}$ & $(2.440)^{* *}$ \\
\hline \multirow[t]{2}{*}{ SDDU*Bad_News, t-1 } & 0.00 & 0.00 & 0.00 & 0.00 & 0.00 & 0.00 \\
\hline & $(1.34)$ & $(1.65)$ & $(1.56)$ & $(1.33)$ & $(1.24)$ & $(1.12)$ \\
\hline \multirow[t]{2}{*}{ Return, t-1 } & -0.0269 & -0.0294 & -0.0274 & -0.0291 & -0.026 & -0.0274 \\
\hline & $(-3.177)^{* * *}$ & $(-3.619) * * *$ & $(-3.252)^{* * *}$ & $(-3.439)^{* * *}$ & $(-3.087)^{* * *}$ & $(-3.366)^{* * *}$ \\
\hline \multirow[t]{2}{*}{ Return, $\mathrm{t}-2$ to $\mathrm{t}-12$} & $-7.22 \mathrm{E}-03$ & $-7.74 \mathrm{E}-03$ & $-7.40 \mathrm{E}-03$ & $-6.76 \mathrm{E}-03$ & -0.00818 & -0.00738 \\
\hline & $(-1.279)$ & $(-1.378)$ & $(-1.302)$ & $(-1.167)$ & $(-1.426)$ & $(-1.268)$ \\
\hline \multirow[t]{2}{*}{$\mathrm{IO}, \mathrm{t}-3$} & & -0.0118 & & & & \\
\hline & & $(-4.450)^{* * *}$ & & & & \\
\hline \multirow[t]{2}{*}{ Volume, $\mathrm{t}-1$ to $\mathrm{t}-6$} & & -0.161 & & & & \\
\hline & & $(-1.759)^{*}$ & & & & \\
\hline \multirow[t]{2}{*}{$\log (1+\#$ Analyst $), t-1$} & & & -0.00129 & & & \\
\hline & & & $(-2.273)^{* *}$ & & & \\
\hline \multirow[t]{2}{*}{$\log (1+\#$ News $), \mathrm{t}-1$} & & & $-2.46 \mathrm{E}-03$ & & & \\
\hline & & & $(-0.673)$ & & & \\
\hline \multirow[t]{2}{*}{$\log (\mathrm{ME}), \mathrm{t}-1$} & & & & -0.00074 & & \\
\hline & & & & $(-1.665)^{*}$ & & \\
\hline \multirow[t]{2}{*}{$\mathrm{ME} / \mathrm{BE}, \mathrm{t}-1$} & & & & $-1.60 \mathrm{E}-04$ & & \\
\hline & & & & $(-1.720)^{*}$ & & \\
\hline \multirow[t]{2}{*}{ Debt Ratio } & & & & & 0.0015 & \\
\hline & & & & & $(0.41)$ & \\
\hline \multirow[t]{2}{*}{ Current Ratio } & & & & & $(0.00)$ & \\
\hline & & & & & $(-0.820)$ & \\
\hline \multirow[t]{2}{*}{ Asset Turnover } & & & & & & 0.01 \\
\hline & & & & & & $(3.247)^{* * *}$ \\
\hline \multirow[t]{2}{*}{ Profit Margin } & & & & & & 0.00 \\
\hline & & & & & & $(0.74)$ \\
\hline \multirow[t]{2}{*}{ EPS/Price } & & & & & & 0.00 \\
\hline & & & & & & $(3.426)^{* * *}$ \\
\hline Constant & 0.00873 & 0.0303 & 0.0231 & -0.00054 & 0.00945 & -0.00665 \\
\hline & $(0.72)$ & $(2.261)^{* *}$ & $(1.706)^{*}$ & $(-0.0435)$ & $(0.73)$ & $(-0.431)$ \\
\hline Observations & 118,320 & 118,320 & 118,320 & 114,324 & 99,968 & 115,033 \\
\hline R-squared & 0.107 & 0.113 & 0.108 & 0.107 & 0.104 & 0.11 \\
\hline Industry Dummy & Yes & Yes & Yes & Yes & Yes & Yes \\
\hline Number of groups & 84 & 84 & 84 & 84 & 84 & 84 \\
\hline
\end{tabular}


Table 9: Portfolio Analysis of Combining Good/Bad News and Information Supply/Demand

Panel A splits stocks into good news subsample and bad news subsample, where a stock is defined as being accompanied be good news if its average IBES analyst recommendation is above its 12 months average. Within each subsample, it reports the abnormal return of a portfolio to go long the stocks with the increase in both information supply and demand (i.e. SUDU=1) and go short the other stocks (i.e. SUDU=0). The long and short portfolio is an equal weight portfolio and monthly rebalanced based on the information supply and demand in the previous month. Panel B splits stocks into subsamples by information supply and demand "pairs". Within each subsample, Panel B repots the abnormal return of a portfolio of buying stocks with good news and short selling stocks with bad news. The sample period is from 2005M1 to 2011M12.

\begin{tabular}{lcccc}
\hline \multicolumn{5}{c}{ Panel A: Buy Stocks with SUDU=1 and Short Sell other Stocks in Bad/Good News Subsample } \\
\hline \multicolumn{5}{c}{ Good News Subsample } \\
\multicolumn{4}{c}{ By Ticker } & \multicolumn{2}{c}{ By Ticker } \\
Raw Return & 0.0186 & $(7.634)^{* * *}$ & 0.024 & $(7.527)^{* * *}$ \\
DGTW Adjusted Return & 0.0144 & $(8.217)^{* * *}$ & 0.0195 & $(7.898)^{* * *}$ \\
CAPM Alpha & 0.0181 & $(8.252)^{* * *}$ & 0.0236 & $(7.709)^{* * *}$ \\
3 Factor Alpha & 0.0177 & $(8.570)^{* * *}$ & 0.0229 & $(7.936)^{* * *}$ \\
4 Factor Alpha & 0.0178 & $(9.305)^{* * *}$ & 0.023 & $(9.519)^{* * *}$ \\
\hline \multicolumn{5}{c}{ Bad News Subsample } \\
& \multicolumn{5}{c}{ By Ticker } \\
Raw Return & \multicolumn{5}{c}{ By Ticker } & -0.00263 & $(-2.032)^{* *}$ \\
DGTW Adjusted Return & -0.00258 & $(-1.841)^{*}$ & -0.00201 & $(-1.786)^{*}$ \\
CAPM Alpha & -0.00201 & $(-1.509)$ & -0.00253 & $(-1.970)^{*}$ \\
3 Factor Alpha & -0.00233 & $(-1.798)^{*}$ & -0.00259 & $(-2.004)^{* *}$ \\
4 Factor Alpha & -0.00231 & $(-1.758)^{*}$ & -0.00263 & $(-2.310)^{* *}$ \\
\hline
\end{tabular}


Panel B: Buy Stocks with Goodl News and Short Sell Stocks with Bad News in the Each Information State Subsample with SUDU=1

\begin{tabular}{|c|c|c|c|c|}
\hline \multirow[b]{2}{*}{ Raw Return } & \multicolumn{2}{|c|}{ By Ticker } & \multicolumn{2}{|c|}{ By Ticker } \\
\hline & 0.0219 & $(6.226)^{* * *}$ & 0.0265 & $(6.145)^{* * *}$ \\
\hline DGTW Adjusted Return & 0.0168 & $(6.324)^{* * *}$ & 0.0208 & $(6.213)^{* * *}$ \\
\hline CAPM Alpha & 0.0212 & $(6.714)^{* * *}$ & 0.0259 & $(6.248)^{* * *}$ \\
\hline 3 Factor Alpha & 0.0208 & $(6.816)^{* * *}$ & 0.0253 & $(6.341)^{* * *}$ \\
\hline \multirow[t]{3}{*}{4 Factor Alpha } & 0.0209 & $(9.007)^{* * *}$ & 0.0255 & $(9.586)^{* * *}$ \\
\hline & \multicolumn{4}{|c|}{ Subsample with SUDD=1 } \\
\hline & \multicolumn{2}{|c|}{ By Ticker } & \multicolumn{2}{|c|}{ By Ticker } \\
\hline Raw Return & 0.00195 & (0.93) & -0.00171 & $(-1.018)$ \\
\hline DGTW Adjusted Return & 0.00197 & $(1.02)$ & -0.00186 & $(-1.184)$ \\
\hline CAPM Alpha & 0.00203 & $(0.96)$ & -0.00183 & $(-1.095)$ \\
\hline 3 Factor Alpha & 0.00205 & $(0.98)$ & -0.0018 & $(-1.076)$ \\
\hline \multirow[t]{3}{*}{ 4 Factor Alpha } & 0.00216 & $(1.43)$ & -0.00174 & $(-1.206)$ \\
\hline & \multicolumn{4}{|c|}{ Subsample with SDDU=1 } \\
\hline & \multicolumn{2}{|c|}{ By Ticker } & \multicolumn{2}{|c|}{ By Ticker } \\
\hline Raw Return & 0.00206 & (1.24) & 0.00296 & $(1.673)^{*}$ \\
\hline DGTW Adjusted Return & 0.000807 & $(0.51)$ & 0.00166 & $(1.02)$ \\
\hline CAPM Alpha & 0.00204 & $(1.22)$ & 0.00306 & $(1.729)^{*}$ \\
\hline 3 Factor Alpha & 0.00201 & $(1.23)$ & 0.00295 & $(1.747)^{*}$ \\
\hline \multirow[t]{3}{*}{4 Factor Alpha } & 0.00206 & $(1.36)$ & 0.003 & $(1.941)^{*}$ \\
\hline & \multicolumn{4}{|c|}{ Subsample with SDDD $=1$} \\
\hline & \multicolumn{2}{|c|}{ By Ticker } & \multicolumn{2}{|c|}{ By Ticker } \\
\hline Raw Return & -0.00184 & $(-1.562)$ & -0.00173 & $(-1.169)$ \\
\hline DGTW Adjusted Return & -0.00173 & $(-1.538)$ & -0.00186 & $(-1.365)$ \\
\hline CAPM Alpha & -0.00183 & $(-1.541)$ & -0.00181 & $(-1.225)$ \\
\hline 3 Factor Alpha & -0.00179 & $(-1.507)$ & -0.00181 & $(-1.275)$ \\
\hline 4 Factor Alpha & -0.00176 & $(-1.563)$ & -0.00175 & $(-1.436)$ \\
\hline
\end{tabular}




\section{Table 10: Wikipedia Traffic as the Measure of Information Demand}

The table reports the relationship between the abnormal return and the lagged shift in both supply and demand for information, where the web traffic of the company page on Wikipedia is used as the proxy for information demand. Since Wikipedia information is more static than the real time internet news, the traffic to the Wikipedia page captures the activities of the investors who are less aware of the firms. The regression model is Fama Macbeth regression with Newey-West for 3 lags: Abnormal_Return ${ }_{t}=\alpha_{t}+\beta_{1} S U D U_{-} W i k i_{t-1}+\beta_{2} S U D D \_W i k i_{t-1}+$ $\beta_{3} S D D U_{-} W i k i_{t-1}+\beta_{4} r_{j, t-1}+\beta_{5} r_{j, t-12,-2}+\beta_{6} I O_{j, t-3}+\beta_{7}$ Volume $_{j, t-7, t-1}+$

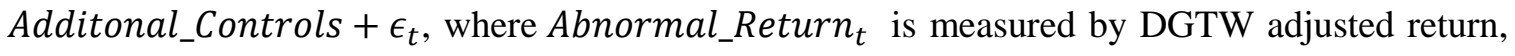

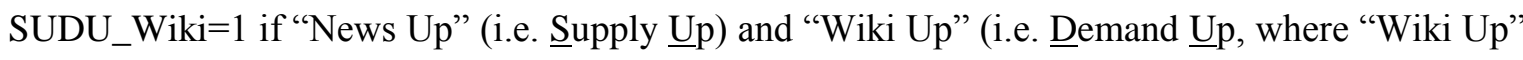
happens if the Wikipedia traffic to the company page is above its 12 months moving average), SUDD_Wiki= 1 if "News Up" and "Wiki Down", SDDU_Wiki=1 if "News Down" and "Wiki Up", SDDD_Wiki=1 if "News Down" and "Wiki Down", $r_{j, t-1}$ is the last month's return, $r_{j, t-12,-2}$ is the return from month $t-12$ to $t-2, I O_{j, t-3}$ is the institutional ownership in the previous quarter, and Volume $_{j, t-7,-1}$ is the average trading volume during previous 6 months scaled by the total number of shares outstanding. The Additional_Controls include $\log (1+\#$ Analyst $)$ where \#Analyst is the number of analysts who cover the firm, $\log (1+\#$ News $)$ where \#News is the number of news articles about the firm, $\log (\mathrm{ME})$ where $\mathrm{ME}$ is the market equity value in time $\mathrm{t}$ 1 , market equity to book equity ratio, debt ratio, current ratio, asset turnover, earning per share to price ratio, and dummies for two digits SIC code. Panel A reports the result for query-by-ticker sample ad Panel B presents the result for query-by-ticker sample. The sample period is between 2009M1 and 2011M12. 


\begin{tabular}{|c|c|c|c|c|c|c|}
\hline \multicolumn{7}{|c|}{ Panel A: Query-by-Ticker Sample } \\
\hline & Model1 & Model2 & Model3 & Model4 & Model5 & Model6 \\
\hline Abnormal Return & \multicolumn{6}{|c|}{ DGTW Adjusted Return } \\
\hline SUDU_Wiki,t-1 & $\begin{array}{c}0.00575 \\
(2.670)^{* *}\end{array}$ & $\begin{array}{c}0.00569 \\
(2.606)^{* *}\end{array}$ & $\begin{array}{c}0.00546 \\
(2.359)^{* *}\end{array}$ & $\begin{array}{c}0.00503 \\
(2.337)^{* *}\end{array}$ & $\begin{array}{c}0.00552 \\
(2.570)^{* *}\end{array}$ & $\begin{array}{c}0.00567 \\
(2.563) * *\end{array}$ \\
\hline SUDD_Wiki,t-1 & $\begin{array}{c}0.0016 \\
(0.88)\end{array}$ & $\begin{array}{c}0.0016 \\
(0.90)\end{array}$ & $\begin{array}{c}0.0012 \\
(0.66)\end{array}$ & $\begin{array}{c}0.0018 \\
(0.96)\end{array}$ & $\begin{array}{c}0.0016 \\
(1.01)\end{array}$ & $\begin{array}{c}0.0015 \\
(0.85)\end{array}$ \\
\hline SDDU_Wiki,t-1 & $\begin{array}{l}-0.0026 \\
(-1.511)\end{array}$ & $\begin{array}{l}-0.0025 \\
(-1.524)\end{array}$ & $\begin{array}{l}-0.0026 \\
(-1.557)\end{array}$ & $\begin{array}{l}-0.0028 \\
(-1.584)\end{array}$ & $\begin{array}{c}-0.0035 \\
(-2.329) * *\end{array}$ & $\begin{array}{l}-0.0024 \\
(-1.460)\end{array}$ \\
\hline Return, t-1 & $\begin{array}{c}-0.0267 \\
(-1.776)^{*}\end{array}$ & $\begin{array}{c}-0.0264 \\
(-1.803)^{*}\end{array}$ & $\begin{array}{c}-0.027 \\
(-1.782)^{*}\end{array}$ & $\begin{array}{l}-3.07 \mathrm{E}-02 \\
(-2.069) * *\end{array}$ & $\begin{array}{c}-0.0266 \\
(-1.731)^{*}\end{array}$ & $\begin{array}{c}-0.0298 \\
(-2.015)^{*}\end{array}$ \\
\hline Return, $\mathrm{t}-2$ to $\mathrm{t}-12$ & $\begin{array}{l}-0.0174 \\
(-1.301)\end{array}$ & $\begin{array}{l}-0.0179 \\
(-1.266)\end{array}$ & $\begin{array}{l}-0.0174 \\
(-1.301)\end{array}$ & $\begin{array}{l}-0.0176 \\
(-1.333)\end{array}$ & $\begin{array}{l}-0.0174 \\
(-1.261)\end{array}$ & $\begin{array}{l}-0.0181 \\
(-1.348)\end{array}$ \\
\hline $\mathrm{IO}, \mathrm{t}-3$ & & $\begin{array}{c}-0.00175 \\
(-1.023)\end{array}$ & & & & \\
\hline Volume, $\mathrm{t}-1$ to $\mathrm{t}-6$ & & $\begin{array}{l}-9.89 \mathrm{E}-02 \\
(-1.821)^{*}\end{array}$ & & & & \\
\hline $\log (1+\#$ Analyst $), \mathrm{t}-1$ & & & $\begin{array}{l}0.00165 \\
(1.828)^{*}\end{array}$ & & & \\
\hline $\log (1+\#$ News $), t-1$ & & & $\begin{array}{c}-0.00059 \\
(-0.477)\end{array}$ & & & \\
\hline $\log (\mathrm{ME}), \mathrm{t}-1$ & & & & $\begin{array}{l}-0.00105 \\
(-1.844)^{*}\end{array}$ & & \\
\hline $\mathrm{ME} / \mathrm{BE}, \mathrm{t}-1$ & & & & $\begin{array}{l}0.000392 \\
(2.083)^{* *}\end{array}$ & & \\
\hline Debt Ratio & & & & & $\begin{array}{c}-0.00203 \\
(-0.245)\end{array}$ & \\
\hline Current Ratio & & & & & $\begin{array}{c}-0.00052 \\
(-0.797)\end{array}$ & \\
\hline Asset Turnover & & & & & & $\begin{array}{c}4.01 \mathrm{E}-03 \\
(0.77)\end{array}$ \\
\hline Profit Margin & & & & & & $\begin{array}{c}0.01 \\
(1.755)^{*}\end{array}$ \\
\hline EPS/Price & & & & & & $\begin{array}{c}0.00 \\
(2.054)^{* *}\end{array}$ \\
\hline Constant & $\begin{array}{l}-0.0037 \\
(-0.165)\end{array}$ & $\begin{array}{c}0.0114 \\
(0.59)\end{array}$ & $\begin{array}{l}-0.00092 \\
(-0.0407)\end{array}$ & $\begin{array}{c}0.0112 \\
(0.72)\end{array}$ & $\begin{array}{l}-0.0167 \\
(-0.919)\end{array}$ & $\begin{array}{l}0.027 \\
(1.23)\end{array}$ \\
\hline Observations & 28,979 & 28,979 & 28,979 & 28,252 & 24,856 & 28,799 \\
\hline R-squared & 0.146 & 0.153 & 0.147 & 0.151 & 0.15 & 0.152 \\
\hline Industry Dummy & Yes & Yes & Yes & Yes & Yes & Yes \\
\hline Number of groups & 36 & 36 & 36 & 36 & 36 & 36 \\
\hline
\end{tabular}




\begin{tabular}{|c|c|c|c|c|c|c|}
\hline \multicolumn{7}{|c|}{ Panel B: Query-by-Name Sample } \\
\hline & Model1 & Model2 & Model3 & Model4 & Model5 & Model6 \\
\hline & \multicolumn{6}{|c|}{ DGTW Adjusted Return } \\
\hline SUDU_Wiki,t-1 & $\begin{array}{c}0.00942 \\
(3.092)^{* * *}\end{array}$ & $\begin{array}{c}0.00922 \\
(2.992)^{* * *}\end{array}$ & $\begin{array}{c}0.00896 \\
(2.852)^{* * * *}\end{array}$ & $\begin{array}{c}0.0084 \\
(3.199)^{* * *}\end{array}$ & $\begin{array}{c}0.0083 \\
(2.986)^{* * *}\end{array}$ & $\begin{array}{c}0.00887 \\
(2.932)^{* * *}\end{array}$ \\
\hline SUDD_Wiki,t-1 & $\begin{array}{c}0.0030 \\
(1.30)\end{array}$ & $\begin{array}{c}0.0029 \\
(1.27)\end{array}$ & $\begin{array}{c}0.0027 \\
(1.11)\end{array}$ & $\begin{array}{c}0.0029 \\
(1.32)\end{array}$ & $\begin{array}{c}0.0024 \\
(1.27)\end{array}$ & $\begin{array}{c}0.0027 \\
(1.14)\end{array}$ \\
\hline SDDU_Wiki,t-1 & $\begin{array}{c}0.0050 \\
(2.451)^{* *}\end{array}$ & $\begin{array}{c}0.0047 \\
(2.243)^{* *}\end{array}$ & $\begin{array}{c}0.0045 \\
(2.268)^{* *}\end{array}$ & $\begin{array}{c}0.0040 \\
(1.866)^{*}\end{array}$ & $\begin{array}{c}0.0025 \\
(1.11)\end{array}$ & $\begin{array}{c}0.0046 \\
(2.313)^{* *}\end{array}$ \\
\hline Return, t-1 & $\begin{array}{c}-0.027 \\
(-1.502)\end{array}$ & $\begin{array}{l}-0.0264 \\
(-1.542)\end{array}$ & $\begin{array}{l}-0.0269 \\
(-1.497)\end{array}$ & $\begin{array}{l}-3.27 \mathrm{E}-02 \\
(-1.873)^{*}\end{array}$ & $\begin{array}{l}-0.0254 \\
(-1.464)\end{array}$ & $\begin{array}{l}-0.0279 \\
(-1.580)\end{array}$ \\
\hline Return, $\mathrm{t}-2$ to $\mathrm{t}-12$ & $\begin{array}{l}-0.0181 \\
(-1.341)\end{array}$ & $\begin{array}{l}-0.0185 \\
(-1.279)\end{array}$ & $\begin{array}{c}-0.018 \\
(-1.330)\end{array}$ & $\begin{array}{l}-0.0182 \\
(-1.347)\end{array}$ & $\begin{array}{l}-0.0185 \\
(-1.296)\end{array}$ & $\begin{array}{l}-0.0193 \\
(-1.407)\end{array}$ \\
\hline $\mathrm{IO}, \mathrm{t}-3$ & & $\begin{array}{c}-0.00367 \\
(-1.564)\end{array}$ & & & & \\
\hline Volume, $\mathrm{t}-1$ to $\mathrm{t}-6$ & & $\begin{array}{c}-7.21 \mathrm{E}-02 \\
(-1.095)\end{array}$ & & & & \\
\hline $\log (1+\#$ Analyst $), t-1$ & & & $\begin{array}{c}0.00111 \\
(1.41)\end{array}$ & & & \\
\hline $\log (1+\#$ News $), t-1$ & & & $\begin{array}{c}-0.00234 \\
(-1.368)\end{array}$ & & & \\
\hline Market Equity, t-1 & & & & $\begin{array}{c}-0.00095 \\
(-1.646)\end{array}$ & & \\
\hline ME/BE, t-1 & & & & $\begin{array}{l}0.000474 \\
(2.489)^{* *}\end{array}$ & & \\
\hline Debt Ratio & & & & & $\begin{array}{c}0.00144 \\
(0.13)\end{array}$ & \\
\hline Current Ratio & & & & & $\begin{array}{c}-0.00124 \\
(-1.101)\end{array}$ & \\
\hline Asset Turnover & & & & & & $\begin{array}{c}3.74 \mathrm{E}-03 \\
(0.64)\end{array}$ \\
\hline Profit Margin & & & & & & $\begin{array}{c}0.01 \\
(1.822)^{*}\end{array}$ \\
\hline EPS/Price & & & & & & $\begin{array}{c}0.00 \\
(1.746)^{*}\end{array}$ \\
\hline Constant & $\begin{array}{l}-0.0172 \\
(-0.817)\end{array}$ & $\begin{array}{l}-0.00585 \\
(-0.325)\end{array}$ & $\begin{array}{l}-0.0299 \\
(-1.324)\end{array}$ & $\begin{array}{c}0.00792 \\
(0.57)\end{array}$ & $\begin{array}{l}-0.0222 \\
(-1.199)\end{array}$ & $\begin{array}{l}-0.0268 \\
(-1.407)\end{array}$ \\
\hline Observations & 24,425 & 24,425 & 24,425 & 23,544 & 21,060 & 24,077 \\
\hline R-squared & 0.158 & 0.166 & 0.159 & 0.162 & 0.162 & 0.162 \\
\hline Industry Dummy & Yes & Yes & Yes & Yes & Yes & Yes \\
\hline Number of groups & 36 & 36 & 36 & 36 & 36 & 36 \\
\hline
\end{tabular}


Table 11: Search Volume Net of Wikipedia Traffic as the Measure of Information Demand

The table reports the relationship between the abnormal return and the lagged shift in both supply and demand for information, where the search volume in Google net of web traffic of the company page on Wikipedia is used as the proxy for information demand. Specifically, the demand measure is Search_Residual ${ }_{s, t}=$ Search_Volume $_{s, t}-\hat{\gamma} \times$ Wiki_Volume $_{s, t}$ where $\hat{\gamma}$ is the coefficient in the regression Search_Volume $e_{s, t}=\gamma \times$ Wiki_Volume $_{s, t}+\epsilon_{s, t}$ for each stock $\mathrm{s}$ over the entire time series, Search_Volume is the Google search volume and Wiki_Volume is the web traffic to the company page on Wikipedia. The regression model is Fama Macbeth regression with Newey-West for 3 lags: $\quad$ Abnormal_Return $_{t}=\alpha_{t}+$ $\beta_{1} S U D U \_R_{-}$sidual $t_{t-1}+\beta_{2} S U D D \_R_{\text {Residual }}+\beta_{3} S D D U \_$Residual $_{t-1}+\beta_{4} r_{j, t-1}+$

$\beta_{5} r_{j, t-12,-2}+\beta_{6} I O_{j, t-3}+\beta_{7}$ Volume $_{j, t-7, t-1}+$ Additonal_Controls $+\epsilon_{t} \quad, \quad$ where Abnormal_Return $t$ is measured by DGTW adjusted return, SUDU_Residual=1 if "News Up"

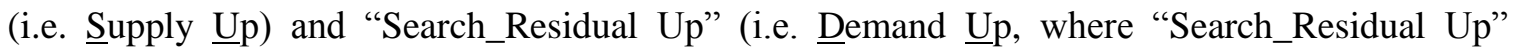
happens if the Google search volume net of Wikipedia traffic to the company page is above its 12 months moving average), SUDD_Residual = 1 if "News Up" and "Search_Residual Down", SDDU_Residual $=1$ if "News Down" and "Search_Residual Up", SDDD_Residual $=1$ if "News Down" and "Search_Residual Down", $r_{j, t-1}$ is the last month's return, $r_{j, t-12,-2}$ is the return from month $t-12$ to $t-2, I O_{j, t-3}$ is the institutional ownership in the previous quarter, and Volume $_{j, t-7,-1}$ is the average trading volume during previous 6 months scaled by the total number of shares outstanding. The Additional_Controls include $\log (1+\#$ Analyst $)$ where \#Analyst is the number of analysts who cover the firm, $\log (1+\#$ News $)$ where \#News is the number of news articles about the firm, $\log (\mathrm{ME})$ where $\mathrm{ME}$ is the market equity value in time $\mathrm{t}-1$, market equity to book equity ratio, debt ratio, current ratio, asset turnover, earning per share to price ratio, and dummies for two digits SIC code. Panel A reports the result for query-by-ticker sample ad Panel B presents the result for query-by-ticker sample. The sample period is between 2009M1 and $2011 \mathrm{M} 12$. 


\begin{tabular}{|c|c|c|c|c|c|c|}
\hline \multicolumn{7}{|c|}{ Panel A: Query-by-Ticker Sample } \\
\hline & Model1 & Model2 & Model3 & Model4 & Model5 & Model6 \\
\hline Abnormal Return & & & DGTW Adj & sted Return & & \\
\hline SUDU_Residual,t-1 & $\begin{array}{c}0.00229 \\
(3.094) * * *\end{array}$ & $\begin{array}{c}0.00222 \\
(3.048) * * *\end{array}$ & $\begin{array}{c}0.00245 \\
(3.019)^{* * *}\end{array}$ & $\begin{array}{c}0.00161 \\
(2.169)^{* *}\end{array}$ & $\begin{array}{c}0.00211 \\
(2.733)^{* * * *}\end{array}$ & $\begin{array}{c}0.00235 \\
(3.444)^{* * *}\end{array}$ \\
\hline SUDD_Residual,t-1 & $\begin{array}{c}0.0011 \\
(0.38)\end{array}$ & $\begin{array}{r}0.0007 \\
(0.24)\end{array}$ & $\begin{array}{c}0.0013 \\
(0.44)\end{array}$ & $\begin{array}{c}0.0009 \\
(0.32)\end{array}$ & $\begin{array}{c}0.0014 \\
(0.58)\end{array}$ & $\begin{array}{c}0.0013 \\
(0.45)\end{array}$ \\
\hline SDDU_Residual,t-1 & $\begin{array}{l}-0.0035 \\
(-1.662)\end{array}$ & $\begin{array}{c}-0.0033 \\
(-1.773)^{*}\end{array}$ & $\begin{array}{l}-0.0036 \\
(-1.672)\end{array}$ & $\begin{array}{c}-0.0041 \\
(-2.049)^{* *}\end{array}$ & $\begin{array}{l}-0.0037 \\
(-1.326)\end{array}$ & $\begin{array}{l}-0.0028 \\
(-1.392)\end{array}$ \\
\hline Return, $\mathrm{t}-1$ & $\begin{array}{c}-0.0259 \\
(-1.722)^{*}\end{array}$ & $\begin{array}{c}-0.0255 \\
(-1.747)^{*}\end{array}$ & $\begin{array}{c}-0.0263 \\
(-1.738)^{*}\end{array}$ & $\begin{array}{l}-3.00 \mathrm{E}-02 \\
(-2.038)^{* *}\end{array}$ & $\begin{array}{c}-0.0259 \\
(-1.699)^{*}\end{array}$ & $\begin{array}{c}-0.0289 \\
(-1.958)^{*}\end{array}$ \\
\hline Return, $\mathrm{t}-2$ to $\mathrm{t}-12$ & $\begin{array}{l}-0.0172 \\
(-1.286)\end{array}$ & $\begin{array}{l}-0.0178 \\
(-1.252)\end{array}$ & $\begin{array}{l}-0.0173 \\
(-1.284)\end{array}$ & $\begin{array}{l}-0.0174 \\
(-1.315)\end{array}$ & $\begin{array}{l}-0.0173 \\
(-1.242)\end{array}$ & $\begin{array}{c}-0.018 \\
(-1.337)\end{array}$ \\
\hline $\mathrm{IO}, \mathrm{t}-3$ & & $\begin{array}{c}-0.00138 \\
(-0.750)\end{array}$ & & & & \\
\hline Volume, $\mathrm{t}-1$ to $\mathrm{t}-6$ & & $\begin{array}{l}-9.88 \mathrm{E}-02 \\
(-1.802)^{*}\end{array}$ & & & & \\
\hline $\log (1+\#$ Analyst $), t-1$ & & & $\begin{array}{l}0.00174 \\
(1.984)^{*}\end{array}$ & & & \\
\hline $\log (1+\#$ News $), t-1$ & & & $\begin{array}{c}-0.00112 \\
(-0.927)\end{array}$ & & & \\
\hline $\log (\mathrm{ME}), \mathrm{t}-1$ & & & & $\begin{array}{l}-0.00105 \\
(-1.802)^{*}\end{array}$ & & \\
\hline $\mathrm{ME} / \mathrm{BE}, \mathrm{t}-1$ & & & & $\begin{array}{l}0.000414 \\
(2.322)^{* *}\end{array}$ & & \\
\hline Debt Ratio & & & & & $\begin{array}{c}-0.00175 \\
(-0.208)\end{array}$ & \\
\hline Current Ratio & & & & & $\begin{array}{c}-4.90 \mathrm{E}-04 \\
(-0.742)\end{array}$ & \\
\hline Asset Turnover & & & & & & $\begin{array}{c}4.14 \mathrm{E}-03 \\
(0.78)\end{array}$ \\
\hline Profit Margin & & & & & & $\begin{array}{c}0.01 \\
(1.830)^{*}\end{array}$ \\
\hline EPS/Price & & & & & & $\begin{array}{c}0.00 \\
(2.130)^{* *}\end{array}$ \\
\hline Constant & $\begin{array}{c}-0.00225 \\
(-0.105)\end{array}$ & $\begin{array}{c}0.0138 \\
(0.74)\end{array}$ & $\begin{array}{l}-0.00111 \\
(-0.0513)\end{array}$ & $\begin{array}{c}0.0214 \\
(1.25)\end{array}$ & $\begin{array}{l}-0.0201 \\
(-1.208)\end{array}$ & $\begin{array}{c}0.0102 \\
(0.76)\end{array}$ \\
\hline Observations & 28,979 & 28,979 & 28,979 & 28,252 & 24,856 & 28,799 \\
\hline R-squared & 0.145 & 0.151 & 0.146 & 0.149 & 0.149 & 0.15 \\
\hline Industry Dummy & Yes & Yes & Yes & Yes & Yes & Yes \\
\hline Number of groups & 36 & 36 & 36 & 36 & 36 & 36 \\
\hline
\end{tabular}




\begin{tabular}{|c|c|c|c|c|c|c|}
\hline \multicolumn{7}{|c|}{ Panel B: Query-by-Name Sample } \\
\hline & Model1 & Model2 & Model3 & Model4 & Model5 & Model6 \\
\hline & \multicolumn{6}{|c|}{ DGTW Adjusted Return } \\
\hline SUDU_Residual,t-1 & $\begin{array}{c}0.00599 \\
(4.442) * * *\end{array}$ & $\begin{array}{c}0.00571 \\
(4.260)^{* * *}\end{array}$ & $\begin{array}{c}0.0057 \\
(4.359)^{* * * *}\end{array}$ & $\begin{array}{c}0.00507 \\
(3.788) * * *\end{array}$ & $\begin{array}{c}0.00487 \\
(4.024)^{* * * *}\end{array}$ & $\begin{array}{c}0.00573 \\
(4.189)^{* * * *}\end{array}$ \\
\hline SUDD_Residual,t-1 & $\begin{array}{l}-0.0017 \\
(-0.877)\end{array}$ & $\begin{array}{l}-0.0018 \\
(-0.975)\end{array}$ & $\begin{array}{l}-0.0019 \\
(-0.903)\end{array}$ & $\begin{array}{l}-0.0017 \\
(-0.877)\end{array}$ & $\begin{array}{l}-0.0004 \\
(-0.233)\end{array}$ & $\begin{array}{l}-0.0026 \\
(-1.185)\end{array}$ \\
\hline SDDU_Residual,t-1 & $\begin{array}{c}0.0003 \\
(0.09)\end{array}$ & $\begin{array}{c}0.0010 \\
(0.33)\end{array}$ & $\begin{array}{c}-0.0002 \\
(-0.0527)\end{array}$ & $\begin{array}{l}-0.0006 \\
(-0.187)\end{array}$ & $\begin{array}{c}0.0045 \\
(1.62)\end{array}$ & $\begin{array}{l}-0.0005 \\
(-0.150)\end{array}$ \\
\hline Return, $\mathrm{t}-1$ & $\begin{array}{l}-0.0259 \\
(-1.432)\end{array}$ & $\begin{array}{l}-0.0254 \\
(-1.476)\end{array}$ & $\begin{array}{l}-0.0259 \\
(-1.429)\end{array}$ & $\begin{array}{c}-3.18 \mathrm{E}-02 \\
(-1.803)^{*}\end{array}$ & $\begin{array}{l}-0.0246 \\
(-1.392)\end{array}$ & $\begin{array}{c}-0.027 \\
(-1.520)\end{array}$ \\
\hline Return, $\mathrm{t}-2$ to $\mathrm{t}-12$ & $\begin{array}{l}-0.0182 \\
(-1.323)\end{array}$ & $\begin{array}{l}-0.0186 \\
(-1.262)\end{array}$ & $\begin{array}{l}-0.0181 \\
(-1.307)\end{array}$ & $\begin{array}{l}-0.0183 \\
(-1.329)\end{array}$ & $\begin{array}{l}-0.0188 \\
(-1.281)\end{array}$ & $\begin{array}{l}-0.0196 \\
(-1.394)\end{array}$ \\
\hline $\mathrm{IO}, \mathrm{t}-3$ & & $\begin{array}{c}-0.00354 \\
(-1.483)\end{array}$ & & & & \\
\hline Volume, $\mathrm{t}-1$ to $\mathrm{t}-6$ & & $\begin{array}{c}-7.08 \mathrm{E}-02 \\
(-1.086)\end{array}$ & & & & \\
\hline $\log (1+\#$ Analyst $), t-1$ & & & $\begin{array}{c}0.00113 \\
(1.58)\end{array}$ & & & \\
\hline $\log (1+\#$ News $), t-1$ & & & $\begin{array}{c}-0.00278 \\
(-1.516)\end{array}$ & & & \\
\hline Market Equity, t-1 & & & & $\begin{array}{l}-0.00103 \\
(-1.708)^{*}\end{array}$ & & \\
\hline $\mathrm{ME} / \mathrm{BE}, \mathrm{t}-1$ & & & & $\begin{array}{l}0.000518 \\
(2.711)^{* *}\end{array}$ & & \\
\hline Debt Ratio & & & & & $\begin{array}{c}0.00237 \\
(0.22)\end{array}$ & \\
\hline Current Ratio & & & & & $\begin{array}{c}-0.00106 \\
(-0.967)\end{array}$ & \\
\hline Asset Turnover & & & & & & $\begin{array}{c}4.14 \mathrm{E}-03 \\
(0.72)\end{array}$ \\
\hline Profit Margin & & & & & & $\begin{array}{c}0.01 \\
(1.821)^{*}\end{array}$ \\
\hline EPS/Price & & & & & & $\begin{array}{c}0.00 \\
(1.693)^{*}\end{array}$ \\
\hline Constant & $\begin{array}{c}-0.0404 \\
(-2.214)^{* *}\end{array}$ & $\begin{array}{c}-0.0273 \\
(-2.084)^{* *}\end{array}$ & $\begin{array}{l}-0.0366 \\
(-1.638)\end{array}$ & $\begin{array}{l}0.017 \\
(0.71)\end{array}$ & $\begin{array}{c}-0.022 \\
(-1.050)\end{array}$ & $\begin{array}{c}-0.0246 \\
(-1.896)^{*}\end{array}$ \\
\hline Observations & 24,425 & 24,425 & 24,425 & 23,544 & 21,060 & 24,077 \\
\hline R-squared & 0.158 & 0.165 & 0.158 & 0.161 & 0.161 & 0.162 \\
\hline Industry Dummy & Yes & Yes & Yes & Yes & Yes & Yes \\
\hline Number of groups & 36 & 36 & 36 & 36 & 36 & 36 \\
\hline
\end{tabular}




\section{Appendix 1: Extra Tables}

\section{Table A1: Impact of Supply OR Demand for Information on Stock Return}

Table A1 reports the relationship between the abnormal return and the lagged shift in information supply and information demand. The regression model is Fama Macbeth regression with NeweyWest for 3 lags:

Abnormal_Return $_{t}=\alpha_{t}+\beta_{1} N e w s_{-} U p_{t-1}+\beta_{2}$ Search_Up $_{t-1}+\beta_{3} r_{j, t-1}+\beta_{4} r_{j, t-12,-2}+$ $\beta_{5} I O_{j, t-3}+\beta_{6}$ Volume $_{j, t-7,-1}+\epsilon_{j, t}$, where Abnormal_Return A $_{t}$ is measured by DGTW adjusted return, News_Up is 1 if \#News above its 12 month moving average and 0 otherwise, Search_Up is 1 if the search volume is below its 12 month moving average and 0 otherwise, $r_{j, t-1}$ is the previous month's return, $r_{j, t-12,-2}$ is the return from month $t-12$ to $t-2, I O_{j, t-3}$ is the institutional ownership in the previous quarter, and Volume $_{j, t-7,-1}$ is the average trading volume during last 6 months scaled by the total number of shares outstanding. Panel A reports the result of query-by-ticker sample and Panel B presents the result for query-by-name sample. The sample period is between 2005M1 and 2011M12. 


\begin{tabular}{|c|c|c|c|c|c|c|}
\hline \multicolumn{7}{|c|}{ Panel A: Query-by-Ticker Sample } \\
\hline & Model1 & Model2 & Model3 & Model4 & Model5 & Model6 \\
\hline Abnormal Return & \multicolumn{6}{|c|}{ DGTW Adjusted Return } \\
\hline News_Up, t-1 & $\begin{array}{c}0.00574 \\
(6.659)^{* * * *}\end{array}$ & $\begin{array}{c}0.00572 \\
(6.466)^{* * *}\end{array}$ & $\begin{array}{c}0.00867 \\
(3.397)^{* * *}\end{array}$ & $\begin{array}{c}0.0056 \\
(6.418)^{* * *}\end{array}$ & $\begin{array}{c}0.00622 \\
(6.696)^{* * *}\end{array}$ & $\begin{array}{c}0.00553 \\
(6.706)^{* * *}\end{array}$ \\
\hline Search_Up, t-1 & $\begin{array}{c}0.0067 \\
(6.211)^{* * * *}\end{array}$ & $\begin{array}{c}0.0066 \\
(6.044)^{* * *}\end{array}$ & $\begin{array}{c}0.0067 \\
(6.177)^{* * *}\end{array}$ & $\begin{array}{c}0.0061 \\
(6.180)^{* * * *}\end{array}$ & $\begin{array}{c}0.0072 \\
(6.814)^{* * * *}\end{array}$ & $\begin{array}{c}0.0064 \\
(6.165)^{* * *}\end{array}$ \\
\hline Return, t-1 & $\begin{array}{c}-0.0306 \\
(-3.977) * * * *\end{array}$ & $\begin{array}{c}-0.0313 \\
(-4.124)^{* * * *}\end{array}$ & $\begin{array}{c}-0.0308 \\
(-4.055)^{* * * *}\end{array}$ & $\begin{array}{c}-2.92 \mathrm{E}-02 \\
(-3.697) * * *\end{array}$ & $\begin{array}{c}-0.0295 \\
(-3.815) * * *\end{array}$ & $\begin{array}{c}-0.0301 \\
(-3.847)^{* * * *}\end{array}$ \\
\hline Return, $\mathrm{t}-2$ to $\mathrm{t}-12$ & $\begin{array}{c}-0.007 \\
(-1.378)\end{array}$ & $\begin{array}{c}-0.00731 \\
(-1.438)\end{array}$ & $\begin{array}{c}-0.00715 \\
(-1.411)\end{array}$ & $\begin{array}{c}-0.00726 \\
(-1.355)\end{array}$ & $\begin{array}{c}-0.00859 \\
(-1.615)\end{array}$ & $\begin{array}{c}-0.00852 \\
(-1.615)\end{array}$ \\
\hline $\mathrm{IO}, \mathrm{t}-3$ & & $\begin{array}{c}-0.00579 \\
(-3.421)^{* * * *}\end{array}$ & & & & \\
\hline Volume, $\mathrm{t}-1$ to $\mathrm{t}-6$ & & $\begin{array}{c}-8.46 \mathrm{E}-03 \\
(-1.873)^{*}\end{array}$ & & & & \\
\hline $\log (1+\#$ Analyst $), t-1$ & & & $\begin{array}{c}-0.00025 \\
(-0.483)\end{array}$ & & & \\
\hline $\log (1+\#$ News $), t-1$ & & & $\begin{array}{c}0.00425 \\
(1.20)\end{array}$ & & & \\
\hline $\log (\mathrm{ME}), \mathrm{t}-1$ & & & & $\begin{array}{c}-0.00166 \\
(-3.688)^{* * *}\end{array}$ & & \\
\hline $\mathrm{ME} / \mathrm{BE}, \mathrm{t}-1$ & & & & $\begin{array}{c}-0.00017 \\
(-1.420)\end{array}$ & & \\
\hline Debt Ratio & & & & & $\begin{array}{c}0.00249 \\
(0.71)\end{array}$ & \\
\hline Current Ratio & & & & & $\begin{array}{c}5.57 \mathrm{E}-05 \\
(0.49)\end{array}$ & \\
\hline Asset Turnover & & & & & & $\begin{array}{c}1.29 \mathrm{E}-02 \\
(5.444)^{* * *}\end{array}$ \\
\hline Profit Margin & & & & & & $\begin{array}{c}(0.00) \\
(-1.189)\end{array}$ \\
\hline EPS/Price & & & & & & $\begin{array}{c}0.00 \\
(2.862)^{* * *}\end{array}$ \\
\hline Constant & $\begin{array}{c}0.00328 \\
(0.35)\end{array}$ & $\begin{array}{c}0.00594 \\
(0.68)\end{array}$ & $\begin{array}{l}-0.00033 \\
(-0.0306)\end{array}$ & $\begin{array}{c}0.041 \\
(3.205)^{* * *}\end{array}$ & $\begin{array}{c}-0.00431 \\
(-0.390)\end{array}$ & $\begin{array}{c}-0.00519 \\
(-0.488)\end{array}$ \\
\hline Observations & 173,793 & 173,793 & 173,793 & 169,023 & 143,509 & 169,623 \\
\hline R-squared & 0.081 & 0.083 & 0.082 & 0.085 & 0.077 & 0.085 \\
\hline Industry Dummy & Yes & Yes & Yes & Yes & Yes & Yes \\
\hline Number of groups & 84 & 84 & 84 & 84 & 84 & 84 \\
\hline
\end{tabular}




\begin{tabular}{|c|c|c|c|c|c|c|}
\hline \multicolumn{7}{|c|}{ Panel B: Query-by-Name Sample } \\
\hline & Model1 & Model2 & Model3 & Model4 & Model5 & Model6 \\
\hline & \multicolumn{6}{|c|}{ DGTW Adjusted Return } \\
\hline News_Up, t-1 & $\begin{array}{c}0.00682 \\
(5.434) * * *\end{array}$ & $\begin{array}{c}0.00694 \\
(5.525) * * *\end{array}$ & $\begin{array}{c}0.00517 \\
(2.818)^{* * * *}\end{array}$ & $\begin{array}{c}0.00598 \\
(5.480)^{* * * *}\end{array}$ & $\begin{array}{c}0.0071 \\
(5.398)^{* * * *}\end{array}$ & $\begin{array}{c}0.00636 \\
(5.335)^{* * * *}\end{array}$ \\
\hline Search_Up, t-1 & $\begin{array}{c}0.0092 \\
(6.909) * * *\end{array}$ & $\begin{array}{c}0.0092 \\
(6.932) * * *\end{array}$ & $\begin{array}{c}0.0093 \\
(6.986)^{* * * *}\end{array}$ & $\begin{array}{c}0.0083 \\
(7.025)^{* * * *}\end{array}$ & $\begin{array}{c}0.0093 \\
(6.798)^{* * * *}\end{array}$ & $\begin{array}{c}0.0088 \\
(6.887)^{* * *}\end{array}$ \\
\hline Return, t-1 & $\begin{array}{c}-0.0238 \\
(-3.024)^{* * *}\end{array}$ & $\begin{array}{c}-0.025 \\
(-3.204)^{* * * *}\end{array}$ & $\begin{array}{c}-0.0241 \\
(-3.070)^{* * *}\end{array}$ & $\begin{array}{c}-2.31 \mathrm{E}-02 \\
(-2.811)^{* * *}\end{array}$ & $\begin{array}{c}-0.0233 \\
(-2.886) * * *\end{array}$ & $\begin{array}{c}-0.0235 \\
(-2.973)^{* * * *}\end{array}$ \\
\hline Return, $\mathrm{t}-2$ to $\mathrm{t}-12$ & $\begin{array}{c}-0.00806 \\
(-1.473)\end{array}$ & $\begin{array}{c}-0.00859 \\
(-1.571)\end{array}$ & $\begin{array}{c}-0.00827 \\
(-1.513)\end{array}$ & $\begin{array}{c}-0.00824 \\
(-1.434)\end{array}$ & $\begin{array}{c}-0.00915 \\
(-1.618)\end{array}$ & $\begin{array}{c}-0.00938 \\
(-1.648)\end{array}$ \\
\hline $\mathrm{IO}, \mathrm{t}-3$ & & $\begin{array}{c}-0.00877 \\
(-5.122) * * *\end{array}$ & & & & \\
\hline Volume, $\mathrm{t}-1$ to $\mathrm{t}-6$ & & $\begin{array}{l}-6.32 \mathrm{E}-03 \\
(-1.801)^{*}\end{array}$ & & & & \\
\hline $\log (1+\#$ Analyst $), t-1$ & & & $\begin{array}{c}-0.00125 \\
(-2.842)^{* * * *}\end{array}$ & & & \\
\hline $\log (1+\#$ News $), \mathrm{t}-1$ & & & $\begin{array}{c}-0.00256 \\
(-0.973)\end{array}$ & & & \\
\hline Market Equity, t-1 & & & & $\begin{array}{c}-0.00232 \\
(-4.653)^{* * *}\end{array}$ & & \\
\hline $\mathrm{ME} / \mathrm{BE}, \mathrm{t}-1$ & & & & $\begin{array}{c}-0.0000779 \\
(-0.580)\end{array}$ & & \\
\hline Debt Ratio & & & & & $\begin{array}{c}0.000967 \\
(0.26)\end{array}$ & \\
\hline Current Ratio & & & & & $\begin{array}{c}-0.0000582 \\
(-0.466)\end{array}$ & \\
\hline Asset Turnover & & & & & & $\begin{array}{c}1.19 \mathrm{E}-02 \\
(4.437)^{* * * *}\end{array}$ \\
\hline Profit Margin & & & & & & $\begin{array}{c}(0.00) \\
(-1.485)\end{array}$ \\
\hline EPS/Price & & & & & & $\begin{array}{c}0.00 \\
(2.764)^{* * *}\end{array}$ \\
\hline Constant & $\begin{array}{c}0.00262 \\
(0.22)\end{array}$ & $\begin{array}{c}0.00694 \\
(0.58)\end{array}$ & $\begin{array}{c}-0.00304 \\
(-0.282)\end{array}$ & $\begin{array}{c}0.0525 \\
(3.436)^{* * *}\end{array}$ & $\begin{array}{c}-0.02 \\
(-2.134)^{* *}\end{array}$ & $\begin{array}{l}-0.0105 \\
(-1.186)\end{array}$ \\
\hline Observations & 130,729 & 130,729 & 130,729 & 126,925 & 111,665 & 127,781 \\
\hline R-squared & 0.089 & 0.092 & 0.09 & 0.094 & 0.088 & 0.094 \\
\hline Industry Dummy & Yes & Yes & Yes & Yes & Yes & Yes \\
\hline Number of groups & 84 & 84 & 84 & 84 & 84 & 84 \\
\hline
\end{tabular}




\section{Table A2: Event Type on Information Supply and Demand}

The table reports the relationship between the occurrence of various types of corporate events and the information supply and demand shifts. The regression model is Fama Macbeth regression with Newey-West for 3 lags: Shift $t_{t}=\alpha_{t}+\beta_{1}$ Event $_{k, t}+\beta_{5} r_{j, t-1}+\beta_{6} r_{j, t-12,-2}+\beta_{7} I O_{j, t-3}+$ $\beta_{8}$ Volume $_{j, t-7,-1}+\epsilon_{j, t}$, where Shift $t_{t} \in\left\{N e w s_{-} U p_{t}\right.$, Search_Up $\left._{t}, S U D U_{t}\right\}$, Event $_{k, t}$ is 1 if event type $k$ happens for the firm in month $t$, News_Up is 1 if \#News is above its 12 month moving average and 0 otherwise, Search_Up is 1 if the search volume is above its 12 month moving average and 0 otherwise, $S U D U$ is 1 if both "News Up" and "Search Up" and 0 otherwise , $r_{j, t-1}$ is the last month's return, $r_{j, t-12,-2}$ is the return from month $t-12$ to $t-2, I O_{j, t-3}$ is the institutional ownership in the previous quarter, and Volume $_{j, t-7,-1}$ is the average trading volume during previous 6 months scaled by the total number of shares outstanding. The sample period is between 2005M1 and $2011 \mathrm{M} 12$.

\begin{tabular}{|c|c|c|c|c|c|c|c|c|c|c|c|c|}
\hline \multicolumn{13}{|c|}{ Events Type on Information Supply and Demand } \\
\hline Dependent Variable & \multicolumn{2}{|c|}{$\begin{array}{c}\text { Model1 } \\
\text { News_Up }\end{array}$} & \multicolumn{2}{|c|}{$\begin{array}{c}\text { Model2 } \\
\text { Search_Up }\end{array}$} & \multicolumn{2}{|c|}{$\begin{array}{l}\text { Model3 } \\
\text { SUDU }\end{array}$} & \multicolumn{2}{|c|}{$\begin{array}{l}\text { Model4 } \\
\text { News_Up }\end{array}$} & \multicolumn{2}{|c|}{$\begin{array}{c}\text { Model5 } \\
\text { Search_Up }\end{array}$} & \multicolumn{2}{|c|}{$\begin{array}{l}\text { Model6 } \\
\text { SUDU }\end{array}$} \\
\hline Client Announcement & 0.0845 & $(15.75)^{* * *}$ & 0.0190 & $(1.897)^{*}$ & 0.0526 & $(9.219)^{* * *}$ & 0.0549 & $(9.764)^{* * *}$ & -0.0033 & $(-0.517)$ & 0.0203 & $(4.634) * * *$ \\
\hline Announcement of Earnings & 0.3360 & $(40.10)^{* * *}$ & 0.0241 & $(6.076)^{* * *}$ & 0.1540 & $(20.94)^{* * *}$ & 0.3240 & $(49.31)^{* * *}$ & 0.0195 & $(4.002)^{* * *}$ & 0.1220 & $(18.17)^{* * *}$ \\
\hline Product-Related Announcement & 0.0867 & $(14.06)^{* * *}$ & 0.0244 & $(2.180)^{* *}$ & 0.0599 & $(10.08)^{* * *}$ & 0.0632 & $(10.69)^{* * *}$ & -0.0088 & $(-1.282)$ & 0.0201 & $(3.779)^{* * *}$ \\
\hline Ex-Div Date (Regular) & -0.0074 & $(-1.375)$ & 0.0066 & $(1.17)$ & -0.0114 & $(-2.323)^{* *}$ & -0.0170 & $(-3.404)^{* * *}$ & -0.0099 & $(-1.574)$ & -0.0183 & $(-3.843)^{* * *}$ \\
\hline Company Conference Presentation & 0.0280 & $(3.570)^{* * *}$ & -0.0045 & $(-0.534)$ & 0.0086 & $(1.706)^{*}$ & -0.0047 & $(-0.905)$ & -0.0211 & $(-2.547)^{* *}$ & -0.0133 & $(-2.775)^{* * *}$ \\
\hline Earnings Call & 0.4365 & $(51.21)^{* * *}$ & 0.0428 & $(13.02)^{* * *}$ & 0.2130 & $(32.07)^{* * *}$ & 0.4040 & $(50.08)^{* * *}$ & 0.0198 & $(5.427)^{* * *}$ & 0.1550 & $(17.68)^{* * *}$ \\
\hline M\&A Transaction Closing & 0.1280 & $(27.50)^{* * *}$ & 0.0234 & $(3.598)^{* * *}$ & 0.0697 & $(16.22)^{* * * *}$ & 0.1020 & $(21.06)^{* * *}$ & 0.0266 & $(5.545)^{* * *}$ & 0.0498 & $(11.72)^{* * *}$ \\
\hline Business Expansion & 0.0630 & $(11.20)^{* * *}$ & 0.0347 & $(2.609)^{* *}$ & 0.0459 & $(6.472)^{* * *}$ & 0.0433 & $(6.708)^{* * *}$ & 0.0339 & $(3.991)^{* * *}$ & 0.0330 & $(5.206)^{* * *}$ \\
\hline M\&A Transaction Announcement & 0.2210 & $(25.29)^{* * * *}$ & 0.0360 & $(4.625)^{* * *}$ & 0.1240 & $(14.61)^{* * * *}$ & 0.1940 & $(22.71)^{* * *}$ & 0.0651 & $(9.450)^{* * *}$ & 0.1230 & $(15.06)^{* * *}$ \\
\hline Dividend Affirmation & 0.1460 & $(19.99)^{* * *}$ & 0.0141 & $(1.974)^{*}$ & 0.0596 & $(8.154)^{* * *}$ & 0.1200 & $(22.17)^{* * *}$ & -0.0099 & $(-1.315)$ & 0.0298 & $(4.729)^{* * *}$ \\
\hline Private Placement & 0.1230 & $(9.170)^{* * * *}$ & 0.0403 & $(3.650)^{* * *}$ & 0.0810 & $(7.309)^{* * *}$ & 0.1020 & $(8.682)^{* * *}$ & 0.0362 & $(3.420)^{* * *}$ & 0.0670 & $(6.562)^{* * *}$ \\
\hline Delayed SEC Filing & 0.1940 & $(9.163)^{* * *}$ & 0.0162 & $(0.77)$ & 0.1020 & $(5.758)^{* * *}$ & 0.1840 & $(6.927)^{* * *}$ & 0.0407 & $(1.58)$ & 0.0913 & $(4.087)^{* * *}$ \\
\hline Lawsuits \& Legal Issue & 0.1020 & $(11.78)^{* * *}$ & 0.0496 & $(2.978)^{* * *}$ & 0.0776 & $(7.021)^{* * *}$ & 0.0814 & $(7.499)^{* * *}$ & 0.0338 & $(3.135)^{* * *}$ & 0.0475 & $(6.448)^{* * * *}$ \\
\hline Fixed Income Offering & 0.1660 & $(14.00)^{* * *}$ & 0.0635 & $(4.758)^{* * *}$ & 0.1110 & $(10.62)^{* * *}$ & 0.1720 & $(13.08)^{* * *}$ & 0.0605 & $(6.011)^{* * *}$ & 0.1110 & $(12.07)^{* * *}$ \\
\hline
\end{tabular}




\begin{tabular}{|c|c|c|c|c|c|c|c|c|c|c|c|c|}
\hline \multicolumn{13}{|c|}{ Events Type on Information Supply and Demand (Continued) } \\
\hline \multirow{4}{*}{$\begin{array}{l}\text { Dependent Variable } \\
\text { Announcement of Earnings, } \\
\text { Corporate Guidance - New/Confirmed }\end{array}$} & \multicolumn{6}{|c|}{ Query-by-Ticker } & \multicolumn{6}{|c|}{ Query-by-Name } \\
\hline & \multirow{2}{*}{\multicolumn{2}{|c|}{$\begin{array}{l}\text { Model1 } \\
\text { News_Up }\end{array}$}} & \multirow{2}{*}{\multicolumn{2}{|c|}{$\begin{array}{c}\text { Model2 } \\
\text { Search_Up }\end{array}$}} & \multirow{2}{*}{\multicolumn{2}{|c|}{$\begin{array}{l}\text { Model3 } \\
\text { SUDU }\end{array}$}} & \multirow{2}{*}{\multicolumn{2}{|c|}{$\begin{array}{l}\text { Model4 } \\
\text { News_Up }\end{array}$}} & \multirow{2}{*}{\multicolumn{2}{|c|}{$\begin{array}{c}\text { Model5 } \\
\text { Search_Up }\end{array}$}} & \multirow{2}{*}{\multicolumn{2}{|c|}{$\begin{array}{l}\text { Model6 } \\
\text { SUDU }\end{array}$}} \\
\hline & & & & & & & & & & & & \\
\hline & 0.3480 & $(34.32) * * *$ & 0.0356 & $(5.292)^{* * *}$ & 0.1710 & $(20.79)^{* * *}$ & 0.3180 & $(28.90)^{* * *}$ & 0.0200 & $(3.144)^{* * *}$ & 0.1230 & $(14.80)^{* * *}$ \\
\hline Strategic Alliance & 0.0909 & $(10.78)^{* * *}$ & 0.0464 & $(3.105)^{* * *}$ & 0.0716 & $(9.229)^{* * *}$ & 0.0651 & $(5.667)^{* * *}$ & 0.0092 & $(1.05)$ & 0.0346 & $(4.661)^{* * *}$ \\
\hline Shelf Registration Filing & 0.0956 & $(11.50)^{* * *}$ & 0.0226 & $(2.982)^{* * *}$ & 0.0535 & $(8.018)^{* * *}$ & 0.0758 & $(9.836)^{* * *}$ & 0.0132 & $(1.50)$ & 0.0418 & $(6.015)^{* * *}$ \\
\hline Seeking Acquisition/Investment & 0.1890 & $(13.41)^{* * *}$ & 0.0413 & $(4.069) * * *$ & 0.1000 & $(19.00)^{* * *}$ & 0.1840 & $(16.84)^{* * *}$ & 0.0187 & $(2.327)^{* *}$ & 0.0815 & $(14.60)^{* * *}$ \\
\hline Index Constituent Add & 0.1010 & $(7.676)^{* * * *}$ & 0.0466 & $(2.557)^{* *}$ & 0.0761 & $(5.760)^{* * *}$ & 0.0821 & $(3.740)^{* * *}$ & 0.0302 & $(2.049)^{* *}$ & 0.0541 & $(3.842)^{* * *}$ \\
\hline M\&A Rumors and Discussion & 0.1200 & $(10.54)^{* * *}$ & 0.0665 & $(3.122)^{* * *}$ & 0.1030 & $(7.408)^{* * *}$ & 0.0853 & $(6.107)^{* * *}$ & 0.0467 & $(3.921)^{* * *}$ & 0.0703 & $(6.134)^{* * *}$ \\
\hline Corporate Guidance - New/Confirmed & 0.2750 & $(26.87)^{* * *}$ & 0.0597 & $(5.585)^{* * * *}$ & 0.1590 & $(19.62)^{* * *}$ & 0.2520 & $(23.81)^{* * *}$ & 0.0123 & $(1.58)$ & 0.0979 & $(11.03)^{* * * *}$ \\
\hline Discontinued Operations/Downsizing & 0.1100 & $(10.10)^{* * *}$ & 0.0641 & $(4.355)^{* * *}$ & 0.0833 & $(7.123)^{* * *}$ & 0.0944 & $(8.490)^{* * *}$ & 0.0390 & $(3.450)^{* * *}$ & 0.0560 & $(6.035)^{* * *}$ \\
\hline Index Constituent Drop & 0.0707 & $(3.562)^{* * *}$ & 0.0785 & $(3.565)^{* * * *}$ & 0.0867 & $(4.438)^{* * *}$ & 0.0669 & $(2.266)^{* *}$ & 0.0107 & $(0.43)$ & 0.0293 & $(1.18)$ \\
\hline Change in Company Bylaws/Rules & 0.0652 & $(6.894)^{* * *}$ & 0.0232 & $(2.613)^{* *}$ & 0.0409 & $(4.987)^{* * *}$ & 0.0777 & $(5.643)^{* * *}$ & 0.0284 & $(2.907)^{* * * *}$ & 0.0409 & $(5.272)^{* * * *}$ \\
\hline Announcements of Sales/Trading Statement & 0.0720 & $(4.980)^{* * *}$ & 0.0494 & $(2.965) * * *$ & 0.0554 & $(4.285)^{* * *}$ & 0.0097 & $(0.95)$ & 0.0701 & $(4.698)^{* * *}$ & 0.0376 & $(4.223)^{* * *}$ \\
\hline $\begin{array}{l}\text { Executive/Board Change - } \\
\text { Other, Executive Change - CEO }\end{array}$ & 0.2600 & $(18.81)^{* * *}$ & 0.0376 & $(2.421)^{* *}$ & 0.1250 & $(10.05)^{* * * *}$ & 0.2450 & $(14.52)^{* * *}$ & 0.0135 & $(0.91)$ & 0.0953 & $(7.776) * * *$ \\
\hline
\end{tabular}

